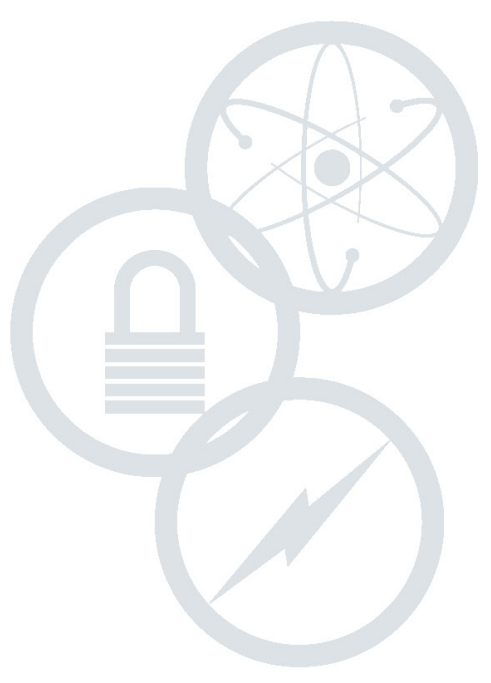

\title{
NSUF Annual Report
}

\section{April 2021}

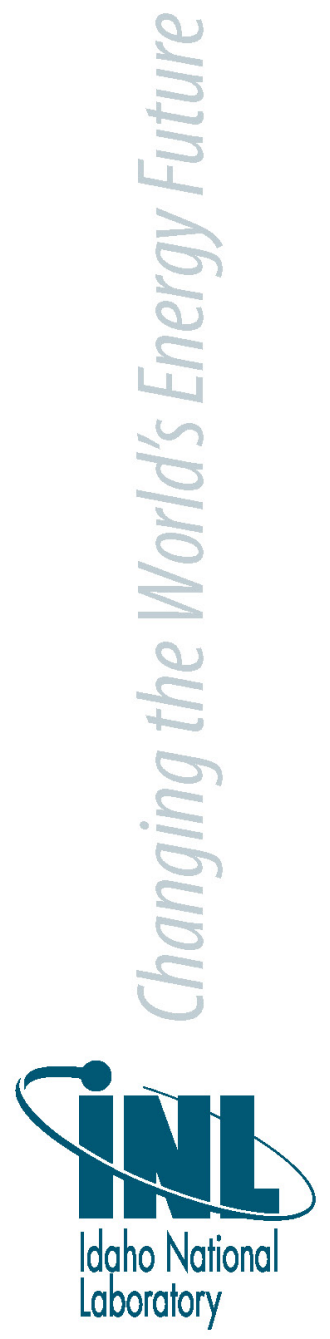

Tiffany M Adams 


\section{DISCLAIMER}

This information was prepared as an account of work sponsored by an agency of the U.S. Government. Neither the U.S. Government nor any agency thereof, nor any of their employees, makes any warranty, expressed or implied, or assumes any legal liability or responsibility for the accuracy, completeness, or usefulness, of any information, apparatus, product, or process disclosed, or represents that its use would not infringe privately owned rights. References herein to any specific commercial product, process, or service by trade name, trade mark, manufacturer, or otherwise, does not necessarily constitute or imply its endorsement, recommendation, or favoring by the U.S. Government or any agency thereof. The views and opinions of authors expressed herein do not necessarily state or reflect those of the U.S. Government or any agency thereof. 


\title{
NSUF Annual Report
}

\author{
Tiffany M Adams
}

April 2021

\section{Idaho National Laboratory Idaho Falls, Idaho 83415}

\author{
http://www.inl.gov
}

\author{
Prepared for the \\ U.S. Department of Energy \\ Under DOE Idaho Operations Office \\ Contract DE-AC07-05ID14517
}




\section{ANNUAL REPORT}




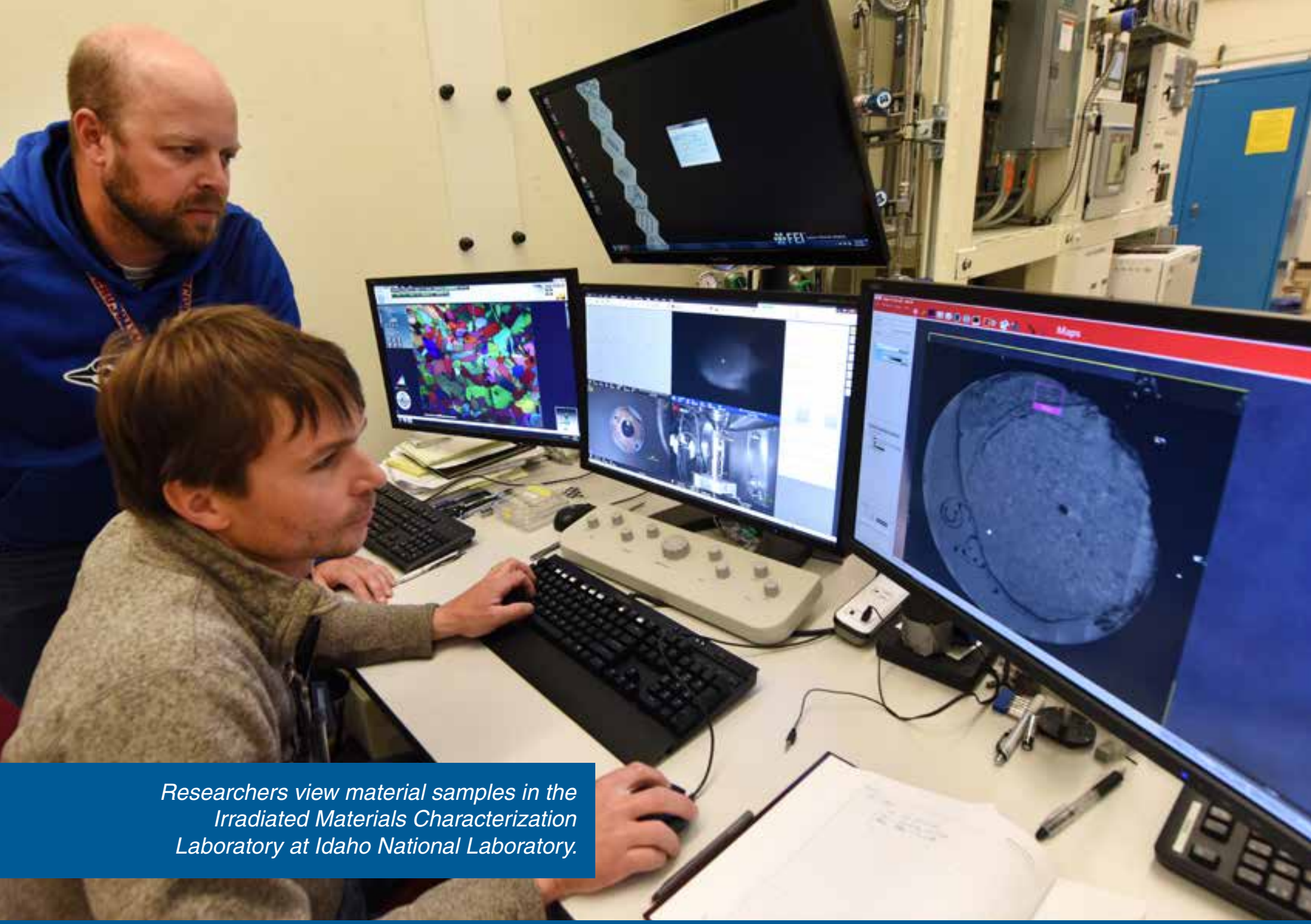

\section{Nuclear Science User Facilities 995 MK Simpson Blvd. Idaho Falls, ID 83401-3553}

\section{nsuf.inl.gov}

On the front and back cover: Sandia National Laboratories' Annular Core Research Reactor has been in operation for more than 32 years and uses photons and neutrons to irradiate test materials (photo courtesy of Sandia National Laboratories)

\section{Disclaimer}

This information was prepared as an account of work sponsored by an agency of the U.S. Government. Neither the U.S. Government nor any agency thereof, nor any of their employees, makes any warranty, expressed or implied, or assumes any legal liability or responsibility for the accuracy, completeness, or usefulness, of any information, apparatus, product, or process disclosed, or represents that its use would not infringe privately owned rights. References herein to any specific commercial product, process, or service by trade name, trade mark, manufacturer, or otherwise, does not necessarily constitute or imply its endorsement, recommendation, or favoring by the U.S. Government or any agency thereof. The views and opinions of authors expressed herein do not necessarily state or reflect those of the U.S. Government or any agency thereof.

Editor: Tiffany Adams

Writers: Tiffany Adams, Hank Hogan, Paul Menser, Steven Peterson

Graphic Designer: Kristyn St. Clair 


\section{CONTENTS}

\section{Nuclear Science User Facilities}

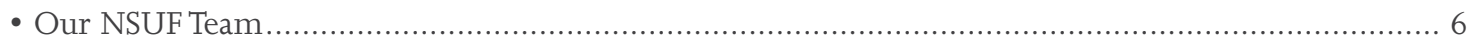

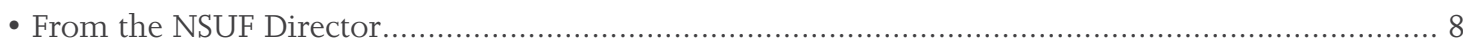

\section{NSUF Overview}

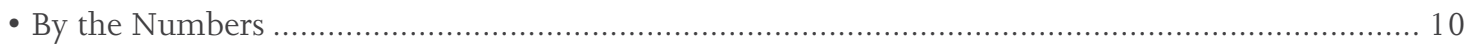

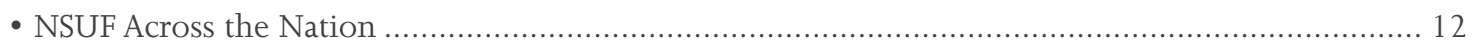

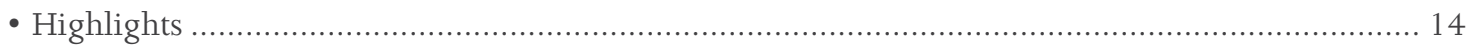

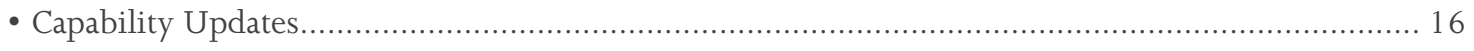

\section{NSUF Features}

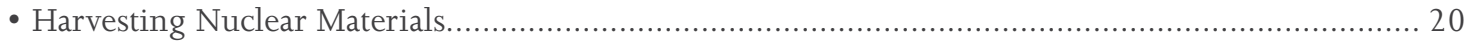

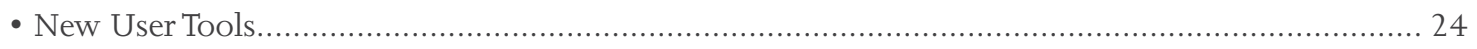

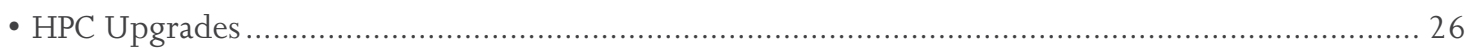

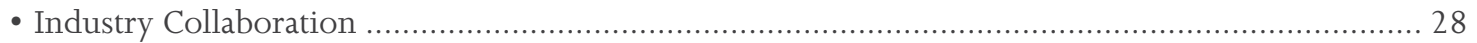

\section{NSUF Awarded Projects}

- Awarded Projects

- Radiation-Enhanced Diffusion of Ag, Ag-Pd, Eu, and Sr in Neutron Irradiated PyC/SiC Diffusion Couples

- HPC Access to Advance Understanding of Fission Gas Behavior in Nuclear Fuel

- Microstructural Characterization of the Radiation Tolerance of Advanced Joining

Techniques for Oxide Dispersion Strengthened Steels under Ion Irradiation.....

- In Situ Ion Irradiation of Second Phase Particles in Zirconium Fuel Cladding.

- Hydrogen Analysis and Oxide Characterization of Reactor Irradiated Zr-Nb Alloy..... 80

Continued on next page 
- APT and TEM Study of Redistribution of Alloying Elements in ZrNb Alloys

Following Proton Irradiation: Effects on In-reactor Corrosion Kinetics. 82

- Irradiation Responses of Ultrastrong Nano Precipitation Martensite Steel

- Study of the Factors Affecting the Radiation Tolerance of MAX Phases for Innovative Fuel Cladding Concepts.

- Micro-mechanical Characterization of Long Range Order in Ni-Cr Alloys and

Their Response to Radiation Damage 90

- Mechanical Characterization of Three Heats (ORNL, LANL and EBR II) of

HT-9 after Side-by-side Neutron Irradiation at LWR and Fast Reactor Relevant Temperatures

- Synchrotron XRD Characterization of Long Range Order in Ni-Cr Alloys

Formed by Isothermal Aging or Irradiation

- Irradiation Damage in (Hf0.2Zr0.2Ta0.2Nb0.2Ti0.2)C High-Entropy Ceramics 98

\section{Resources}

- Acronyms 100

- Index 


\section{OUR NSUF PROGRAM OFFICE TEAM}

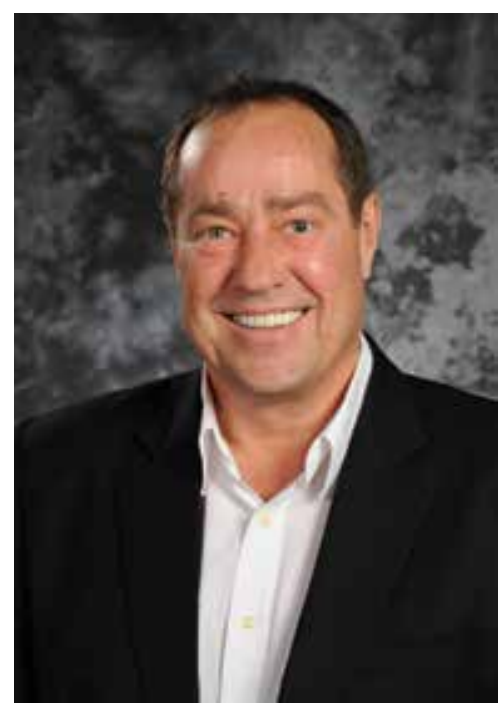

J. Rory Kennedy, Ph.D.

Director

(208) 526-5522

rory.kennedy@inl.gov

\author{
Dan Ogden \\ Deputy Director \\ (208) 526-4400 \\ dan.ogden@inl.gov
}
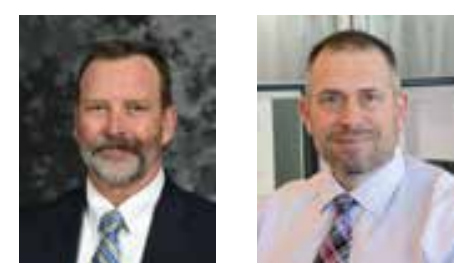

Brenden Heidrich, Ph.D.

Chief Irradiation Scientist

(208) 533-8210

brenden.heidrich@inl.gov

\section{Simon Pimblott, D. Phil.}

Chief Post-irradiation Scientist

(208) 526-7499

simon.pimblott@inl.gov
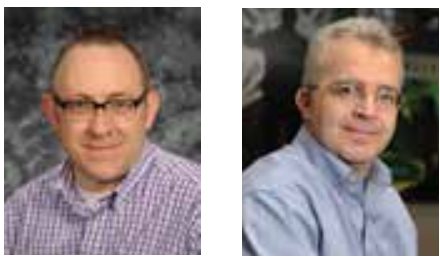

\section{Collin Knight}

Post-irradiation

Examination Project Manager (208) 533-7707

collin.knight@inl.gov

\section{Keith Jewell, Ph.D.}

Technical Lead

(208) 526-3944 james.jewell@inl.gov
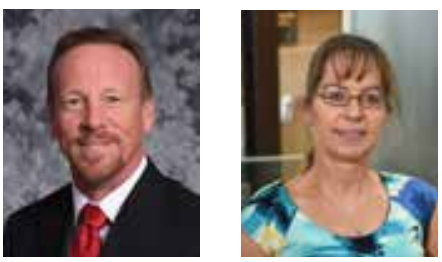

\section{Donna Guillen, Ph.D.}

Technical Lead

(208) 526-1744

donna.guillen@inl.gov

Thomas Maddock

Technical Lead

(International)

(208) 526-2714 thomas.maddock@inl.gov
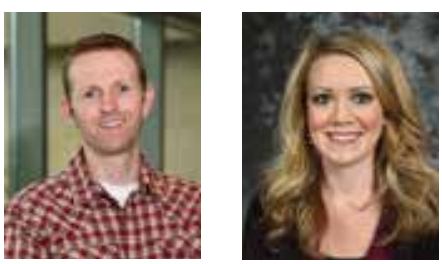

\section{Katie Anderson}

Experiment Manager (208) 526-0049

katie.anderson@inl.gov
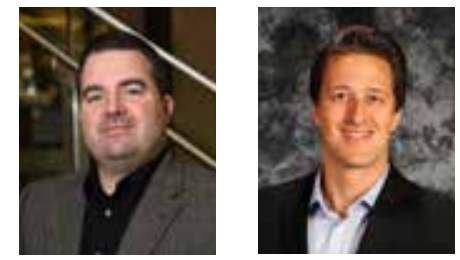

\section{Matthew Arrowood}

Experiment Manager

(208) 526-3527

matthew.arrowood@inl.gov

John Coody

Project Scheduler (until January 2020)

(208) 526-2964 john.coody@inl.gov
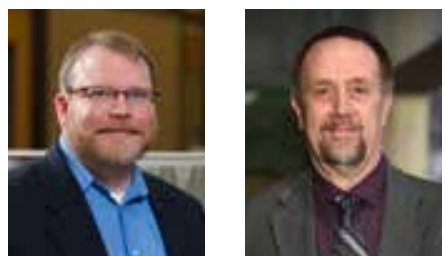

\section{E. Kim Stosich}

Project Scheduler (From January 2020-August 2020)

(208) 526-8218

e.stosich@inl.gov 


\section{William McClung}

Project Scheduler

(Starting August 2020)

william.mcclung@inl.gov
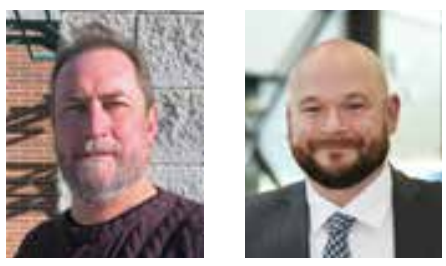

Lindy Bean

Consolidated Innovative

Nuclear Research Administrator

(208) 526-4662

lindy.bean@inl.gov
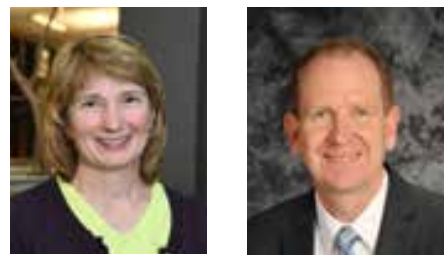

Jeff Benson

Rapid Turnaround

Experiment Administrator

(208) 526-3841

jeff.benson@inl.gov

\section{Kelly Cunningham}

Nuclear Fuels and Materials Library Coordinator and RTE Administrator

(208) 526-2369

kelly.cunningham@inl.gov
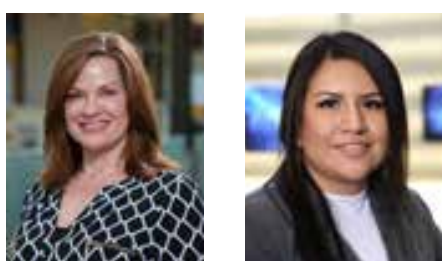

\section{Angelica Mata Cruz}

Content Coordinator

(208) 533-8167

angelica.matacruz@inl.gov

\section{Micah Gale \\ Content Coordinator \\ (208) 533-8141 \\ micah.gale@inl.gov}
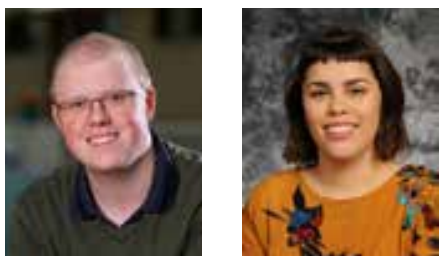

Rachel Jones

Planning and Financial

Controls Specialist

(208) 526-4315

rachel.jones@inl.gov
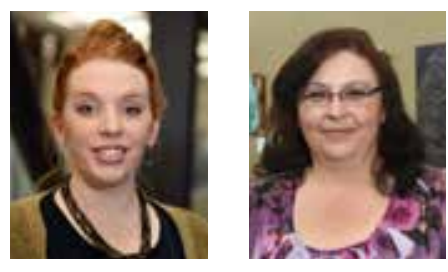

\section{Renae Tripp}

Administrative Assistant

(208) 526-6918

renae.soelberg@inl.gov

\section{Tiffany Adams}

(208) 526-4081

tiffany.adams@inl.gov

\section{Dain White}

Technical Lead Software Engineer

(208) 533-8210 dain.white@inl.gov

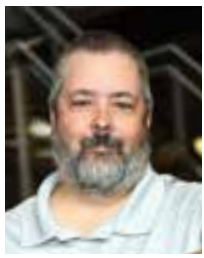




\section{FROM THE NSUF \\ DIRECTOR}

\section{J. Rory Kennedy, Ph.D. \\ Director \\ (208) 526-5522 \\ rory.kennedy@inl.gov}

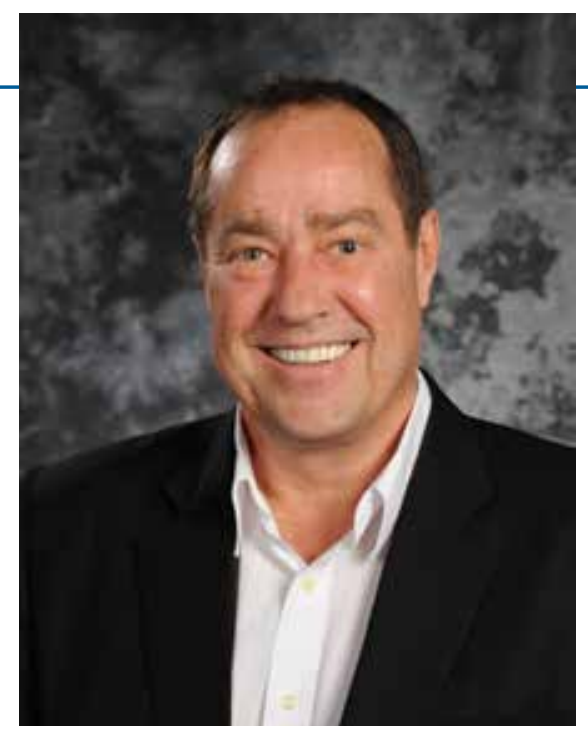

The Journal of Nuclear Materials continues to be the preferred venue for NSUF research publications. Related to this, the NSUF organized sessions at both the Winter 2019 and Annual 2020 American Nuclear Society meetings, with the latter being held virtually. I look forward to organizing and chairing more sessions in FY 2021, so please prepare as you will be hearing from me.

During this year, NSUF released several new online applications to help users more effectively plan out irradiation experiments including the Nuclear Experiment Wizard and the Reactor Activation and Damage (RAD) Calculator. The Wizard, as it is more informally known, is primarily focused on building the preliminary experiment design for CINR proposals and pulls together several INL tools like the Nuclear Fuels and Materials Library, the Nuclear Energy Infrastructure Database, the Nuclear Energy Researcher Database, and the RAD Calculator to streamline the experiment design process and thus the proposal preparation process. 


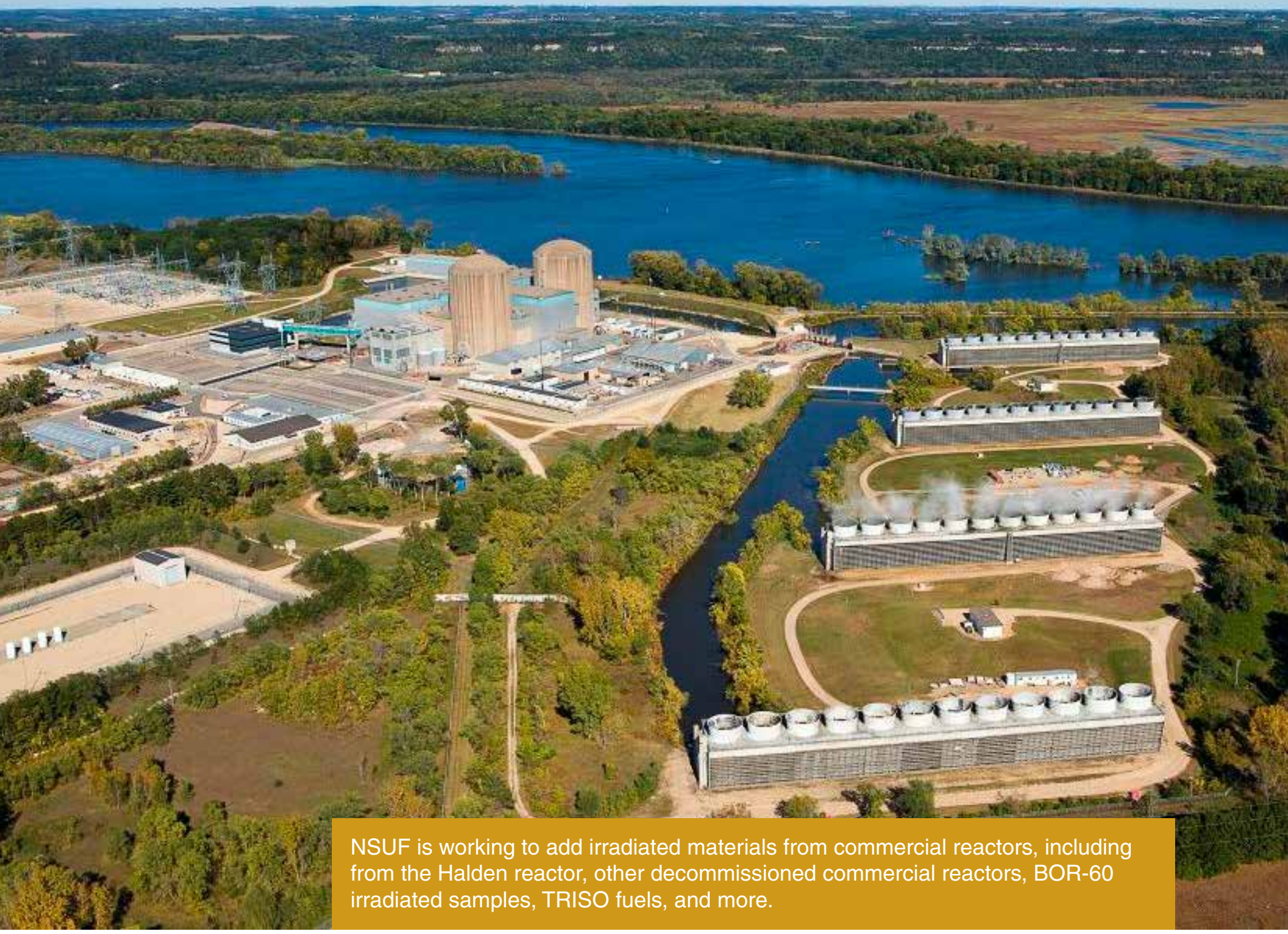

In addition to our annual survey on infrastructure needs, which had a record response this year, we introduced a similar survey on materials needs, which had a pretty good response. Also, thanks to our Nuclear Fuels and Materials Library lead Kelly Cunningham and industry liaison Colin Judge (who joined us in FY 2020 replacing John Jackson. Thanks for your hard work over the years, John), the NSUF is pursuing many sources of irradiated materials to be added to the NFML including materials from the Halden reactor, decommissioned commercial reactors, BOR-60 irradiated samples, TRISO fuels, and more.

Finally, NSUF welcomed a new Deputy Assistant Secretary for Reactor Fleet and Advanced Reactor Deployment to the Department of Energy Office of Nuclear Energy (DOE-NE), Alice Caponiti. We look forward to working with her closely as we continue to advance the NSUF's and DOE-NE's important mission.

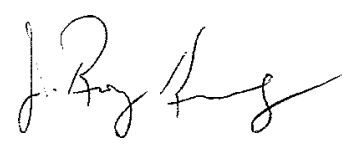

J. Rory Kennedy 


\section{NSUF BY THE \\ NUMBERS}

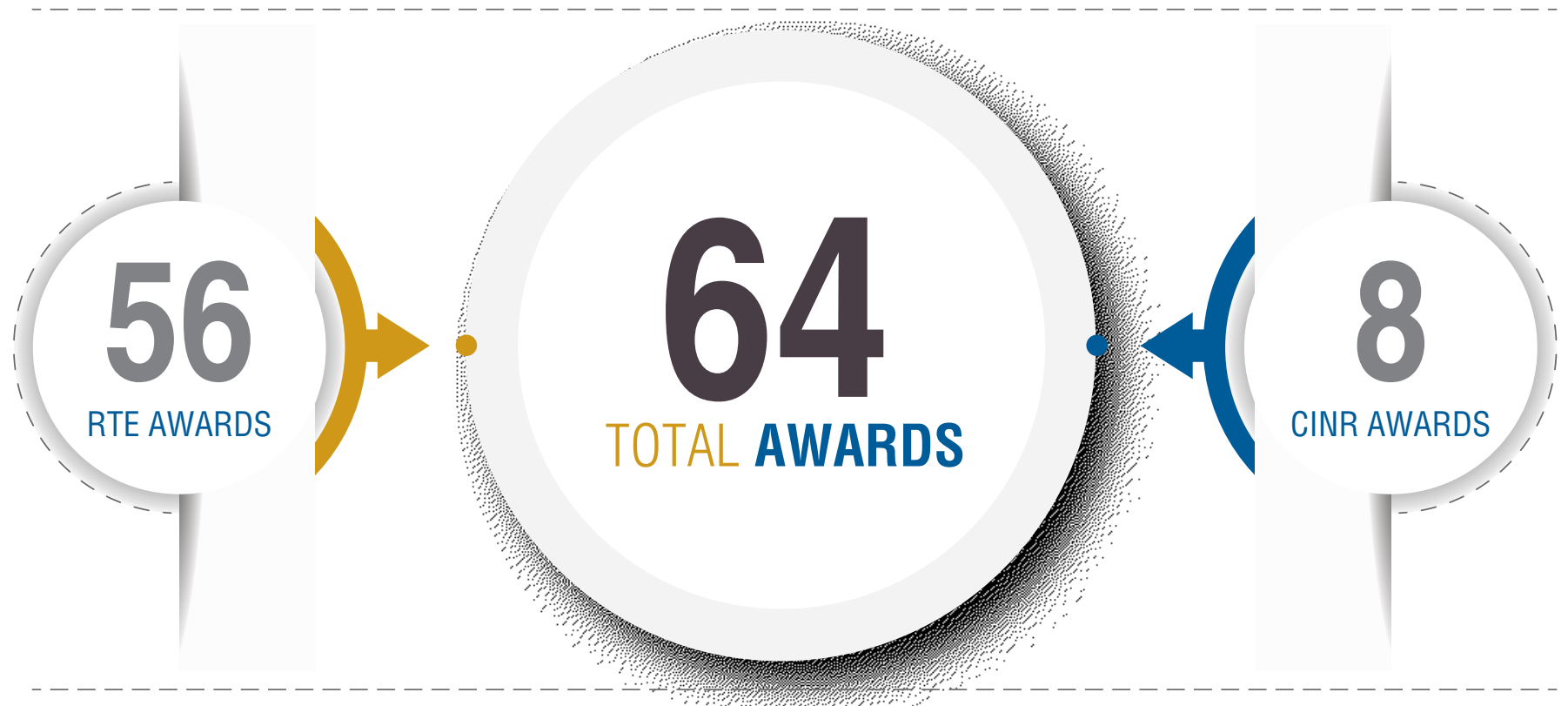

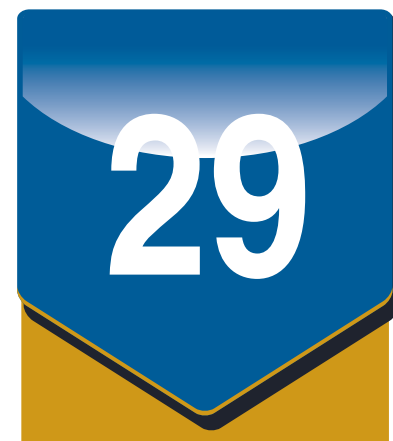

user

institutions

received

awards

in FY-20

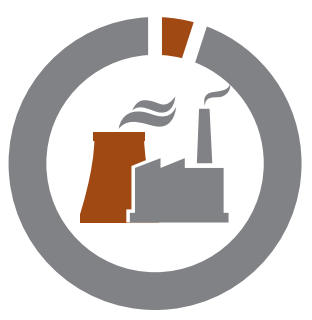

0

$5 \%$

Industry

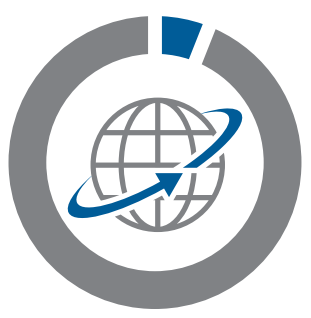

O

$6 \%$

International Organizations

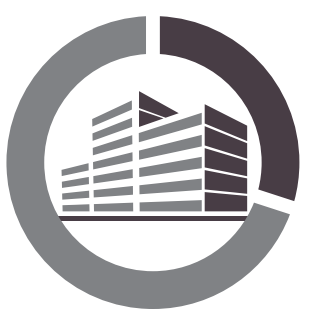

O

$30 \%$

National Laboratories

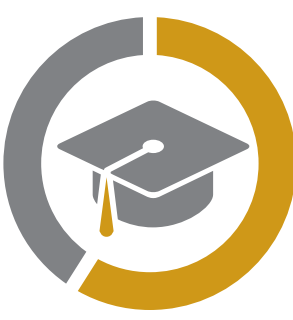

$-0$

$59 \%$

Universities

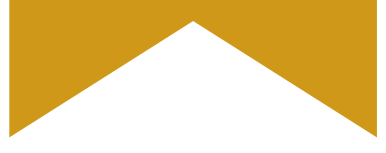




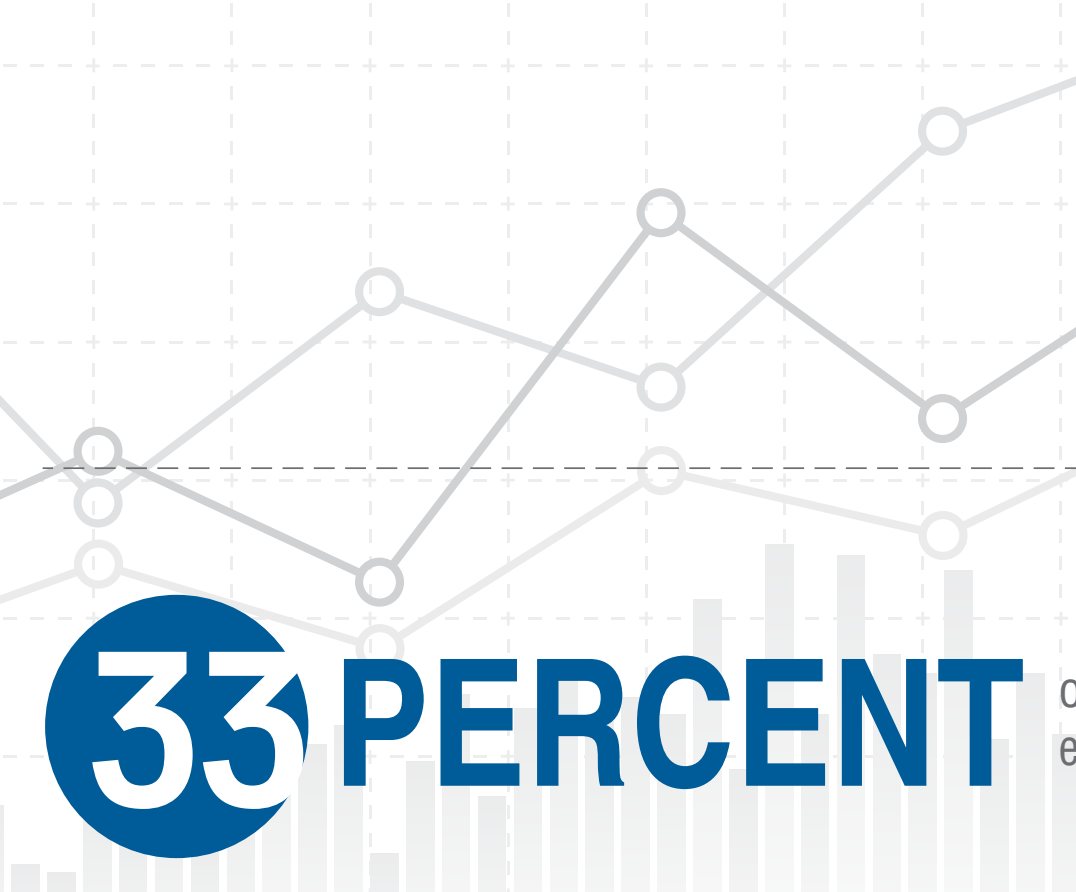

of projects involve a graduate student, either as a PI or a collaborator
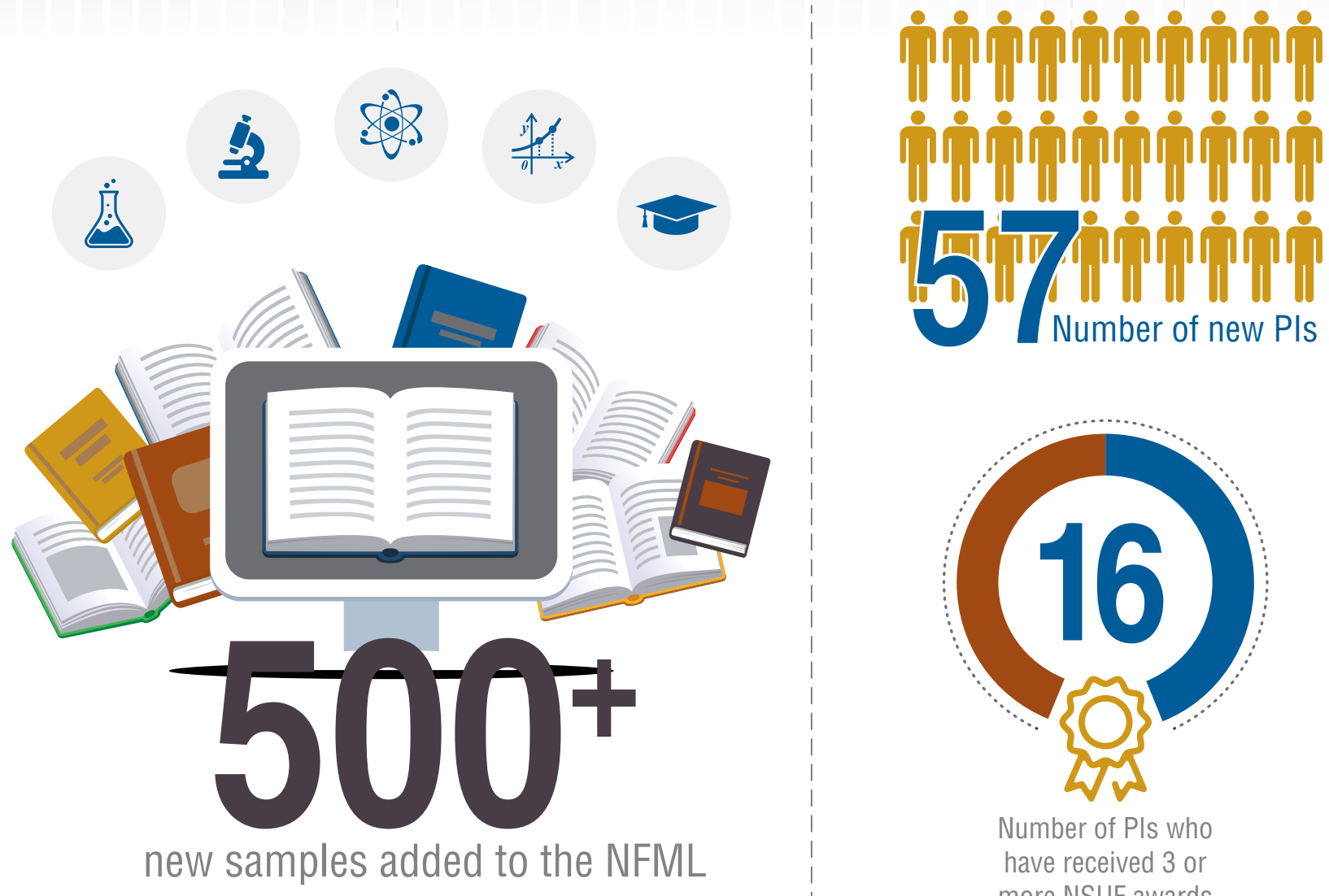

Number of PIs who

have received 3 or more NSUF awards 


\section{NSUF ACROSS THE NATION}

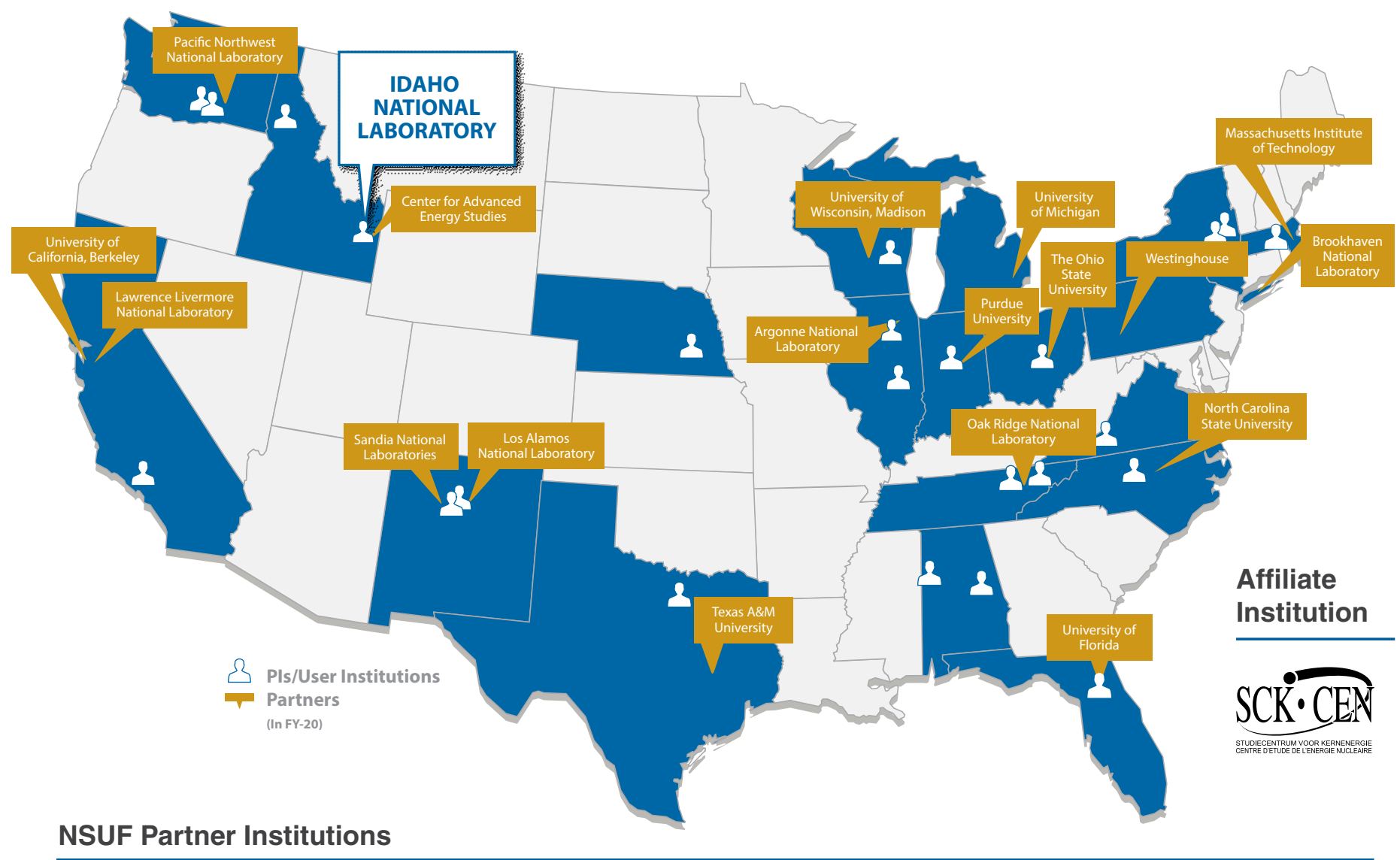

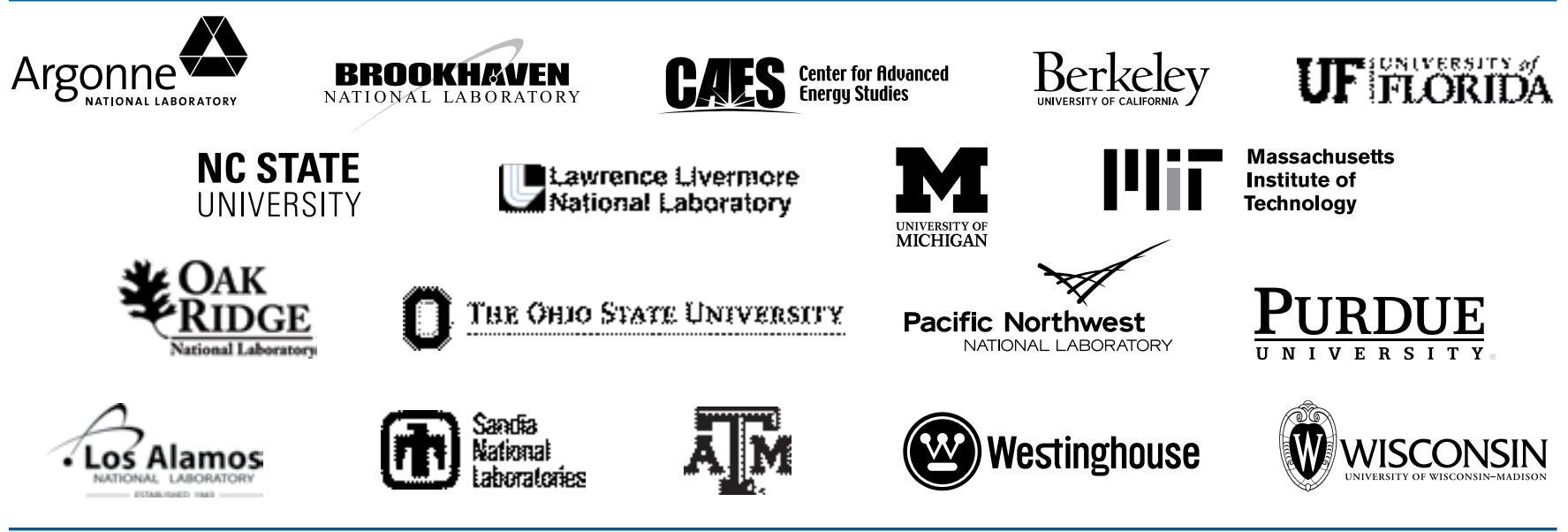



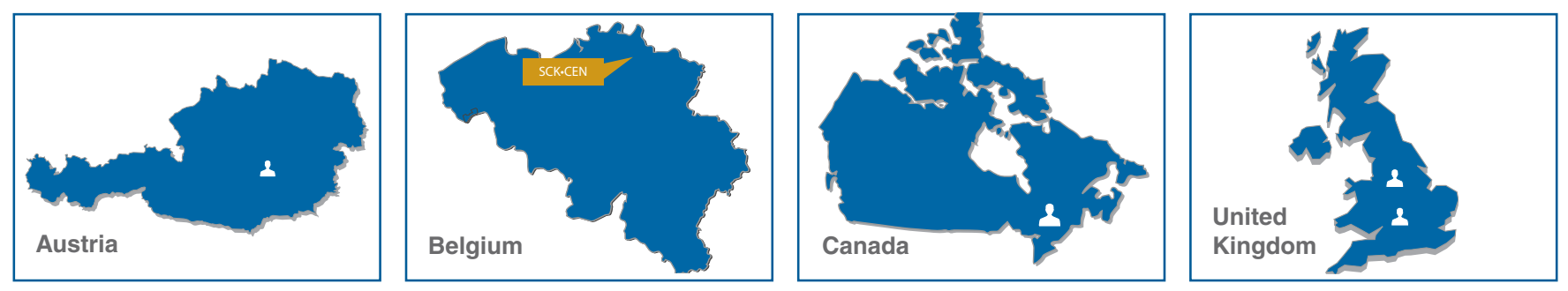

NSUF User Institutions (FY-20)

\section{Alabama \\ Auburn University \\ University of Alabama}

\section{California}

University of California, Irvine

\section{Florida}

University of Florida

\section{Idaho}

Idaho National Laboratory

University of Idaho

\section{Illinois}

Argonne National Laboratory

University of Illinois

\section{Indiana}

Purdue University

\section{Massachusetts}

Massachusetts Institute of Technology

\section{Nebraska}

University of Nebraska

\section{New Mexico}

Los Alamos National Laboratory

University of New Mexico

\section{New York}

General Electric Global Research

Rensselaer Polytechnic Institute

\section{North Carolina}

Electric Power Research Institute North Carolina State University

\section{Ohio}

The Ohio State University

\section{Tennessee}

Oak Ridge National Laboratory University of Tennessee

\section{Texas}

University of North Texas

\section{Virginia}

Virginia Polytechnic Institute and State University

\section{Washington}

Pacific Northwest National Laboratory Radiation Effects Consulting

\section{Wisconsin}

University of Wisconsin

\section{Austria}

Montanuniversitaet Leoben

\section{Canada}

Queen's University

\section{United Kingdom}

University of Huddersfield

University of Oxford 


\section{FROM \\ THE YEAR}

\section{NSUF hosts two sessions at ANS}

NSUF Director Dr. Rory Kennedy chaired two sessions at the American Nuclear Society (ANS) Winter Meeting in November 2019 and two sessions at the Annual Meeting in June 2020 to update attendees on the organization's contributions in advanced nuclear research. These bi-yearly forums, as well as a number of other meetings, gather individuals from across national laboratories, academia, and industry to discuss advancements in nuclear energy. NSUF's chaired sessions provide a platform for its users to share their research with colleagues across the nuclear energy sector. With the COVID-19 pandemic requiring ANS to forgo an in-person event this summer, the celebration of research, collaboration, and achievements had to be held virtually. Even though the move to a digital format presented a set of challenges, it also allowed more people to hear about the work the NSUF helps bring to life. The purpose of the sessions is to highlight the organization's projects in addition to helping advance the careers of its users and promote collaboration. For Kennedy, the ANS meetings do just that. "I take great pride in the researchers' achievements and what the NSUF makes possible," Kennedy said.

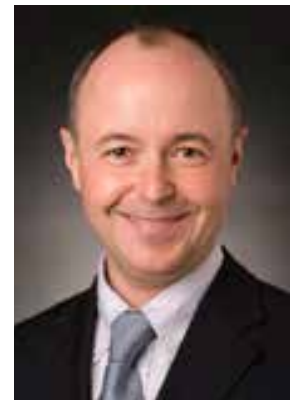

Dr. Igor Jovanovic University of Michigan

\section{NSUF PI builds NSUF project} into international collaboration

A professor at the University of Michigan and NSUF user, Dr. Igor Jovanovic, led a DOE-NE International Nuclear Energy Research Initiative (INERI) project that was built off Jovanovic's FY-19 NSUF-1.1 award. A research and development cooperative, the INERI aims to foster partnerships across research, academia, and industry, and it often involves national laboratories and their advanced facilities. The focus of Jovanovic's ongoing project, In situ Laser Spectroscopic Sensors for Advanced Nuclear Reactor Systems, is to study the effect of radiation damage in optical materials used in sensors that monitor the cooling systems of nuclear reactors. The project involves collaborating with researchers from the Korea Advanced Institute of Science and Technology, Idaho National Laboratory, and the nuclear industry at large. While the primary goal of the research is to develop radiation-resilient sensing techniques and devices for monitoring the aforementioned cooling systems of nuclear reactors, the group is also working to apply their findings for use in high temperature molten salt environments. NSUF provides Jovanovic access to conduct gamma and neutron irradiation testing at The Ohio State University Research Reactor, one of the NSUF 's many partnered user facilities. 


\section{NSUF software receives Exceptional Innovation Contribution Award}

During FY-20, a software product created by NSUF employees was awarded the Exceptional Innovation Contribution Award by Idaho National Laboratory's Technology Deployment Office. Developed by former NSUF intern John Boyington under the supervision of Michael Reichenberger, Least-squares Unfolding with Python (PySL) provides an easily deployable set of tools to dosimetry scientists and reactor experimenters that aims to give them increased flexibility when it comes to working with nuclear data. These features allow experimenters to easily update cross-section data, perform calculations with higher precision, and overall, expand their access to dosimetry material lists. The technology helps streamline and augment processes related to dosimetry measurement across NSUF partner facilities.

\section{New material analysis technique reduces waste}

Supported by the NSUF Instrument Scientist program, a team composed of INL researchers developed an augmented method of atom probe tomography (APT) during FY-20. Efficient nuclear reactor operations require the ability to predict changes related to a nuclear fuel's composition and microstructure. APT offers the ability to do just that, providing a sample's chemical and isotopic composition in a three dimensional picture. To build this picture during APT analysis, atoms are removed via field evaporation, ions are projected onto a detector, and then an algorithm is used to determine the trajectories of those ions, which are then used to illustrate an image.

The new approach used different running conditions to systematically analyze U-7Mo metallic fuel and to ensure better quantification of the elements, U, Np, and Pu. The researchers found that by using a voltage mode at $20 \%$ pulse fraction, base temperature of $24 \mathrm{~K}$, detection rate of $0.5 \%$ atoms/pulse, and pulse repetition of $200 \mathrm{kHz}$ resulted in the optimum running conditions for this material type.

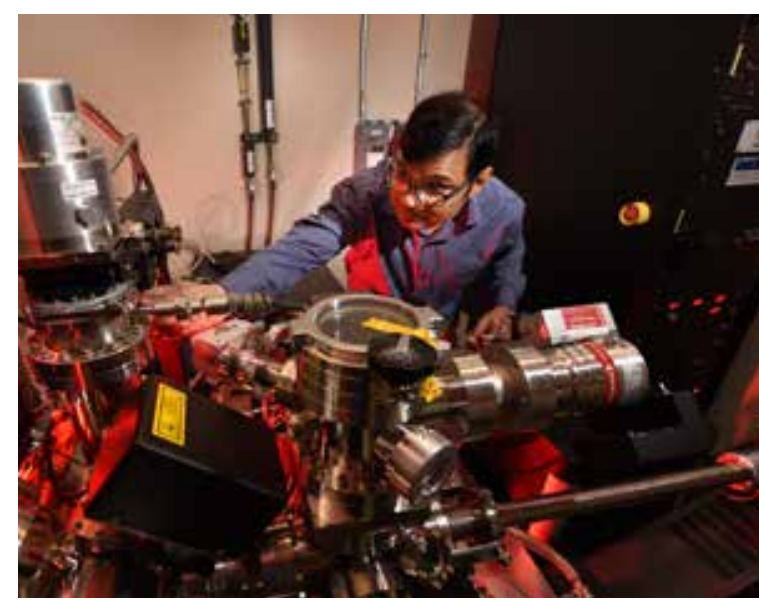




\section{CAPABILITY UPDATES}

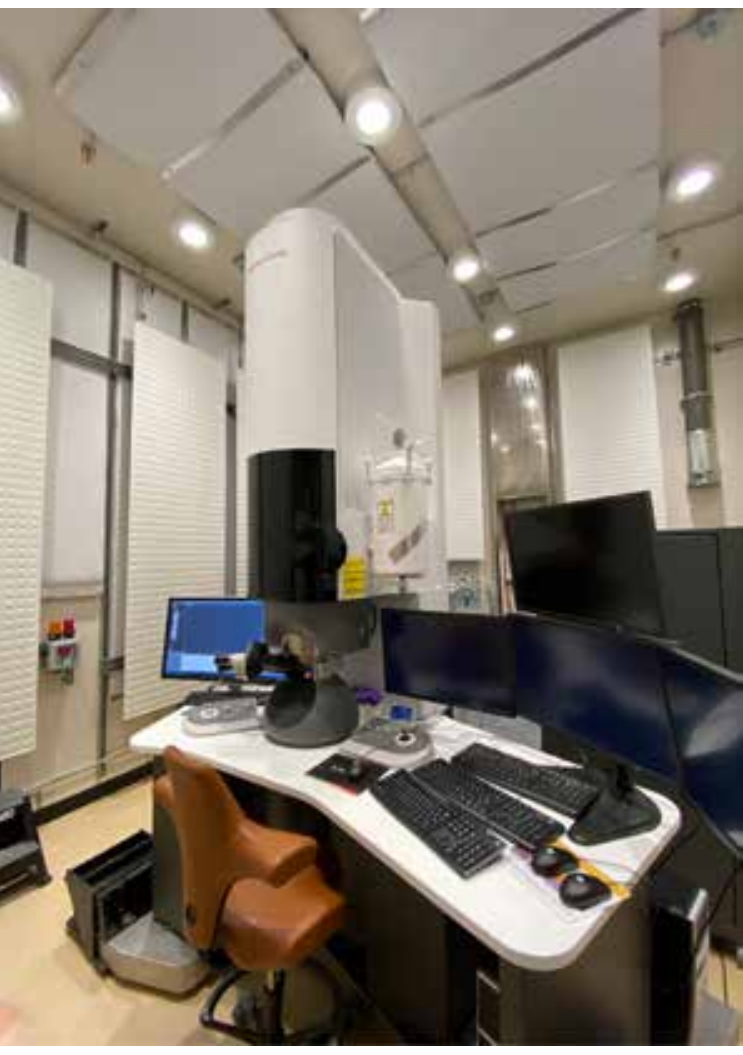

\section{Probe-corrected Titan TEM at INL capable of subatomic resolution imaging}

The Titan transmission electron microscope in the Irradiated Materials Characterization Laboratory (IMCL) at Idaho National Laboratory's Materials \& Fuels Complex (MFC) received an upgrade in 2020 with the addition of a probe corrector, improving the instrument's spatial resolution from $<0.16 \mathrm{~nm}$ to $<0.08 \mathrm{~nm}$. The NSUF sponsored upgrade represents a new cuttingedge capability at INL. Atomic scale transmission electron microscopy (TEM) provides real space images of atomic configurations, including localized structural irregularities and defects in materials.

Additionally, Gatan's Continuum system was installed and training was completed in August 2020 bringing ultrafast dual electron energy loss spectrometry (EELS) mapping to the IMCL. This new capability, plus the recently installed probe corrector, makes the Titan microscope one of the best instruments anywhere for the study of radioactive materials.

EELS is a spectrum technique that analyzes the energy loss of electrons after inelastic interaction with materials. EELS acquisition can be performed at 80 or $200 \mathrm{kV}$, and the energy resolution of EELS is $<1.1 \mathrm{eV}$. Through probing the electronic structures, more information can be revealed about materials, such as atomic composition, chemical states, bonding energies, valence and conduction band electronic properties, surface properties, and element specific pair distance distribution functions. 


\section{Sawtooth supercomputer arrives at INL's Collaborative Computing Center}

NSUF received a huge Christmas present in December 2019 with the arrival of the Sawtooth supercomputer at INL's Collaborative Computing Center. Ranked 37th by Top500.org on its 2019 list of the world's fastest supercomputers, the $\$ 20$ million machine has the power to run complex modeling and simulation applications, which are essential for developing next generation nuclear technologies.

Supercomputing can reduce the need to build physical experiments to test every hypothesis. By using simulations to predict how new fuels and designs will perform in a reactor environment, researchers can select only the most promising technologies for real world experiments.

"With advanced modeling and simulation and the computing power now available, we expect to be able to dramatically shorten the time it takes to test, manufacture, and commercialize new nuclear technologies," said John Wagner, associate laboratory director for INL's Nuclear Science and Technology directorate.

The 67,000-square-foot Collaborative Computing Center, which opened in October 2019, was designed to be the heart of modeling and simulation work for INL. In addition to
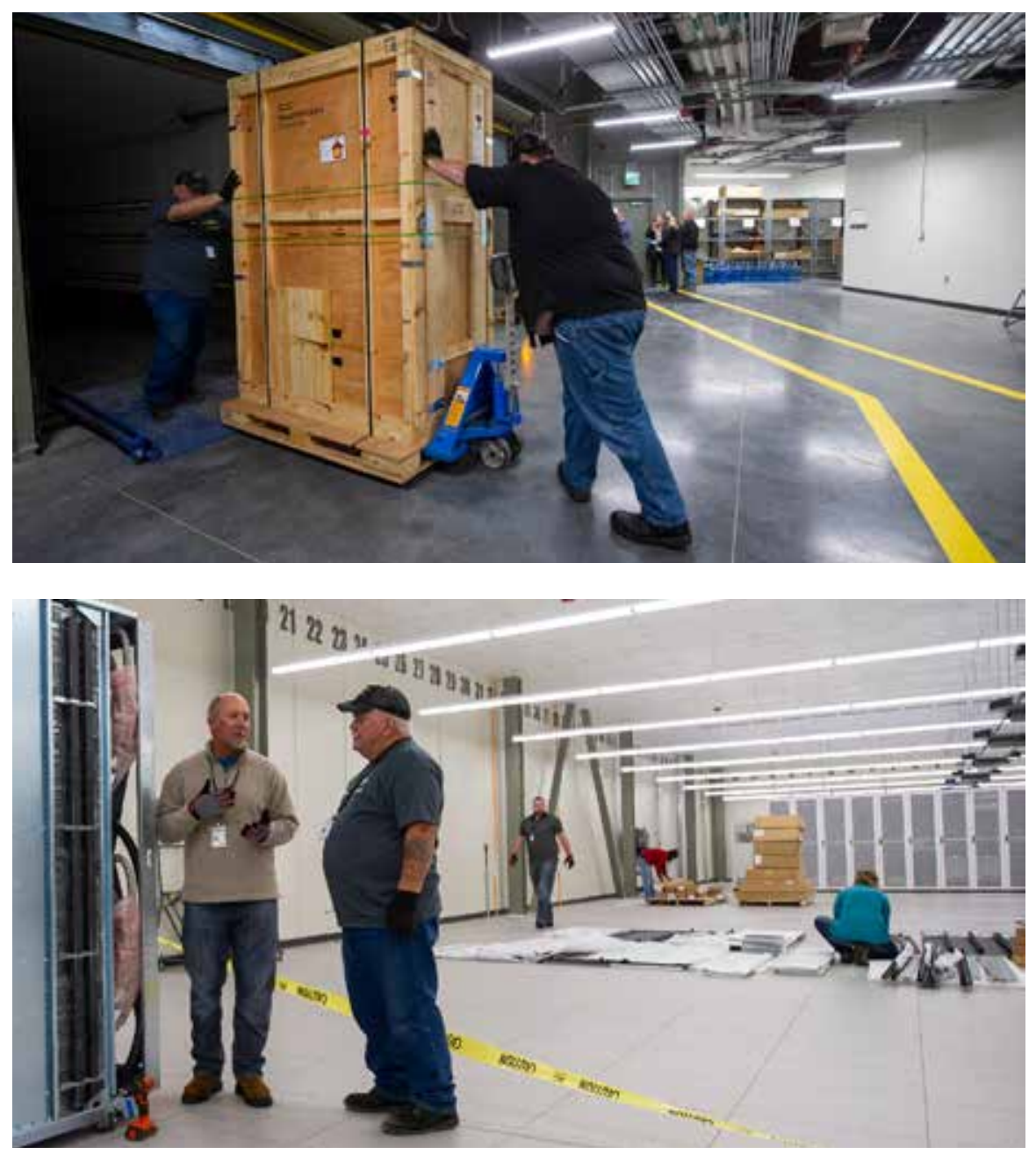

Sawtooth, it provides floor space, power, and cooling to Falcon and Lemhi, INL supercomputing systems that are less powerful than Sawtooth but still integral to the lab's mission. 


\section{Michigan offers combined ion beam/electron beam capabilities}

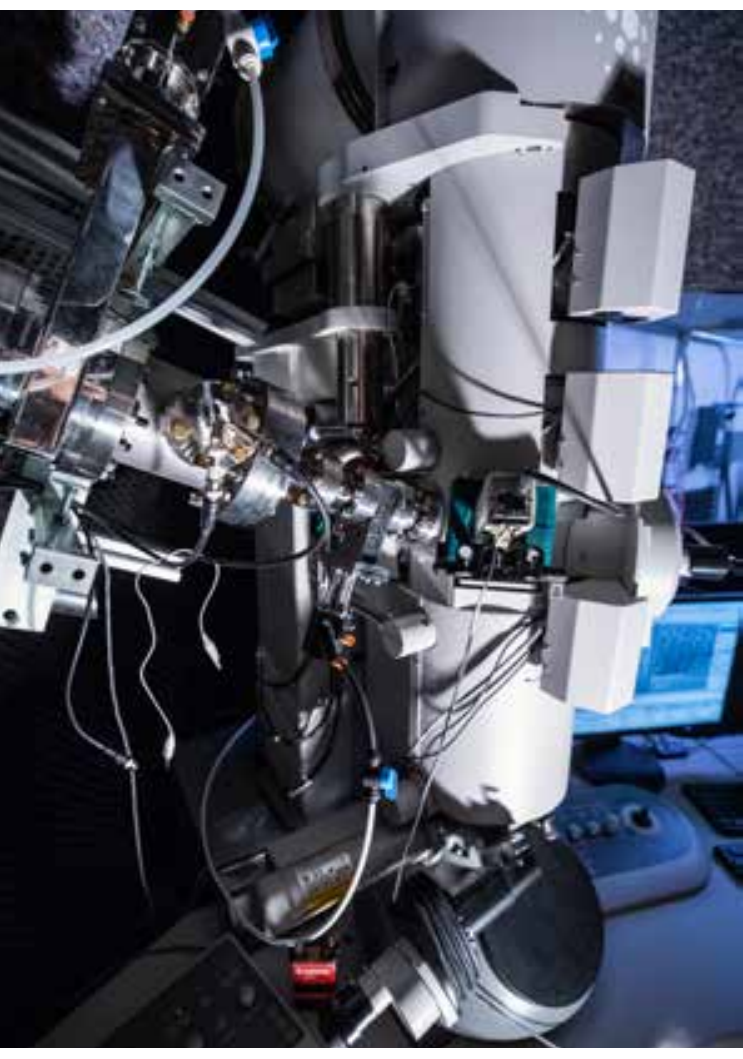

Newly available transmission electron microscope at the University of Michigan.
The Michigan Ion Beam Lab (MIBL), in collaboration with the Michigan Center for Materials Characterization, or $(\mathrm{MC})^{2}$, announced in 2020 the availability of in situ irradiation in a transmission electron microscope. The microscope, a $300 \mathrm{keV}$ FEI Tecnai G2 F30 TWIN, is located at MIBL and can be used both for in situ ion irradiation studies or as a stand alone TEM. This experimental setup makes the University of Michigan one of only three locations in the United States (and currently the only university in the country) to offer an ion beam and electron beam combination.

As part of the University of Michigan NSUF partnership, the microscope should be of particular interest to nuclear research groups. Interfacing the microscope with the accelerator allows for observation of changes in the microstructure of materials under ion irradiation. Two separate ion beams can be combined for delivery to the TEM stage, which is invaluable for simulating the effects of neutron irradiation damage combined with the generation of transmutation gases. This is achieved using a heavy ion to create damage and to fully penetrate through the sample, and a lower energy $\mathrm{He}$ or $\mathrm{H}$ ion that is implanted into the sample. The control of both beams allows for the simulation of the same gas atom loading per dpa of damage as in a reactor.

“This is an important capability, as it allows us to look at the effect of transmutation gases that we inject and how they interact with radiation damage created by the second beam," said Gary Was, professor of nuclear engineering and radiological sciences and director of the MIBL. The ion irradiations can also be configured to simulate fission product damage in nuclear fuel materials.

Two NSUF rapid turnaround experiments have already been scheduled for fall 2020. Was estimates that NSUF is responsible for roughly $15 \%$ of the activity in MIBL. "It's important to us because it brings in folks we might not otherwise meet," he said. "One project may lead to another, so it brings new research opportunities." 


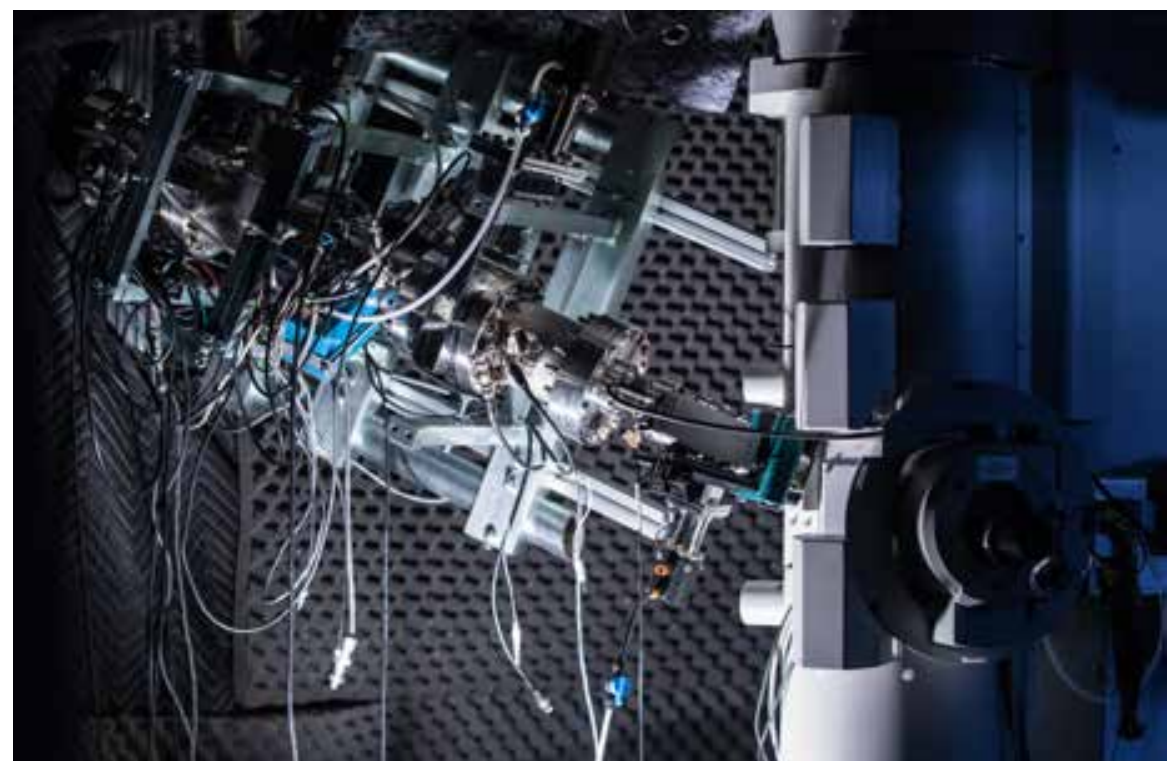

Another angle of the newly available transmission electron microscope at the University of Michigan.

The lab's Wildfire in situ TEM sample holder from DENS Solutions offers new opportunities as well. By virtue of the nanochip design that utilizes focused ion beam (FIB) milled samples, the stage has the capability to reach very high temperatures $\left(1,300^{\circ} \mathrm{C}\right)$ in seconds and continually monitor and control the temperature to within fractions of a degree. The high tilt angles of the double tilt stage provide a large range of imaging conditions.
The microscope can also be used as a TEM independently from the attached ion implanter and complements the other TEMs in $(\mathrm{MC})^{2}-\mathrm{a}$ JEOL $2100 \mathrm{~F}$ and a JEOL3100R05 with aberration corrections, a JEOL2010F and a Thermo Fisher Talos F200X G2 (S/ TEMs). 


\section{HARVESTING}

NUCLEAR MATERIALS

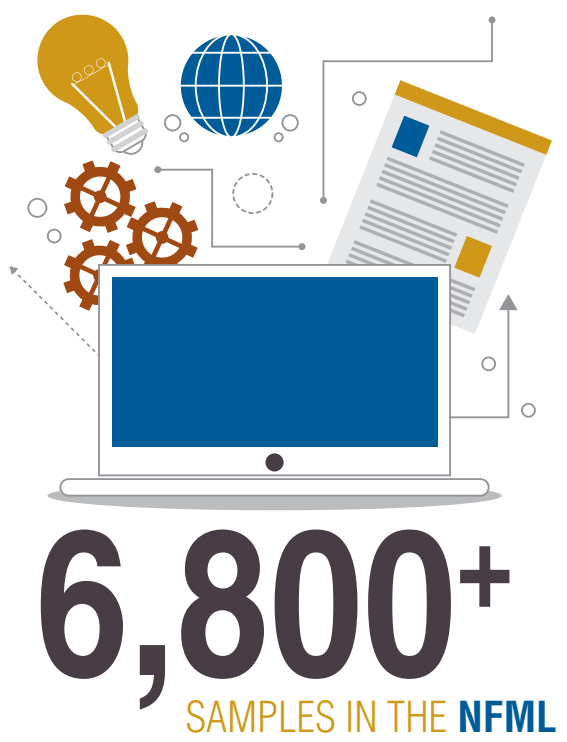

\section{A Unique and Valuable Library for Nuclear Science}

Libraries are valuable research tools - and sometimes what can be most useful isn't found in books. That's the case for the Nuclear Fuels and Materials Library (NFML), a 6,800sample repository of nuclear fuels and materials operated and managed by the Nuclear Science User Facilities. Collected over years, these samples consist of conventional and advanced steels, experimental alloys, ceramics, and fuels that can be used for new or follow-on research.

Nearly all samples in the library have been inside a nuclear reactor, some of which may no longer be operating. Thus, there may be no economical way to duplicate the environment.

"We have some legacy samples from the EBR-II reactor from Idaho National Laboratory," notes NFML coordinator Kelly Cunningham. "A lot of those are stored in hot cells and haven't been touched since the 1980s or 1990s."

The latest push by NFML staff has been to expand collection sources to include more commercial reactors. Cunningham reports some success in working with a commercial partner to make this happen, with more efforts underway.

"We're working with some different companies that harvest materials to put our request in so that the materials just don't go into waste. Because a lot of those are incredibly valuable for researchers," she says.

The collection of these materials faces various legal and logistical obstacles. For instance, the companies doing the material harvesting have timelines and schedules they must meet. So, NFML staff attempt to get a request in as early as possible in the planning process, as that minimizes harvesting operation impact and maximizes sample collection chances.

Whether from commercial or noncommercial reactors, materials that enter the library must have a known pedigree. According to Cunningham, this information includes data about the material's initial composition as well as a history of its environment. If the sample has already been evaluated as part of some previous investigation, then that report also makes 


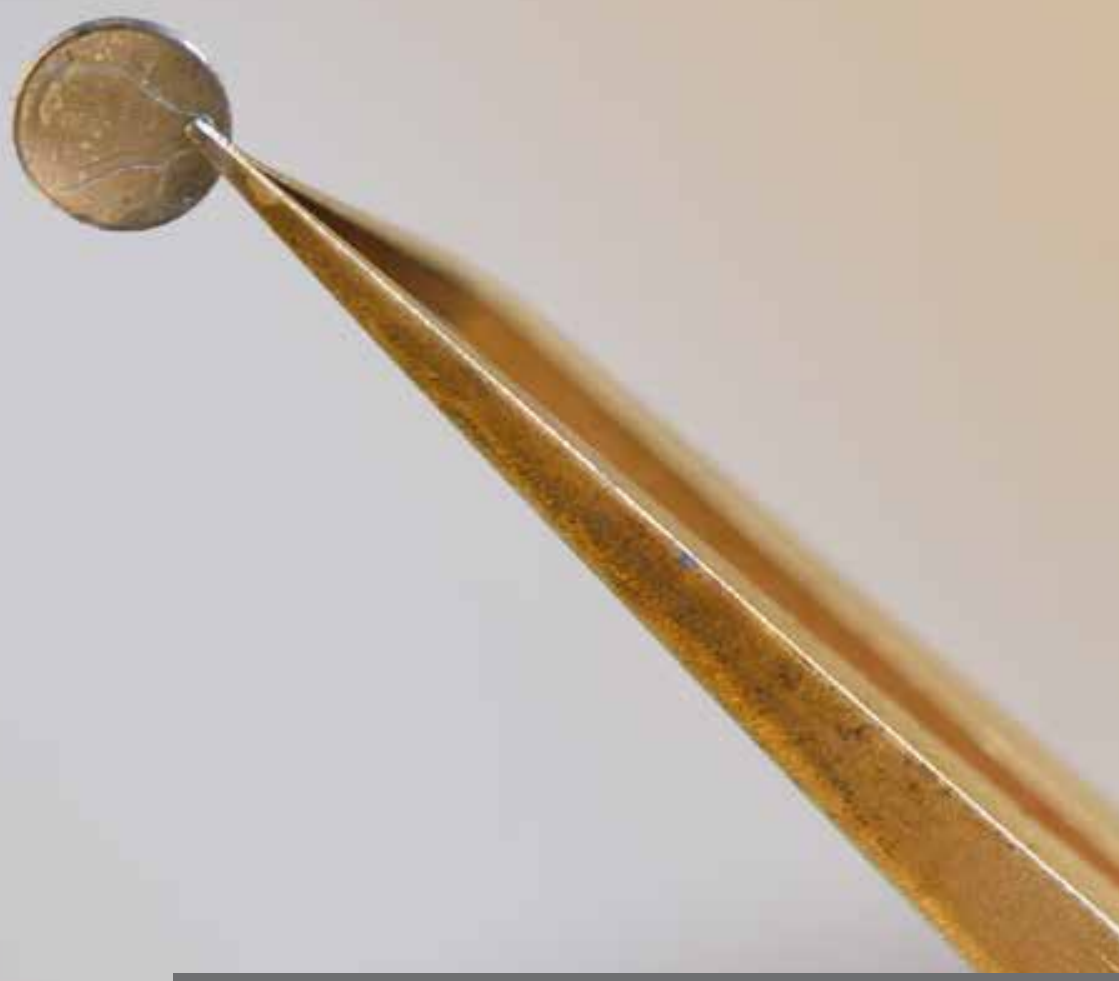

Samples in the NFML include items like the disc specimen shown here.

up part of the pedigree. The more detailed the information above the minimum needed, the better it is for researchers, who can search the NFML database for a sample that meets their desired parameters.

Janelle Wharry, an associate professor of materials engineering at Purdue University, is a researcher who's both used and contributed to the NFML. Before the creation of the library, getting access to nuclear materials for research depended on knowing the right people, those who had the samples. Getting background on the materials could also be challenging, she recalls.
The arrival of the sample library changed that. "It's a lot easier to keep track of where everything came from, what was the radiation dose it was exposed to, the temperature, the rate of delivering that dose. It's just a lot easier to keep track of that stuff when it's centralized in a library," Wharry says.

Her current research projects using NFML materials involve alloys, with examinations of microstructure as well as tensile and fracture tests. One particular area of her investigation is the effect of radiation on laser welds, an important area of research as the findings could impact the structural integrity of piping, tanks, and other components. 


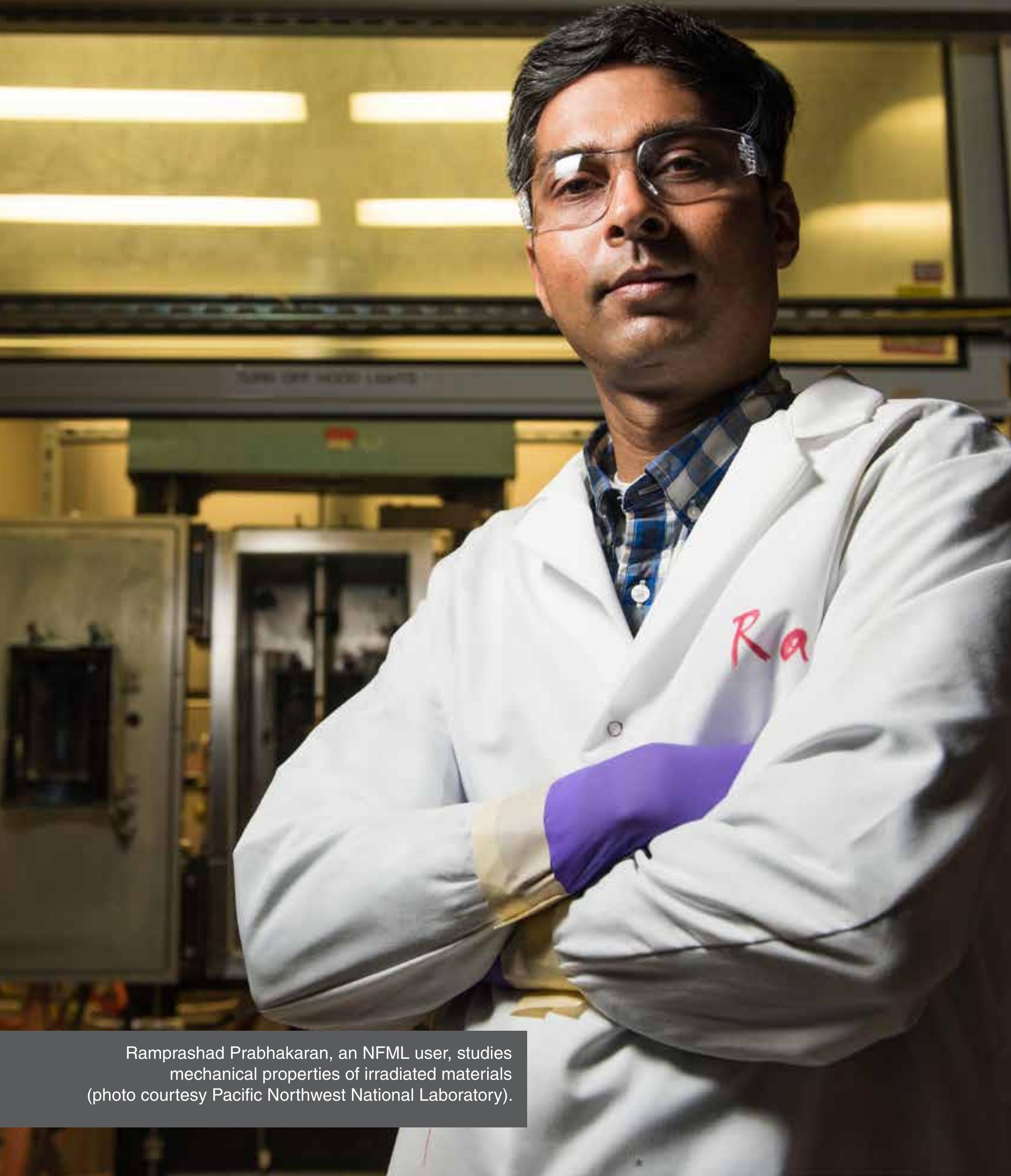


Besides using NFML samples, Wharry generates them by irradiating materials. At the conclusion of her group's project creating such new samples, the materials will go into the library. At a later date, another researcher can use those samples and Wharry's research, as well as potentially collaborating with her, for further work.

The NFML is a significant time and money saver, says Ramprashad Prabhakaran, a materials scientist at Pacific Northwest National Laboratory. He is identifying advanced materials that can be used in next generation nuclear reactors. So, he must evaluate materials and determine if they have the necessary mechanical properties, and high performance radiation and corrosion resistance.

According to Prabhakaran, there are two ways to obtain irradiated materials for testing. One option is to put material candidates in a reactor and let them sit awhile. Accumulating a small radiation dose this way might take a year, getting to a higher dose can take decades.
“That can be done," Prabhakaran says. "Or we can acquire materials present in the library that have been irradiated before to a different or higher dose. These are very valuable materials."

In his research, Prabhakaran characterizes the materials for mechanical properties, such as yield strength and ductility. In doing so, he uses minimally destructive techniques so that samples can be used by other researchers for other studies.

The data generated by Prabhakaran's work goes into models that can be used to predict how proposed materials will behave in next generation reactors.

The research information can also play a role in fine-tuning the composition and manufacture of new materials.

In summing up the impact of the library, NFML's Cunningham says the value of the library and its future can be seen in the reaction of various members of the nuclear community who are volunteering samples. "We've started having people actually contact us and say 'Hey, we've got this. Would you like it?' So, I know the NFML is only going to get bigger and better." 


\section{NEW \\ USER TOOLS}

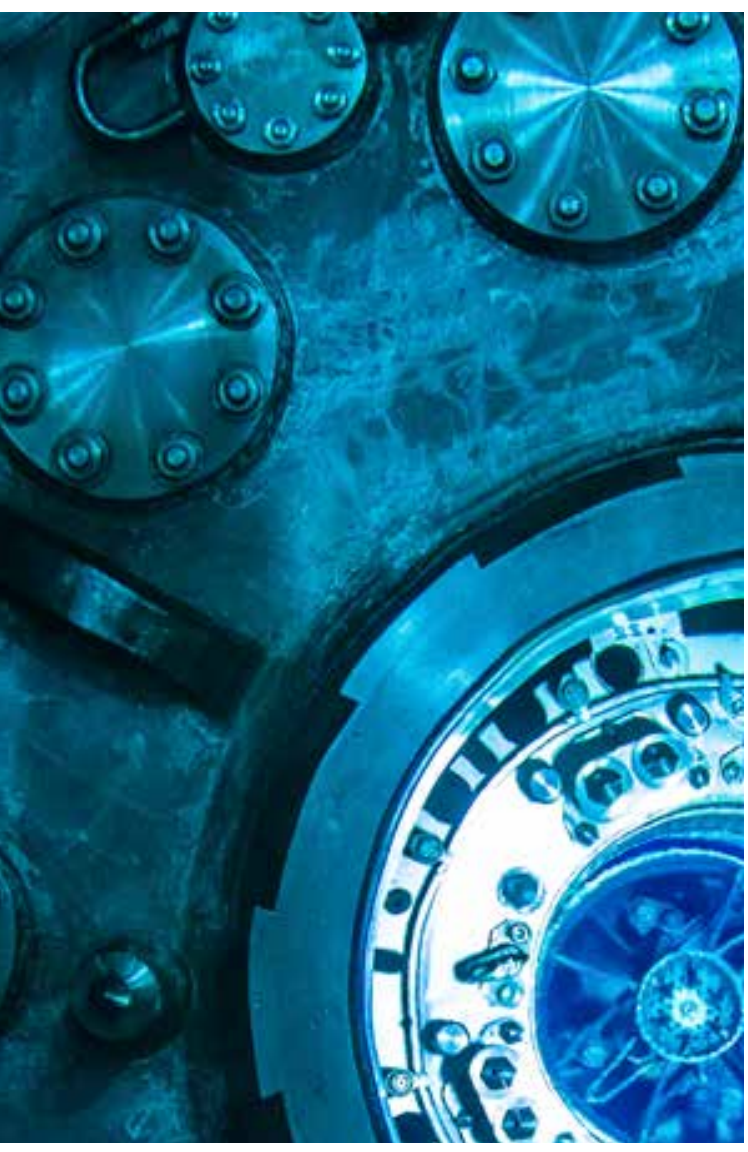

The High Flux Isotope Reactor at Oak Ridge National Laboratory is one of the NSUF reactors included in the RAD Calculator and the Experiment Wizard.

\section{NSUF Unveils the Combined Experiment Toolkit}

In 2020, the Nuclear Science User Facilities released its full Combined Materials Experiment Toolkit (CoMET), the culmination of three years of work by many NSUF Program Office staff and interns.

CoMET pulls together several existing NSUF databases, the Nuclear Energy Infrastructure Database (NEID), the NFML, and the Nuclear Energy Researcher Database (NERD), along with two newly released tools, the Nuclear Experiment Wizard and the Reactor Activation and Damage (RAD) Calculator, to better serve NSUF users.

"As we have worked with users, we have heard where their pain points are," said Brenden Heidrich, CoMET project lead. "The goal of CoMET is to make the lives of NSUF users easier, and I think we created a tool that accomplished that."

\section{RAD Calculator}

The first of the new NSUF tools, the RAD Calculator, helps researchers answer questions they often face when designing an irradiation experiment for a test or research reactor, such as which reactor to choose, where to place a sample in the reactor, how long to irradiate the sample, and what kind of post irradiation experiment facility will be required after the irradiation. Prior to this tool being released, researchers could either do a rough estimate or they could employ a nuclear engineer for a more in-depth analysis. Both methods presented issues; however, the RAD Calculator now offers more flexibility for a reasonably accurate and quickly generated real world outcome.

Available via NSUF's website, the tool lets users calculate radiation damage by either calculating by irradiation time or to a radiation damage goal. After selecting the calculation method and entering the sample's material composition, the RAD Calculator displays possible experiment locations in all NSUF reactors as well as the estimated radioactivity of the sample, which can help guide where post irradiation examination should take place.

\section{Nuclear Experiment Wizard}

Like the RAD Calculator, the goal of the Nuclear Experiment Wizard was to simplify a process for NSUF users. In the case of this tool, the Experiment Wizard addresses the process of building a preliminary experiment design for CINR proposals. 


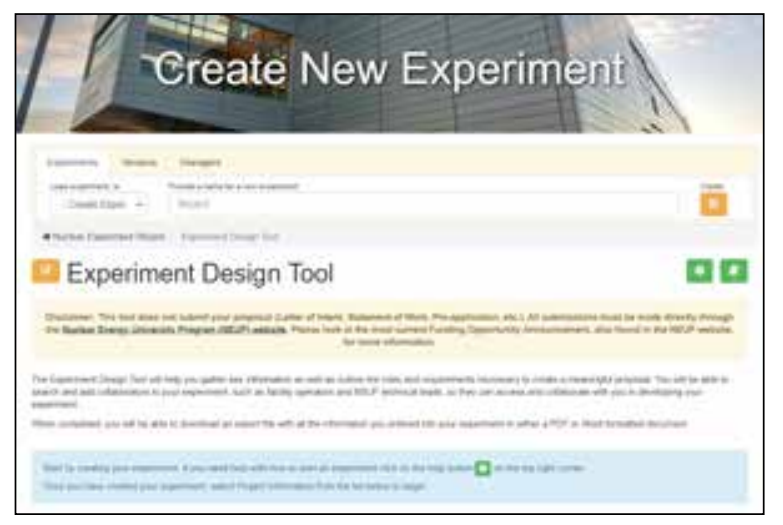

What originally started as a single facility user facility, the NSUF has grown to include 19 partner institutions with 48 facilities among them. Keeping track of these facilities and their capabilities can be difficult for users when they are applying for access. In addition, the CINR proposal process can be extensive and complicated, especially for researchers unfamiliar with it.

Enter the Experiment Wizard. It displays all necessary fields needed to complete a preliminary design document and integrates several NSUF tools and databases, consolidating all information NSUF users need to complete their proposals. Rather than having to go to multiple places to get necessary information, like which facilities have a shielded scanning electron microscope, capability searching

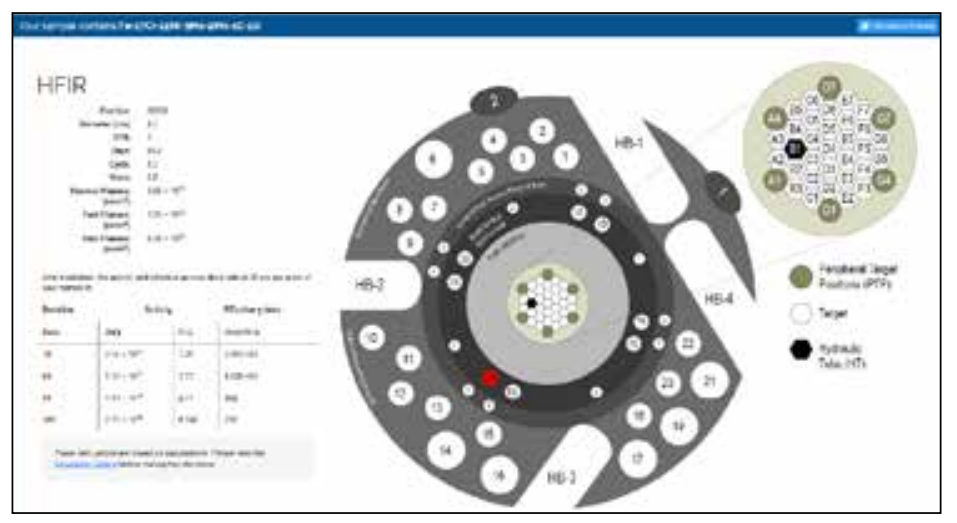

is built right into the Wizard - as is the RAD Calculator and the NERD to find collaborators more easily. After users enter all their data, they can export a document that can be turned into a statement of work for the CINR pre-application for DOE consideration.

\section{Looking toward the future}

While CoMET helps alleviate some challenges facing NSUF users, the development team is always looking at improvements. Slated for future development, the team hopes to add the ability for the RAD Calculator to handle nuclear fuel specimens, estimate nuclear heating, and integrate the RAD Calculator into the NFML.

"Our goal is to never stop improving. We want the NSUF to be as user friendly as possible," Heidrich said.
The Nuclear Experiment Wizard (left) and the RAD Calculator (right) help make designing NSUF experiments easier. 
Clearly, how close a model comes to duplicating the real world is critical. The extra memory and processing power of Sawtooth mean that modeling and simulation run on it can be more complex and of higher fidelity than previously feasible.

The much greater number of GPUs found in Sawtooth also is important. Developed originally for image processing, GPUs excel at certain types of computation as compared to central processing units (CPUs), which are more general purpose and provide nearly all the computing in the two older supercomputers.

GPUs, for instance, are better at deep learning because they are better at the matrix computations repeatedly done as part of deep learning. This capability can be put to use in natural language processing. GPUs also can talk directly to one another, thereby avoiding the bottleneck of communication with the CPU. This approach can lower latency and improve bandwidth, which can speed up such tasks as fluid modeling and simulation as well as other applications.

Shad Staples, department manager for data analytics and visualization within INL, heads a team that has put Sawtooth to work by taking advantage of its GPU capabilities. "The way that we use Sawtooth, specifically for data science, is the AI and machine learning capability," he said.
The new supercomputer has opened the doors to run larger tasks and bigger jobs, Staples added. An example is a natural language model that was created by unsupervised learning of an archived trove of scientific papers. A similar approach has been used by Google and others to allow computers to understand common, everyday language. Once built, this common language model enables the computer to accurately guess which words are missing from a sentence. This basic model can be extended with minimal effort so that computers can do such tasks as determining if a reviewer liked a particular movie or not by scanning a written review.

The language in scientific papers, however, contains specialized words, which vary by field, and the sentence construction also differs from what is used at other times. In building such a scientific language model, the best approach is to start with as large of a data set as possible. So Staples and his team used archived papers to construct a model. Sawtooth made this project run in a reasonable amount of time because of its large number of GPUs, according to Cameron Krome, a data scientist in the group.

There are also other capabilities created by having numerous GPUs. "It allows us to do, basically, rapid prototyping," said data scientist Jared Wadsworth, who also reports to Staples.
In his work, Wadsworth writes different AI models, runs them in parallel on Sawtooth, and then compares the results. The one that works the best will then be further refined, with the variations again run in parallel and compared. Having many multiple GPUs makes this approach work and speeds up the process considerably.

Grimmett notes that the added HPC capabilities should lead to an increase in the number of users and the amount of computation, continuing a trend. While the numbers fluctuate, HPC computation was nearly 60 million core hours in May 2020, as compared to less than 5 million core hours in April 2011. Over that same nine-year span, the average number of users had gone from less than 50 to more than 200.

"We have seen continual growth and expect it to continue," Grimmett said. 


\section{INDUSTRY COLLABORATION}

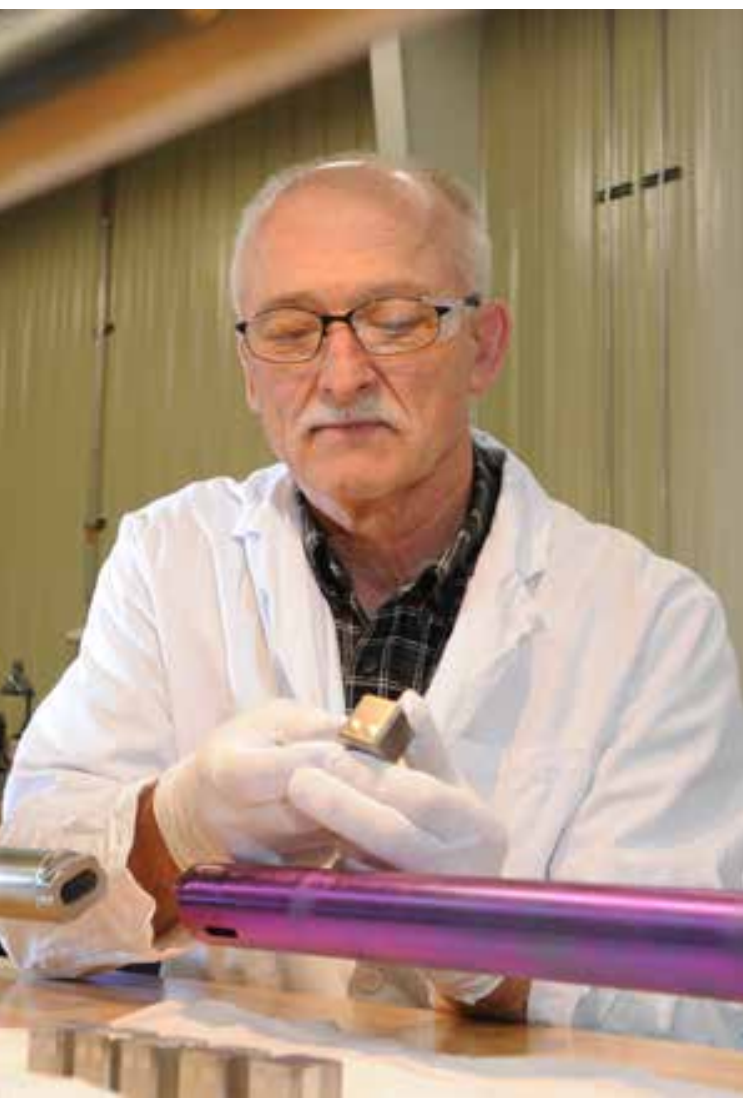

The test train for the EPRI experiment

\section{EPRI Pilot Project creates lasting impacts}

A study that began in 2009 by the U.S. Department of Energy (DOE) and the Electric Power Research Institute (EPRI) has finished its third and final phase. A report on the study provides data in support of the United States' fleet of nuclear power plants well into the future and how joint testing programs are conducted.

Before the study, there was limited data on irradiation assisted stress corrosion cracking (IASCC) behavior and fracture toughness in two materials commonly used in commercial reactor internal components: Alloy X-750 (a nickel based steel alloy) and XM-19 (nitrogen strengthened austenitic stainless steel). For reactor licenses to be extended 40,60 , and even 80 years, more detailed data would be needed, particularly at neutron fluence levels associated with these timespans. Developed by EPRI and the NSUF, the X-750/XM-19 Pilot Project offered a test case in which experimental and administrative protocols for irradiation and PIE experiments conducted by NSUF could be developed while generating valuable data the industry needed.
An independent, nonprofit organization for public interest energy and environmental research, EPRI focuses on electricity generation, delivery, and use in collaboration with the electricity sector, its stakeholders, and others to enhance the quality of life. Collaborative research with DOE involving the Advanced Test Reactor (ATR) became possible after DOE created NSUF in 2007. This made the reactor's unique capabilities and associated research infrastructure available to universities and the commercial nuclear industry. Located at Idaho National Laboratory, ATR had previously been dedicated predominately to experiments for the U.S. Navy along with some focused on DOE programmatic scope.

With the addition of more testing capabilities at other partner national laboratories and universities, NSUF expanded to eventually include 19 other partner organizations. ATR's capabilities remain special, however, because its one-of-a-kind design makes it possible to conduct multiple experiments simultaneously at different irradiation levels. 


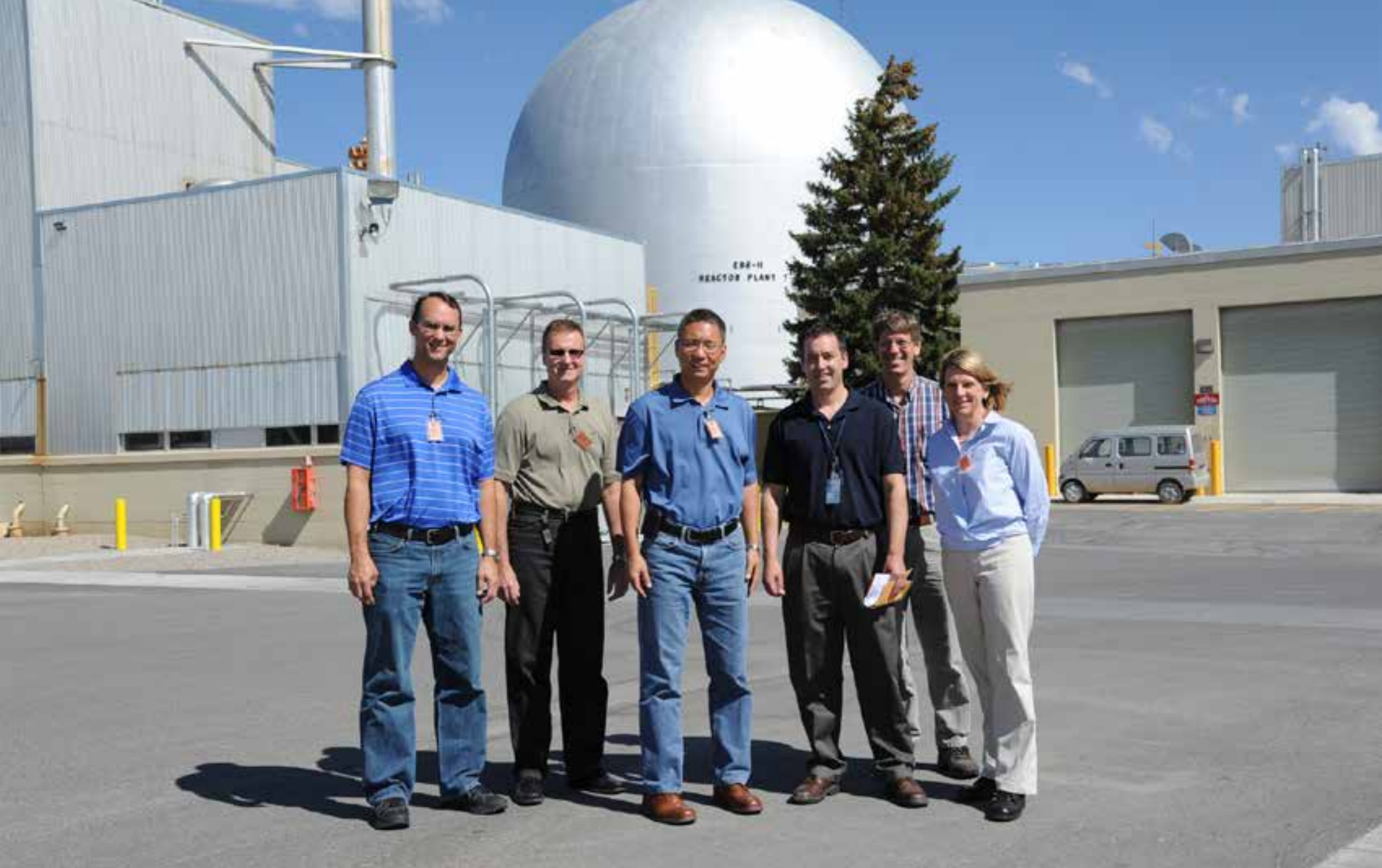

"It's the only available reactor in the U.S. that can perform these kinds of experiments," said Bob Carter, a technical executive with EPRI and the primary project point of contact. "In general, the irradiation program resulted in an outcome that closely met our original objectives. We now have a better understanding of these materials when exposed to neutron irradiation. Without additional data, industry interpretations would contain gaps that would hinder determinations for the remaining service life of the component."

As one of the very first experiments involving access to the facilities, this was a pioneering effort that led to the current "NSUF Access Only" class of awards available to industry through DOE's CINR funding opportunity. Interactions between EPRI and NSUF paved the way to administrative protocols such as the currently utilized "nonproprietary user agreement" as well as experience in experiment related activities, such as shipments between facilities and experiment cataloging and storage. Perhaps most importantly, the pilot project allowed INL staff to develop experience and confidence in conducting irradiations of full size structural material specimens in the controlled water chemistry loop in ATR's center flux trap, and in conducting tests utilizing the newly constructed IASCC hot cells that were installed at INL's Materials and Fuels Complex.
Members of the project team visiting INL. From left to right: Randy Stark, Bob Carter, TG Lian, John Jackson, Craig Harrington, and Jean Smith. 

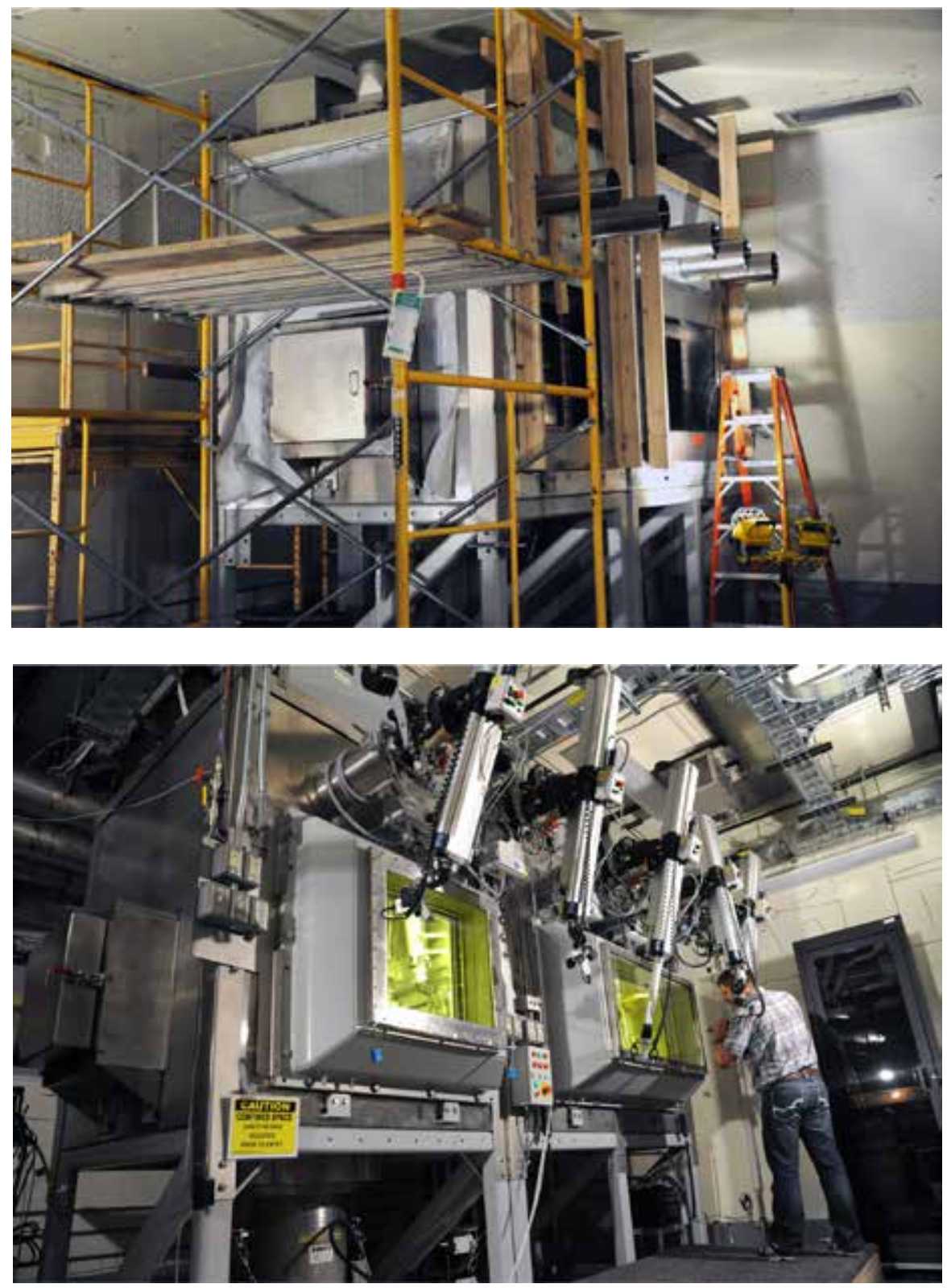

(Top) IASCC hot cell under construction; (Bottom) Completed IASCC hot cell.
Three EPRI capsules were irradiated in ATR between 2013 and 2016, to fluences representing a comparable level to previous related studies (lowest fluence), a level comparable to the medium level experienced by boiling water reactor (BWR) components, and a level comparable to extended life for BWR components. PIE was conducted at INL's Materials \& Fuels Complex and included IASCC crack growth rate testing, fracture toughness testing, tensile testing, and basic TEM to resolve microstructural changes resulting from and evolving with fluence level. A May 2020 final report on Phase III offered the following conclusion:

Although there clearly are opportunities for additional research on the remaining materials from this project (primarily in regard to microstructural analysis), the project is considered a success overall. It is shown that both materials retain a high level of integrity even at the highest fluence, synonymous with beyond end-of-life for (boiling water reactor) components that utilize these materials. Valuable experience was gained in testing protocol and processes, and the path was paved for future NSUF experiments on structural materials involving IASCC. 
"It was not all roses," said John Jackson, distinguished staff scientist at INL who is the NSUF primary point of contact for the pilot project. "In our first irradiation, we were sort of shooting in the dark in terms of water chemistry because it was the first time we had used the water loop in ATR. There were definitely some lessons learned, but by the time of the last irradiation capsule we had flow problems and chemistry issues solved."

“There were unknowns in the BWR environment," said Carter, referring to the ability of structural materials to retain engineering integrity at higher neutron fluences as well as some uncertainty associated with the evolution of these materials in BWR water chemistries. "But we proved the feasibility of using ATR to address these unknowns."

Costs of the project were shared between DOE and EPRI. In addition to gathering data, the program was designed to:

- Develop administrative protocols for cooperative research, such as cooperative agreements and funding.

- Develop research capabilities and staffing required to address future R\&D needs.

- Develop a level of confidence in generating relevant data, particularly IASCC growth rate data.
Jackson said it is worth noting that many of the facilities now available for testing, such as the IASCC test hot cells and the controlled water chemistry loop in the ATR Center Flux Trap, did not exist when the project was first conceived. "Part of the pilot program was building these capabilities," he said.

"With those capabilities established, the way is open to future collaborations," Carter said. Research on light water reactors has been hampered since the shutdown of the Halden research reactor in Norway. "There is a strong push to adopt some of that workload," he said. "In my view, NSUF is a great opportunity for civilian nuclear research. The groundwork has been laid here." 


\section{AWARDED \\ PROJECTS}

\section{Consolidated Innovative Nuclear Research}

\begin{tabular}{|c|c|c|c|}
\hline Title & $\begin{array}{l}\text { Principal } \\
\text { Investigator }\end{array}$ & PI Organization & NSUF Facilities \\
\hline $\begin{array}{l}\text { Demonstration of Self Powered Neutron Detectors } \\
\text { Performance and Reliability }\end{array}$ & Joe Palmer & $\begin{array}{l}\text { Idaho National } \\
\text { Laboratory }\end{array}$ & $\begin{array}{l}\text { Massachusetts } \\
\text { Institute of } \\
\text { Technology }\end{array}$ \\
\hline $\begin{array}{l}\text { Effect of Neutron Irradiation on Microstructure and } \\
\text { Mechanical Properties of Nanocrystalline Nickel }\end{array}$ & $\begin{array}{l}\text { Korukonda } \\
\text { Murty }\end{array}$ & $\begin{array}{l}\text { North Carolina State } \\
\text { University }\end{array}$ & $\begin{array}{l}\text { Idaho National } \\
\text { Laboratory } \\
\text { Pacific Northwest } \\
\text { National Laboratory }\end{array}$ \\
\hline $\begin{array}{l}\text { Improving Lifetime Prediction of Electrical Cables } \\
\text { in Containment }\end{array}$ & Leo Fifield & $\begin{array}{l}\text { Pacific Northwest } \\
\text { National Laboratory }\end{array}$ & $\begin{array}{l}\text { Sandia National } \\
\text { Laboratories }\end{array}$ \\
\hline $\begin{array}{l}\text { Investigation of Degradation Mechanisms of } \mathrm{Cr} \\
\text { Coated Zirconium Alloy Cladding in Reactivity } \\
\text { Initiated Accident (RIA) }\end{array}$ & Hwasung Yeom & $\begin{array}{l}\text { University of } \\
\text { Wisconsin }\end{array}$ & $\begin{array}{l}\text { Idaho National } \\
\text { Laboratory }\end{array}$ \\
\hline $\begin{array}{l}\text { Irradiation of Sensors and Adhesive Couplants } \\
\text { for Application in LWR Primary Loop Piping and } \\
\text { Components }\end{array}$ & James Wall & $\begin{array}{l}\text { Electric Power } \\
\text { Research Institute }\end{array}$ & $\begin{array}{l}\text { North Carolina State } \\
\text { University } \\
\text { Oak Ridge National } \\
\text { Laboratory }\end{array}$ \\
\hline $\begin{array}{l}\text { Machine Learning on High-Throughput Databases } \\
\text { of Irradiation Response and Corrosion Properties } \\
\text { of Selected Compositionally Complex Alloys for } \\
\text { Structural Nuclear Materials }\end{array}$ & Dane Morgan & $\begin{array}{l}\text { University of } \\
\text { Wisconsin }\end{array}$ & $\begin{array}{l}\text { University of } \\
\text { Wisconsin } \\
\text { Idaho National } \\
\text { Laboratory } \\
\text { Center for Advanced } \\
\text { Energy Studies }\end{array}$ \\
\hline $\begin{array}{l}\text { Synergy of Radiation Damage with } \\
\text { Corrosion Processes Through a Separate Effect } \\
\text { Investigation Approach }\end{array}$ & Djamel Kaoumi & $\begin{array}{l}\text { North Carolina State } \\
\text { University }\end{array}$ & $\begin{array}{l}\text { Argonne National } \\
\text { Laboratory } \\
\text { Center for Advanced } \\
\text { Energy Studies }\end{array}$ \\
\hline $\begin{array}{l}\text { X-ray Diffraction Tomography Analysis of } \mathrm{SiC} \\
\text { Composite Tubes Neutron-Irradiated with a Radial } \\
\text { High Heat Flux }\end{array}$ & Takaaki Koyanagi & $\begin{array}{l}\text { Oak Ridge National } \\
\text { Laboratory }\end{array}$ & $\begin{array}{l}\text { Oak Ridge National } \\
\text { Laboratory }\end{array}$ \\
\hline
\end{tabular}





\section{Rapid Turnaround Experiments, $1^{\text {st }}$ Call}

\begin{tabular}{|c|c|c|c|}
\hline Title & $\begin{array}{l}\text { Principal } \\
\text { Investigator }\end{array}$ & PI Organization & NSUF Facilities \\
\hline $\begin{array}{l}\text { Atom Probe Characterization of Neutron Irradiated } \\
\text { Commercial ZIRLO }^{\circledR} \text { and AXIOM X2 }{ }^{\circledR} \text { Alloys }\end{array}$ & Mukesh Bachhav & $\begin{array}{l}\text { Idaho National } \\
\text { Laboratory }\end{array}$ & $\begin{array}{l}\text { Center for Advanced } \\
\text { Energy Studies } \\
\text { Idaho National } \\
\text { Laboratory }\end{array}$ \\
\hline $\begin{array}{l}\text { Atom Probe Studies on the Ballistic Mixing } \\
\text { Induced Precipitates in Heavy Ion Irradiated } \\
\text { CuNb Multilayers System }\end{array}$ & Zhexian Zhang & $\begin{array}{l}\text { University of New } \\
\text { Mexico }\end{array}$ & $\begin{array}{l}\text { Center for Advanced } \\
\text { Energy Studies }\end{array}$ \\
\hline $\begin{array}{l}\text { Atom Probe Tomography Study of Elemental } \\
\text { Segregation and Precipitation in Ion-Irradiated } \\
\text { Advanced Austenitic Alloy A709 }\end{array}$ & $\begin{array}{l}\text { Dominic } \\
\text { Piedmont }\end{array}$ & University of Illinois & $\begin{array}{l}\text { Center for Advanced } \\
\text { Energy Studies }\end{array}$ \\
\hline $\begin{array}{l}\text { Creation of Gas Bubble Superlattice in Tungsten } \\
\text { and Tungsten Alloys }\end{array}$ & Jian Gan & $\begin{array}{l}\text { Idaho National } \\
\text { Laboratory }\end{array}$ & $\begin{array}{l}\text { Idaho National } \\
\text { Laboratory } \\
\text { Argonne National } \\
\text { Laboratory }\end{array}$ \\
\hline $\begin{array}{l}\text { Effects of Cold Rolling and Induction Casting on the } \\
\text { Microstructural Evolution in Irradiated Uranium- } \\
\text { 10wt.\% Molybdenum (U-Mo) Alloys }\end{array}$ & Gyuchul Park & Purdue University & $\begin{array}{l}\text { Idaho National } \\
\text { Laboratory }\end{array}$ \\
\hline $\begin{array}{l}\text { Functional Testing of an Optical Fiber Based Gamma } \\
\text { Thermometer in the HFIR Spent Fuel Pool }\end{array}$ & Thomas Blue & $\begin{array}{l}\text { The Ohio State } \\
\text { University }\end{array}$ & $\begin{array}{l}\text { Oak Ridge National } \\
\text { Laboratory }\end{array}$ \\
\hline $\begin{array}{l}\text { Insights into the Forced Chemical Redistribution in } \\
\text { Multi-Layered } \mathrm{Zr} / \mathrm{Nb} \text { Nanocomposites under Heavy } \\
\text { Dose Ion Irradiation }\end{array}$ & $\begin{array}{l}\text { Madhavan } \\
\text { Radhakrishnan }\end{array}$ & $\begin{array}{l}\text { University of New } \\
\text { Mexico }\end{array}$ & $\begin{array}{l}\text { Center for Advanced } \\
\text { Energy Studies }\end{array}$ \\
\hline $\begin{array}{l}\text { In Situ Micro-tensile Testing for Measuring } \\
\text { Grain Boundary Strength of NiCr Alloys under } \\
\text { Simultaneous Irradiation and Corrosion } \\
\text { Environments }\end{array}$ & Weiyue Zhou & $\begin{array}{l}\text { Massachusetts } \\
\text { Institute of } \\
\text { Technology }\end{array}$ & $\begin{array}{l}\text { Idaho National } \\
\text { Laboratory }\end{array}$ \\
\hline $\begin{array}{l}\text { Investigating the Effect of Irradiation on Hydride } \\
\text { Formation and Morphology in Zirconium Alloys }\end{array}$ & Mark Daymond & Queen's University & $\begin{array}{l}\text { Idaho National } \\
\text { Laboratory }\end{array}$ \\
\hline $\begin{array}{l}\text { Investigating the Performance of Refractory } \\
\text { High Entropy Alloys Under Irradiation and } \\
\text { Mechanical Extremes }\end{array}$ & Osman El Atwani & $\begin{array}{l}\text { Los Alamos National } \\
\text { Laboratory }\end{array}$ & $\begin{array}{l}\text { Argonne National } \\
\text { Laboratory }\end{array}$ \\
\hline $\begin{array}{l}\text { Ion Irradiation and TEM Characterization of Polymer } \\
\text { Derived C-SiC-SiOC Nanocomposites }\end{array}$ & Kaustubh Bawane & $\begin{array}{l}\text { Virginia Polytechnic } \\
\text { Institute and State } \\
\text { University }\end{array}$ & $\begin{array}{l}\text { Idaho National } \\
\text { Laboratory } \\
\text { Texas A\&M } \\
\text { University }\end{array}$ \\
\hline
\end{tabular}




\begin{tabular}{|c|c|c|c|}
\hline Title & $\begin{array}{l}\text { Principal } \\
\text { Investigator }\end{array}$ & PI Organization & NSUF Facilities \\
\hline $\begin{array}{l}\text { Microstructural Characterization of Neutron } \\
\text { Irradiated HT-UPS Steel to Support High-Energy } \\
\text { X-ray Studies }\end{array}$ & Sri Tapaswi Nori & Purdue University & $\begin{array}{l}\text { Idaho National } \\
\text { Laboratory }\end{array}$ \\
\hline $\begin{array}{l}\text { Microstructure Characterization of }{ }^{6} \mathrm{Li}(\mathrm{n}, \alpha)^{3} \mathrm{H} \\
\text { Reaction Damage Sapphire Claddings }\end{array}$ & Joshua Jones & $\begin{array}{l}\text { The Ohio State } \\
\text { University }\end{array}$ & $\begin{array}{l}\text { Idaho National } \\
\text { Laboratory } \\
\text { The Ohio State } \\
\text { University }\end{array}$ \\
\hline $\begin{array}{l}\text { Post-Irradiation Microstructure Characterization of } \\
\text { Radiation-Tolerant Piezoelectric Materials }\end{array}$ & Eva Zarkadoula & $\begin{array}{l}\text { Oak Ridge National } \\
\text { Laboratory }\end{array}$ & $\begin{array}{l}\text { Pacific Northwest } \\
\text { National Laboratory }\end{array}$ \\
\hline $\begin{array}{l}\text { Pulsed Neutron Characterization of U-1Pd-10Zr } \\
\text { Irradiated Fuel }\end{array}$ & Jason Harp & $\begin{array}{l}\text { Oak Ridge National } \\
\text { Laboratory }\end{array}$ & $\begin{array}{l}\text { Los Alamos National } \\
\text { Laboratory }\end{array}$ \\
\hline $\begin{array}{l}\text { Radiation-Accelerated, Strain-Induced Martensitic } \\
\text { Transformation and Its Potential Impact on } \\
\text { Performance of } 304 \text { Stainless Steel Irradiated to High } \\
\text { Doses in PWRs Following Plant Life Extension }\end{array}$ & Frank Garner & $\begin{array}{l}\text { Radiation Effects } \\
\text { Consulting }\end{array}$ & $\begin{array}{l}\text { Oak Ridge National } \\
\text { Laboratory }\end{array}$ \\
\hline $\begin{array}{l}\text { Recrystallization Behavior in Irradiated Gadolinium } \\
\text { Titanate as a Proxy for Structural Disorder }\end{array}$ & Jessica Krogstad & University of Illinois & $\begin{array}{l}\text { Argonne National } \\
\text { Laboratory }\end{array}$ \\
\hline $\begin{array}{l}\text { The Origin if Exceptional IASCC Resistance of the } \\
\text { Additively-Manufactured Stainless Steel after Hot } \\
\text { Isostatic Pressing }\end{array}$ & Xiaoyuan Lou & Auburn University & $\begin{array}{l}\text { Center for Advanced } \\
\text { Energy Studies } \\
\text { University of } \\
\text { Michigan }\end{array}$ \\
\hline $\begin{array}{l}\text { Unraveling the Mystery of Irradiation-Induced Void } \\
\text { Closure }\end{array}$ & Janelle Wharry & Purdue University & $\begin{array}{l}\text { Center for Advanced } \\
\text { Energy Studies }\end{array}$ \\
\hline
\end{tabular}




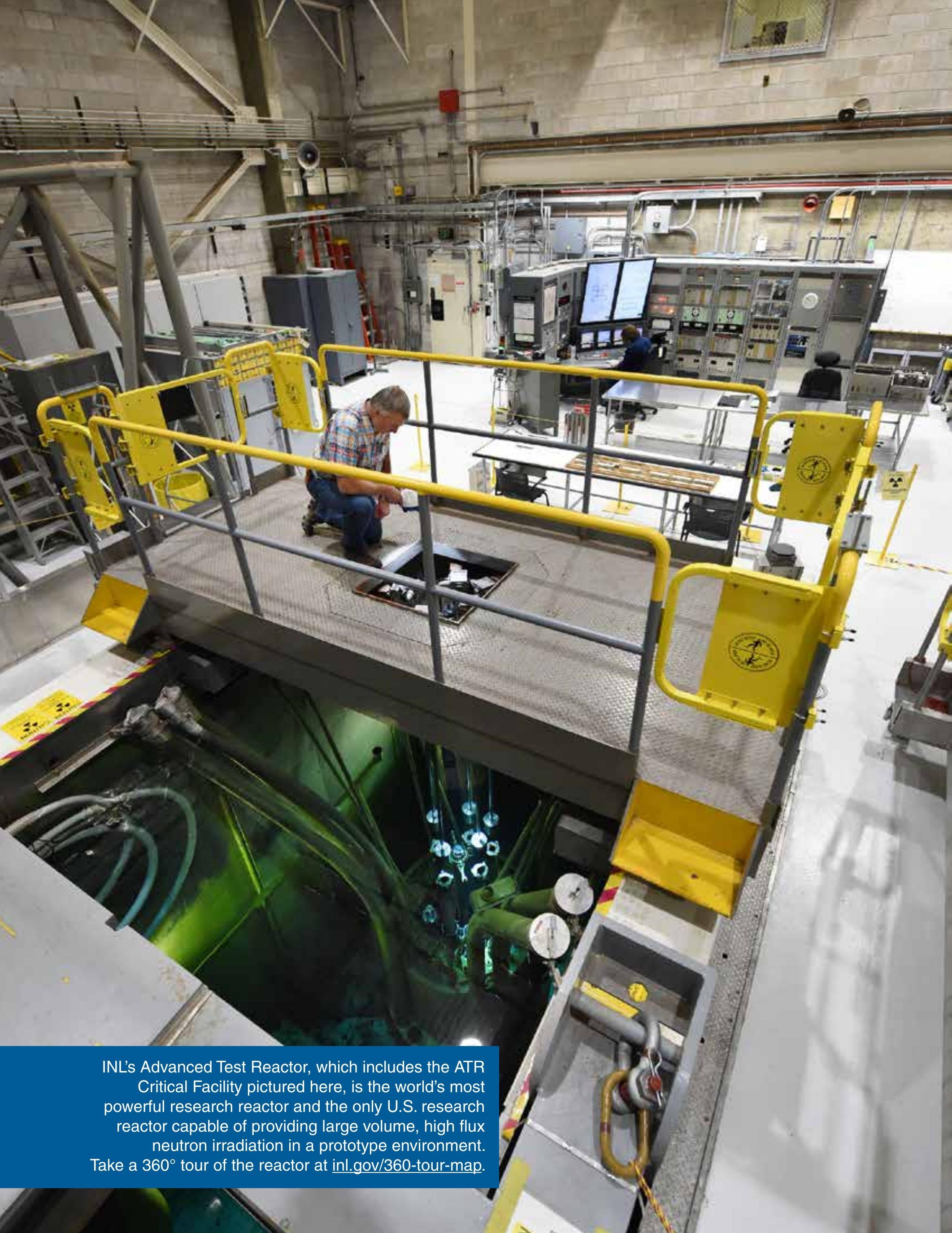




\section{Rapid Turnaround Experiments, $2^{\text {nd }}$ Call}

\begin{tabular}{|c|c|c|c|}
\hline Title & $\begin{array}{l}\text { Principal } \\
\text { Investigator }\end{array}$ & PI Organization & NSUF Facilities \\
\hline $\begin{array}{l}\text { Tritium Permeation from High Temperature FLiBe } \\
\text { under Neutron Irradiation }\end{array}$ & Lin-wen Hu & $\begin{array}{l}\text { Massachusetts } \\
\text { Institute of } \\
\text { Technology }\end{array}$ & $\begin{array}{l}\text { Massachusetts } \\
\text { Institute of } \\
\text { Technology }\end{array}$ \\
\hline 3D Strain and Phase Mapping in AM Fe-9Cr Steel & Ben Eftink & $\begin{array}{l}\text { Los Alamos National } \\
\text { Laboratory }\end{array}$ & $\begin{array}{l}\text { Brookhaven National } \\
\text { Laboratory }\end{array}$ \\
\hline $\begin{array}{l}\text { Characterization of Oxide Porosity in Irradiated } \\
\text { Zirconium Pre-Transition Corrosion Films }\end{array}$ & Adrien Couet & $\begin{array}{l}\text { University of } \\
\text { Wisconsin }\end{array}$ & $\begin{array}{l}\text { North Carolina State } \\
\text { University }\end{array}$ \\
\hline $\begin{array}{l}\text { Chemi STEM Characterization of Bulk Heavy Ion } \\
\text { Irradiated Complex Concentrated Alloys }\end{array}$ & Calvin Parkin & $\begin{array}{l}\text { University of } \\
\text { Wisconsin }\end{array}$ & $\begin{array}{l}\text { Idaho National } \\
\text { Laboratory }\end{array}$ \\
\hline $\begin{array}{l}\text { Crystallization and Phase-Separation in Melt-Derived } \\
\text { Nuclear Waste Forms }\end{array}$ & Maik Lang & $\begin{array}{l}\text { University of } \\
\text { Tennessee }\end{array}$ & $\begin{array}{l}\text { Brookhaven National } \\
\text { Laboratory }\end{array}$ \\
\hline $\begin{array}{l}\text { Determination of the Evolution of Residual Stress in } \\
\text { Nuclear Graphite with Irradiation }\end{array}$ & Boris Khaykovich & $\begin{array}{l}\text { Massachusetts } \\
\text { Institute of } \\
\text { Technology }\end{array}$ & $\begin{array}{l}\text { Los Alamos National } \\
\text { Laboratory } \\
\text { Massachusetts } \\
\text { Institute of } \\
\text { Technology }\end{array}$ \\
\hline $\begin{array}{l}\text { Development of Radiation Tolerant Matrices for Rare- } \\
\text { Earths Designed for Burnable Poisons as Part of the } \\
\text { Nuclear Fuel Array }\end{array}$ & Nestor Zaluzec & $\begin{array}{l}\text { Argonne National } \\
\text { Laboratory }\end{array}$ & $\begin{array}{l}\text { Argonne National } \\
\text { Laboratory }\end{array}$ \\
\hline $\begin{array}{l}\text { Effects of Energy Deposition Resulting in Radiation } \\
\text { Induced Defects on the Thermal Conductivity of } \mathrm{UO}_{2} \\
\text { Fuel Pellets with Negligible Burnup }\end{array}$ & Tro Babikian & $\begin{array}{l}\text { University of } \\
\text { California, Irvine }\end{array}$ & $\begin{array}{l}\text { Idaho National } \\
\text { Laboratory }\end{array}$ \\
\hline $\begin{array}{l}\text { Effects of Helium on the Defect Accumulation under } \\
\text { Ion Implantation in a Fe-9Cr Alloy }\end{array}$ & Hongbing Yu & University of Oxford & $\begin{array}{l}\text { Argonne National } \\
\text { Laboratory }\end{array}$ \\
\hline $\begin{array}{l}\text { Electron Probe Microanalysis (EPMA) of a Metallic } \\
\text { Fuel Transmutation Alloy for Fast Reactor: A } \\
\text { Microchemical Comparison between Fast Reactor } \\
\text { and Simulated Fast Reactor Irradiation }\end{array}$ & Luca Capriotti & $\begin{array}{l}\text { Idaho National } \\
\text { Laboratory }\end{array}$ & $\begin{array}{l}\text { Idaho National } \\
\text { Laboratory }\end{array}$ \\
\hline $\begin{array}{l}\text { Evolution of } \mathrm{Ga}_{2} \mathrm{O}_{3} \text { Native Point Defects, Donors and } \\
\text { Acceptors with Neutron Irradiation }\end{array}$ & Leonard Brillson & $\begin{array}{l}\text { The Ohio State } \\
\text { University }\end{array}$ & $\begin{array}{l}\text { The Ohio State } \\
\text { University }\end{array}$ \\
\hline $\begin{array}{l}\text { Identification of Irradiation-Induced Phase Evolution } \\
\text { in Pu-Am-Zr Fuels }\end{array}$ & Assel Aitkaliyeva & University of Florida & $\begin{array}{l}\text { Idaho National } \\
\text { Laboratory }\end{array}$ \\
\hline $\begin{array}{l}\text { In Situ and Ex Situ Investigations of Irradiation Damage } \\
\text { in Nanostructured ODS High-Entropy Alloys }\end{array}$ & Bai Cui & $\begin{array}{l}\text { University of } \\
\text { Nebraska, Lincoln }\end{array}$ & $\begin{array}{l}\text { University of } \\
\text { Michigan }\end{array}$ \\
\hline
\end{tabular}




\begin{tabular}{|c|c|c|c|}
\hline Title & $\begin{array}{l}\text { Principal } \\
\text { Investigator }\end{array}$ & PI Organization & NSUF Facilities \\
\hline $\begin{array}{l}\text { In Situ Dual Beam Radiation on Additively } \\
\text { Manufactured Haynes } 230 \text { Ni alloys with Precipitates } \\
\text { New Proposal }\end{array}$ & Xinghang Zhang & Purdue University & $\begin{array}{l}\text { Argonne National } \\
\text { Laboratory }\end{array}$ \\
\hline $\begin{array}{l}\text { In Situ High Temperature } \mathrm{UO}_{2} \text { Grain Boundary and } \\
\text { Bulk Mechanics under Irradiation }\end{array}$ & Shen Dillon & University of Illinois & $\begin{array}{l}\text { Sandia National } \\
\text { Laboratories }\end{array}$ \\
\hline $\begin{array}{l}\text { In Situ Microstructural Evolution and Phase Transition } \\
\text { of Irradiated and Transient Metallic Fuel for M\&S } \\
\text { Validation }\end{array}$ & Andrea Jokisaari & $\begin{array}{l}\text { Idaho National } \\
\text { Laboratory }\end{array}$ & $\begin{array}{l}\text { Idaho National } \\
\text { Laboratory }\end{array}$ \\
\hline $\begin{array}{l}\text { In Situ Nano-Tensile Testing of Neutron-Irradiated } \\
\text { HT-9 Steel }\end{array}$ & Tanvi Ajantiwalay & University of Florida & $\begin{array}{l}\text { Center for Advanced } \\
\text { Energy Studies }\end{array}$ \\
\hline $\begin{array}{l}\text { Investigation of the Effects of Neutron Irradiation on } \\
\text { Minerals of Concrete Aggregates }\end{array}$ & $\begin{array}{l}\text { Matheus Araujo } \\
\text { Tunes }\end{array}$ & $\begin{array}{l}\text { Montanuniversitaet } \\
\text { Leoben }\end{array}$ & $\begin{array}{l}\text { Oak Ridge National } \\
\text { Laboratory }\end{array}$ \\
\hline $\begin{array}{l}\text { Investigation of Total Dose Effects on Data Corruption } \\
\text { Rates in High Density 3-D Non-Volatile Memory }\end{array}$ & Biswajit Ray & $\begin{array}{l}\text { University of } \\
\text { Alabama }\end{array}$ & $\begin{array}{l}\text { Sandia National } \\
\text { Laboratories }\end{array}$ \\
\hline $\begin{array}{l}\text { Ion Beam Irradiation and In Situ TEM Characterization } \\
\text { of High Entropy Titanate Pyrochlores }\end{array}$ & Jie Lian & $\begin{array}{l}\text { Rensselaer } \\
\text { Polytechnic Institute }\end{array}$ & $\begin{array}{l}\text { Argonne National } \\
\text { Laboratory }\end{array}$ \\
\hline $\begin{array}{l}\text { Ion Irradiation and Examination of Metastability } \\
\text { Engineered Stainless High Entropy Alloy }\end{array}$ & Rajiv Mishra & $\begin{array}{l}\text { University of North } \\
\text { Texas }\end{array}$ & $\begin{array}{l}\text { Center for Advanced } \\
\text { Energy Studies } \\
\text { Texas A\&M } \\
\text { University }\end{array}$ \\
\hline $\begin{array}{l}\text { Mechanical Testing of Posttest LOCA Sample with } \\
\text { Irradiated High Burnup Fuel Rods }\end{array}$ & Nicholas Brown & $\begin{array}{l}\text { University of } \\
\text { Tennessee }\end{array}$ & $\begin{array}{l}\text { Oak Ridge National } \\
\text { Laboratory }\end{array}$ \\
\hline $\begin{array}{l}\text { Micro-Mechanical Characterization of Proton } \\
\text { Induced Long Range Ordering in Ni-Cr Model Alloy }\end{array}$ & Fei Teng & $\begin{array}{l}\text { Idaho National } \\
\text { Laboratory }\end{array}$ & $\begin{array}{l}\text { University of } \\
\text { California, Berkeley }\end{array}$ \\
\hline $\begin{array}{l}\text { Microstructural Characterization of Neutron } \\
\text { Irradiated HT-9 Heats (ORNL, LANL and EBR II) at } \\
\text { LWR and Fast Reactor Relevant Temperatures }\end{array}$ & Indrajit Charit & University of Idaho & $\begin{array}{l}\text { Pacific Northwest } \\
\text { National Laboratory }\end{array}$ \\
\hline $\begin{array}{l}\text { Morphological Response of Spherical and Platelet } \\
\text { MX-Type Precipitates to In Situ Ion Irradiation in } \\
\text { Novel Fe-Based Alloys }\end{array}$ & Lizhen Tan & $\begin{array}{l}\text { Oak Ridge National } \\
\text { Laboratory }\end{array}$ & $\begin{array}{l}\text { University of } \\
\text { Michigan }\end{array}$ \\
\hline $\begin{array}{l}\text { Phase Stability of } \alpha \text { ' Precipitates in Pre-Aged Fe- } 25 \mathrm{Cr} \\
\text { Model Binary Alloys after Ion Irradiation }\end{array}$ & Ling Wang & $\begin{array}{l}\text { University of } \\
\text { Tennessee }\end{array}$ & $\begin{array}{l}\text { Center for Advanced } \\
\text { Energy Studies }\end{array}$ \\
\hline
\end{tabular}




\begin{tabular}{|c|c|c|c|}
\hline Title & $\begin{array}{l}\text { Principal } \\
\text { Investigator }\end{array}$ & PI Organization & NSUF Facilities \\
\hline $\begin{array}{l}\text { Probing the Mobility of Radiation Induced Defects in } \\
\text { Nickel/Oxide Systems through In Situ TEM Irradiation }\end{array}$ & $\begin{array}{l}\text { Martin Owusu- } \\
\text { Mensah }\end{array}$ & $\begin{array}{l}\text { North Carolina State } \\
\text { University }\end{array}$ & $\begin{array}{l}\text { Argonne National } \\
\text { Laboratory }\end{array}$ \\
\hline $\begin{array}{l}\text { Radiation Effect to the Deformation Mechanism of } \\
\text { Alloys } 800 \mathrm{H} \text { and } 800 \mathrm{H} \text {-TMP }\end{array}$ & Weicheng Zhong & $\begin{array}{l}\text { Oak Ridge National } \\
\text { Laboratory }\end{array}$ & $\begin{array}{l}\text { Oak Ridge National } \\
\text { Laboratory }\end{array}$ \\
\hline $\begin{array}{l}\text { Radiation Tolerance of Advanced Multilayered } \\
\text { Coating: an In Situ TEM Investigation }\end{array}$ & Yinbin Miao & $\begin{array}{l}\text { Argonne National } \\
\text { Laboratory }\end{array}$ & $\begin{array}{l}\text { Argonne National } \\
\text { Laboratory }\end{array}$ \\
\hline $\begin{array}{l}\text { Radiation-Induced Signal Attenuation and Drift of } \\
\text { Single Crystal Sapphire Optical Fiber Sensors }\end{array}$ & Christian Petrie & $\begin{array}{l}\text { Oak Ridge National } \\
\text { Laboratory }\end{array}$ & $\begin{array}{l}\text { Oak Ridge National } \\
\text { Laboratory }\end{array}$ \\
\hline $\begin{array}{l}\text { Secondary Phase Formation in Irradiated Metallic } \\
\text { Fuels: Understanding Phase Structure, Chemistry and } \\
\text { Light-Element Stabilization }\end{array}$ & Karen Wright & $\begin{array}{l}\text { Idaho National } \\
\text { Laboratory }\end{array}$ & $\begin{array}{l}\text { Idaho National } \\
\text { Laboratory }\end{array}$ \\
\hline $\begin{array}{l}\text { Study of Irradiation Effects on Tantalum Alloys for } \\
\text { Fast-Spectrum Self-Powered Neutron Detectors }\end{array}$ & $\begin{array}{l}\text { Kathleen (Callie) } \\
\text { Goetz }\end{array}$ & $\begin{array}{l}\text { University of } \\
\text { Tennessee }\end{array}$ & $\begin{array}{l}\text { Oak Ridge National } \\
\text { Laboratory }\end{array}$ \\
\hline $\begin{array}{l}\text { Study of the Effect of Water Chemistry on the } \\
\text { Performance of CVD-SiC by Means of In Situ Proton } \\
\text { Irradiation-Corrosion Testing }\end{array}$ & $\begin{array}{l}\text { Konstanza } \\
\text { Lambrinou }\end{array}$ & $\begin{array}{l}\text { University of } \\
\text { Huddersfield }\end{array}$ & $\begin{array}{l}\text { University of } \\
\text { Michigan }\end{array}$ \\
\hline $\begin{array}{l}\text { Towards Understanding Fuel Clad Chemical } \\
\text { Interactions in FeCrAl Alloys }\end{array}$ & Andrew Hoffman & $\begin{array}{l}\text { General Electric } \\
\text { Global Research }\end{array}$ & $\begin{array}{l}\text { Idaho National } \\
\text { Laboratory }\end{array}$ \\
\hline $\mathrm{UCl}_{4} / \mathrm{UCl}_{3}$ Speciation & Haiyan Zhao & University of Idaho & $\begin{array}{l}\text { Idaho National } \\
\text { Laboratory }\end{array}$ \\
\hline $\begin{array}{l}\text { Understand the Fission Products Behavior and } \\
\text { Irradiation Effects in UCO Fuel Kernels of Irradiated } \\
\text { AGR-1 and AGR-2 TRISO Fuel Particles by Using } \\
\text { Atom Probe Tomography }\end{array}$ & Zhenyu Fu & University of Florida & $\begin{array}{l}\text { Center for Advanced } \\
\text { Energy Studies }\end{array}$ \\
\hline $\begin{array}{l}\text { Understanding the Effect of Neutron Attenuation on } \\
\text { Cu-Rich Precipitate Formation in Reactor Pressure } \\
\text { Vessel Steels using STEM-EDS }\end{array}$ & $\begin{array}{l}\text { Philip } \\
\text { Edmondson }\end{array}$ & $\begin{array}{l}\text { Oak Ridge National } \\
\text { Laboratory }\end{array}$ & $\begin{array}{l}\text { Oak Ridge National } \\
\text { Laboratory }\end{array}$ \\
\hline
\end{tabular}





\section{Select Project REPORTS}

Ihrough its RTE and CINR calls for proposals, NSUF grants access to its facilities for researchers to conduct their studies to further the 1 understanding of the effects of irradiation on nuclear fuels and materials. The following reports resulted from these NSUF projects.

\section{Technical Reports}

Radiation-Enhanced Diffusion of Ag, Ag-Pd, Eu, and Sr in Neutron Irradiated PyC/SiC Diffusion Couples

HPC Access to Advance Understanding of Fission Gas Behavior in Nuclear Fuel

\section{Short Communications}

Microstructural Characterization of the Radiation Tolerance of Advanced Joining Techniques for Oxide Dispersion Strengthened Steels under Ion Irradiation

In Situ Ion Irradiation of Second Phase Particles in Zirconium Fuel Cladding Hydrogen Analysis and Oxide Characterization of Reactor Irradiated Zr-Nb Alloy APT and TEM Study of Redistribution of Alloying Elements in ZrNb Alloys Following Proton Irradiation: Effects on In-Reactor Corrosion Kinetics Irradiation Responses of Ultrastrong Nano Precipitation Martensite Steel Study of the Factors Affecting the Radiation Tolerance of MAX Phases for Innovative Fuel Cladding Concepts

Micro-mechanical Characterization of Long Range Order in Ni-Cr Alloys and Their Response to Radiation Damage

Mechanical Characterization of Three Heats (ORNL, LANL and EBR II) of HT-9 after Side-by-side Neutron Irradiation at LWR and Fast Reactor Relevant Temperatures

Synchrotron XRD Characterization of Long Range Order in Ni-Cr Alloys Formed by Isothermal Aging or Irradiation

Irradiation Damage in (Hf0.2Zr0.2Ta0.2Nb0.2Ti0.2)C High-Entropy Ceramics 


\title{
Technical Report
}

\section{Radiation Enhanced Diffusion of Ag, Ag-Pd, Eu, and $\mathrm{Sr}$ in Neutron Irradiated PyC/SiC Diffusion Couples}

\author{
Tyler J Gerczak - Oak Ridge National Laboratory - gerczaktj@ornl.gov
}

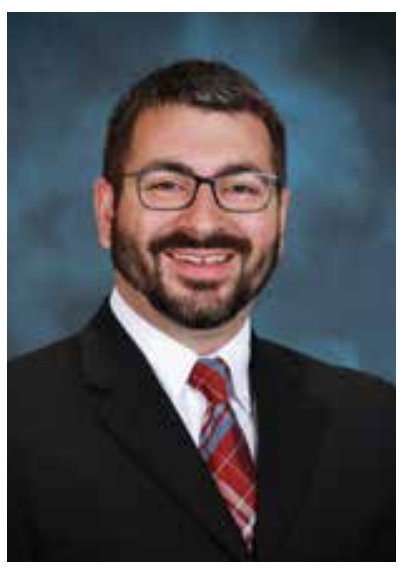

$\perp$ he layers in tristructural isotropic (TRISO) coated particle fuel are engineered to work as an integrated system to limit failure and fission product release. Fission product release from TRISO fuel can occur through multiple mechanisms, including through-layer diffusive release and release due to the failure of some or all three TRISO layers. The primary focus of this project was the development and demonstration of a sample design that could explore representative TRISO layers as well as the impact of intentionally different properties on layer performance. A novel pyrocarbon (PyC) and silicon carbide ( $\mathrm{SiC})$ substrate design was developed that used identical fluidized bed-chemical vapor deposition (FB-CVD) systems to produce TRISO fuel. Following the development of the representative sample design, select samples were exposed to simulated fission products through ion implantation and were subjected to neutron irradiation in the High Flux Isotope Reactor (HFIR) at conditions relevant to high-temperature gas-cooled reactors (HTGRs). A PIE campaign was undertaken to explore the interaction of select fission products with the $\mathrm{PyC} / \mathrm{SiC}$ layers and the response of the layers to irradiation (e.g., structural and mechanical property evolution).

\section{Introduction}

The spherical TRISO particle architecture consists of a fuel kernel surrounded by four isotropic layers, the first layer being a porous carbon buffer layer followed by subsequent layers of inner pyrolytic carbon (IPyC), SiC, and outer pyrolytic carbon (OPyC). Each layer serves a purpose during fabrication and operation. The SiC layer is a primary structural member and a barrier to the release of metallic fission products not retained in the central fuel kernel. The IPyC layer protects the SiC layer from fission product attack at the internal SiC surface, while the IPyC and OPyC layers put the layer under compression during operation. The result is a hybrid fuel system that uses the cooperative nature of the design to promote effective fuel performance under operation. Deeper insight into how specific variations in the IPyC and $\mathrm{SiC}$ layer properties influence the integral nature of the layer response is important to understanding how TRISO particles perform under irradiation and potential accident scenarios.

The release of fission products from TRISO fuel in HTGRs limits the operational lifetime and ultimate operational temperature of the fuel due to potential safety and maintenance concerns. This results in economic penalties that in turn reduce the attractiveness of HTGRs for cost-competitive energy market 
The demonstration of the novel separate effects testing capabilities for relevant TRISO fuel materials and extraction of 3D data structures developed within this project has great potential to provide representative data to support and validate fuel performance models which aim to improve safety and efficiency of advanced reactors looking to deploy the TRISO fuel concept.

sectors. Through-layer diffusive fission product release has been observed for select fission products. For instance, margin safety tests conducted out-ofpile at $1800^{\circ} \mathrm{C}$ for $300 \mathrm{~h}$ have indicated release by through-layer diffusive processes of silver, europium, and strontium in fine grained SiC TRISO variants while larger grained $\mathrm{SiC}$ layer TRISO variants did not exhibit release [1]. The observed release of fission products, particularly silver, at lower temperature in-pile suggests the possibility of radiation enhanced diffusion and the need for testing to explore the influence of neutron irradiation on silver diffusion in particular.

The interaction of fission products with the $\mathrm{SiC}$ layer is influenced by the nature of the IPyC/SiC interface. Significant variation in how fission products are accommodated at the $\mathrm{IPyC} / \mathrm{SiC}$ interface has been observed during PIE of irradiated TRISO fuel particles [2]. It is hypothesized that the structure, particularly interpenetration of $\mathrm{SiC}$ in the IPyC and the open porosity at the interface, impacts the interactions of fission products with the SiC layer. Lastly, the primary failure mechanism for UCO TRISO fuel is fracture of the IPyC, leading to localized through-layer corrosion of the $\mathrm{SiC}$ layer by palladium. The localized corrosion is accelerated due to the exposed nature of the $\mathrm{SiC}$ layer and increased concentration of palladium at the interface [3]. Understanding the influence of layer properties on these observed phenomena and the change in layer properties under irradiation is critical to being able to predict TRISO fuel behavior.

The goals of this project were to establish an approach to explore and measure the diffusion of relevant fission product systems (silver, palladium, europium, and strontium) in representative $\mathrm{PyC} / \mathrm{SiC}$ substrates and $\mathrm{PyC} / \mathrm{SiC}$ substrates with intentionally varied layer properties as well as the 
"This NSUF project

was a great opportunity

to advance TRISO fuel

research and provided

me a platform to develop

investigative skills on the

effects of irradiation on

ceramic materials during

my postdoctoral research."

- Rachel L. Seibert

Research Associate influence of irradiation on the diffusion of select fission product species. An additional focus was to establish a methodology for measuring important interface and layer properties and measure their change as a function of irradiation at HTGR relevant temperatures. Primary measurements include layer properties (e.g., anisotropy, hardness, modulus) and interfacial structure (porosity and interfacial stitching). Measuring the change in these properties is important for predicting fuel performance specifically to provide support for properties used by multiphysics models [4].

\section{Experimental or Technical Approach}

A foundational aspect of the project was the development and validation of a novel specimen geometry. The design, development, and fabrication of the representative $\mathrm{PyC} / \mathrm{SiC}$ samples was accomplished with TRISO behavior and the irradiation capsule design in mind to isolate specific variables and provide "separate effects testing." Fabrication was ultimately governed by targeting specific layer properties representative of the TRISO fuel from the U.S. DOE Advanced Gas Reactor Fuel Qualification and Development (AGR) Program. Other constraints included a thin, planar geometry to facilitate modern depth profiling techniques and reduce thermal gradients across the samples during irradiation. The last constraint was development of a self-isolated system after introduction of simulated fission products to represent the same diffusion environment and pathway present in the TRISO fuel system.

Fabrication was conducted on a 2 in. diameter fluidized bed - chemical vapor deposition (FB-CVD) coater identical to that used to produce fuel for the first AGR irradiation experiment, AGR 1. The feasibility of the approach was determined by first exploring the fluidization behavior of various flat substrates. Optimization of the substrate properties was accomplished by targeting conditions typical of TRISO fuel properties followed by exploration of the change in properties relative to processing conditions, which involved supporting $\mathrm{PyC}$ density and $\mathrm{SiC}$ grain size measurements. The properties relevant to sample variants were grain size and PyC density, with intentionally large grain sizes targeted ( $\mathrm{SiC}$ variant) and intentionally dense $\mathrm{PyC}$ to control the interface being targeted (PyC variant) relative to the baseline sample properties which targeted AGR 2 properties. Simulated fission products were introduced to a subset of specimens using ion implantation through a collaboration with the University of Michigan's Ion Beam Laboratory. Following implantation, a high-temperature $\mathrm{SiC}$ seal coating was applied to the sample surface. This capability was developed under this project and resulted in the development of a novel approach that used FB-CVD techniques to deposit methyl-silane derived $\mathrm{SiC}$ followed by methyl-trichlorosilane derived $\mathrm{SiC}$ deposition. The seal-coating development was essential to create a selfisolated system in which implanted silver was not readily available to volatilize and leave the system during thermal exposure. Figure 1 shows a cross section of the planar $\mathrm{PyC} / \mathrm{SiC}$ substrate design. A thick supporting PyC layer was incorporated into the design to provide some robustness to the samples for survivability and handling. The sample development process is summarized in ref [5]. 


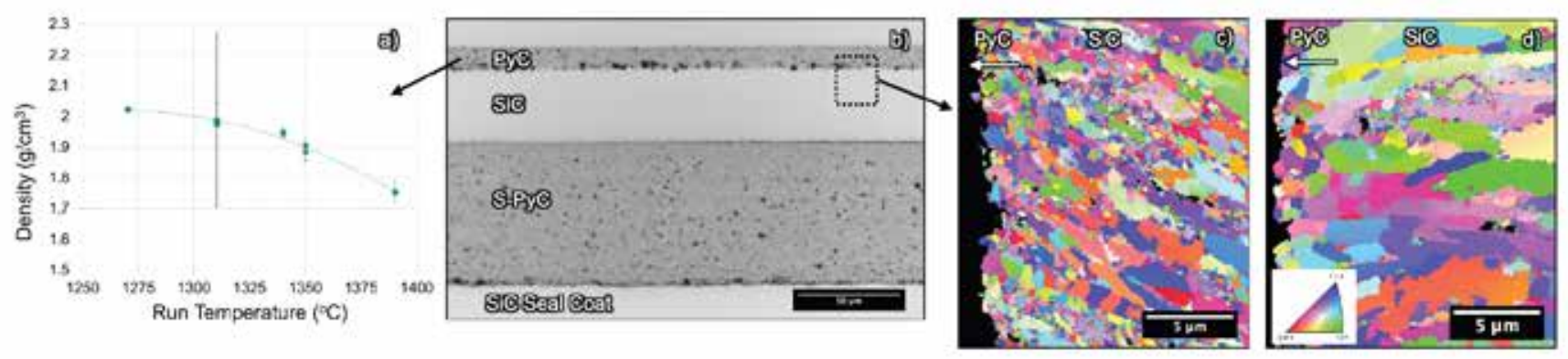

The final construction consisted of a $>20 \mu \mathrm{m}$ thick SiC seal coat on a layered construction of $\sim 8-12 \mu \mathrm{m}$ thick PyC layer, 35-50 $\mu \mathrm{m}$ thick SiC layer, and $>60 \mu \mathrm{m}$ thick support PyC [6]. A total of $59 \mathrm{FB}-\mathrm{CVD}$ runs were required to produce the final test samples.

The irradiation experiment was developed to match temperatures experienced by TRISO fuel in the AGR irradiation program [7] and explore two fluences to observe property changes as a function of time, temperature, and fluence. Two unique capsules were irradiated at $\sim 1027^{\circ} \mathrm{C}$ for $119.9 \mathrm{~h}$ and $\sim 1051^{\circ} \mathrm{C}$ for $245 \mathrm{~h}$, reaching fast fluences $(\mathrm{E}>0.18 \mathrm{MeV})$ of $4.4 \times 10^{24}$ and $9.0 \times 10^{24} \mathrm{n} / \mathrm{m}^{2}$, respectively. These values represent $\sim 0.5$ and $\sim 1.0 \mathrm{dpa}$ (displacements per atom) in the $\mathrm{SiC}$ layer. Property changes, microstructural evolution, and diffusion behavior were evaluated after disassembly and isolation of unique samples in hot cell facilities. Results were compared with as-fabricated, thermally equivalent samples or high-temperature exposure samples (up to $1700^{\circ} \mathrm{C}$ ). This project also represents exploration of the effective use of passive $\mathrm{SiC}$ temperature monitors above $900^{\circ} \mathrm{C}$, which is an important experimental capability for monitoring temperature during irradiation especially as higher temperature irradiations are sought.

\section{Results}

Three substrates were successfully produced to isolate the impact of $\mathrm{SiC}$ grain size ( $\mathrm{SiC}$ variant) and $\mathrm{PyC}$ density (PyC variant) on layer evolution. The $\mathrm{SiC}$ variant had larger grains $(2.50 \mu \mathrm{m}$ and $0.53 \mu \mathrm{m}$ for the major and minor axis along the growth direction) relative to the baseline $(0.85 \mu \mathrm{m}$ and $0.30 \mu \mathrm{m}$ for the major and minor axis along the growth direction). The difference in microstructure is shown in Figure 1. The $\mathrm{PyC}$ variant contained identical $\mathrm{SiC}$ grains in size to the baseline variant, but a higher density $\mathrm{PyC}$ layer, whereas a density of $\sim 2.0 \mathrm{~g} / \mathrm{cm}^{3}$ was obtained for a targeted deposition condition relative to the $\sim 1.9 \mathrm{~g} / \mathrm{cm}^{3}$ of the AGR-2-like baseline [5]. The measured trend in $\mathrm{PyC}$ density as a function of deposition condition is shown in Figure 1.

The planar nature of the $\mathrm{PyC}$ and $\mathrm{SiC}$ samples facilitated one-dimensional diffusion analysis. The introduced simulated fission product concentration was intended to match the yield in an average burnup AGR particle [5]. Multiple depth profiling techniques that were accessible to neutron irradiated samples were initially evaluated to determine the feasibility of the diffusion couple
Figure 1. (a) PyC density as a function of deposition temperature, (b) optical micrograph of $P y C$ and SiC sample architecture, (c) electron backscatter electron microscopy inverse pole figures showing the local variation in the SiC grain structure from baseline, and (d) SiC variants. 


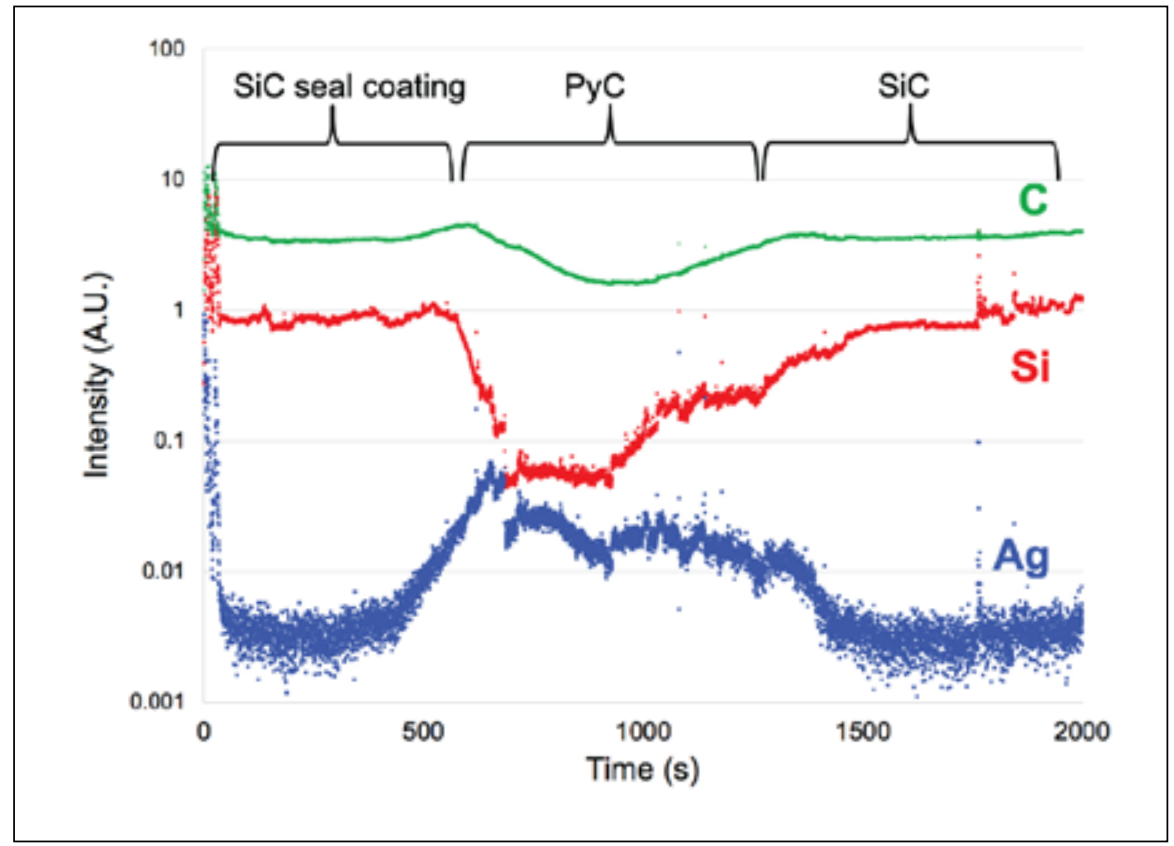

Figure 2. GDOES depth profile of $1700{ }^{\circ} \mathrm{C}, 150 \mathrm{~h}$ baseline: Ag diffusion couple. design and best practice analysis. These techniques included Rutherford backscatter spectrometry (RBS) and glow discharge optical emission spectroscopy (GDOES), while scanning transmission electron microscopy (STEM) analysis was included to support observations. Figure 2 shows the distribution of silver across the PyC layers after exposure to elevated temperatures $\left(1700^{\circ} \mathrm{C}\right)$. The distribution shows the silver follows the expected diffusion pathway, moving through the PyC layer to reach the buried SiC layer. This observation validates the intended PyC and SiC sample design. The analysis indicated a relatively thick interface region based on the change in silicon and carbon intensity; however, the GDOES showed inadequate sensitivity to measure nuanced diffusion in SiC. Similar behavior was observed for the other diffusion species. Subsequent RBS analysis was explored to measure the penetration of simu- lated fission product species. While RBS possessed improved sensitivity to species of interest, the limited analysis depth due to ion range relative to the interface thickness $(\sim 3-7$ $\mu \mathrm{m})$ did not allow accurate diffusion analysis in the SiC layer. Diffusion analysis by secondary ion mass spectrometry (SIMS) techniques on unirradiated samples proved to be the only viable method with sufficient sensitivity and depth analysis. The SIMS analysis was performed in collaboration with the Virginia Polytechnic Institute and State University. Silver diffusion was observed at $1700^{\circ} \mathrm{C}$ in representative $\mathrm{FB}-\mathrm{CVD} \mathrm{SiC}$ using SIMS, but not through RBS or GDOES, demonstrating the necessity of the SIMS technique for diffusional analysis. Unfortunately, no access to dedicated radiological SIMS analysis was available during the PIE stage of the project to accurately explore diffusion in the irradiated samples. Supporting STEM analysis indicated that diffusive transport in the $\mathrm{PyC}$ and $\mathrm{SiC}$ interface and $\mathrm{SiC}$ layer for the thermal equivalent and as-irradiated samples was present in the dilute limit with no clear observation of segregation.

Two-dimensional analysis of the PyC and $\mathrm{SiC}$ interface is not sufficient to capture the complexity of the interface structure. A three-dimensional (3D) analysis was performed to define new ways to describe the interface properties that relate to the fission product interaction with the $\mathrm{SiC}$ layer, as well as how the interface evolves under irradiation. A comparison of the baseline and $\mathrm{PyC}$ variants was made (influence of PyC density on interface structure) along with a comparison of the baseline interface and layer properties as a function of 


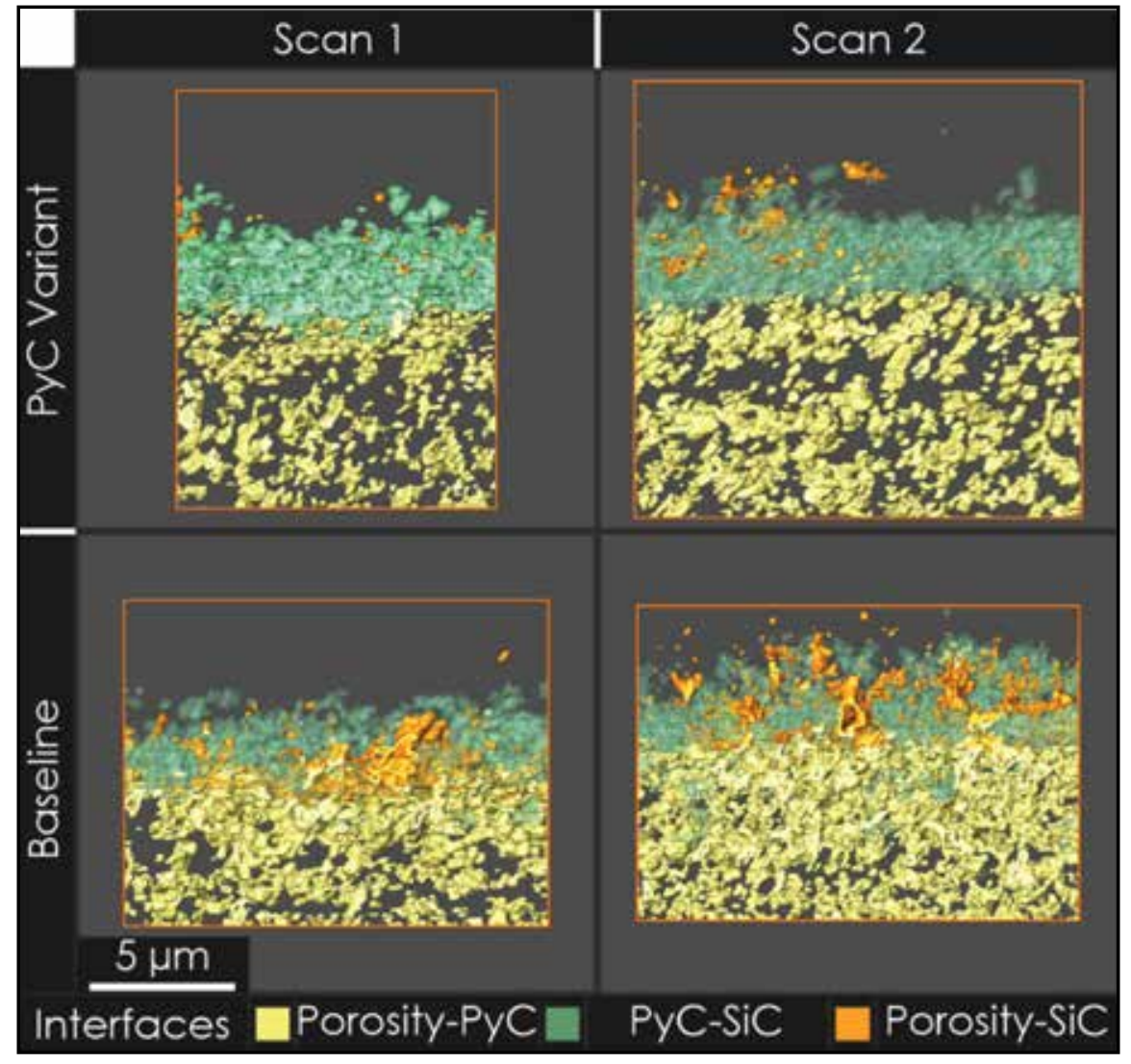

irradiation dose. New metrics were identified for describing the interface. These included the interface region thickness, normalized surface area ( $\mathrm{PyC}$ and $\mathrm{SiC}, \mathrm{PyC}$ porosity, and $\mathrm{SiC}$ porosity), and effective $\mathrm{SiC}$ surface area. The analysis indicated the intentional increase in $\mathrm{PyC}$ density for $\mathrm{PyC}$ variant $(\sim 1.9 \rightarrow 2.0$ $\mathrm{g} / \mathrm{cm}^{3}$ ) was reflected in an $\sim 1 \%$ volume reduction of bulk porosity, suggesting the $\sim 5 \%$ increase in density is accommodated by lower length scale microstructural variations. The interface thickness was measured to be $\sim 6.7 \pm 1.4 \mu \mathrm{m}$ for the baseline variant compared with $3.3 \pm 0.3 \mu \mathrm{m}$ for the PyC variant. Similarly, the total surface area of the relevant phases tracked with the difference in interface thickness, with a clear surface area increase in PyC porosity $(3.2 \times)$, SiC porosity (11.6×), and $\mathrm{PyC}$ and $\mathrm{SiC}(1.5 \times)$ for the baseline sample relative to the $\mathrm{PyC}$ variant sample. Figure 3 shows a rendering of the different interfaces, highlighting the complexity of the structure and extracted data [8]. The established analysis was applied to the irradiated baseline variant samples. No change in bulk PyC porosity was observed as a function of irradiation (up to $9.0 \times 10^{24} \mathrm{n} / \mathrm{m}^{2}$, E > $0.18 \mathrm{MeV}$ ); however, a significant change in the interface porosity $(\sim 4.8 \%$ to $\sim 9.0 \%)$ and interface thickness $(\sim 6.7 \mu \mathrm{m}$ to $\sim 8.4 \mu \mathrm{m})$ was observed. A corresponding increase in $\mathrm{SiC}$ porosity surface area was observed, along with the increase in interface porosity.
Figure 3. Rendering of the different interface surfaces between porosity, $\mathrm{PyC}$, and SiC phases for both variants [8]. 


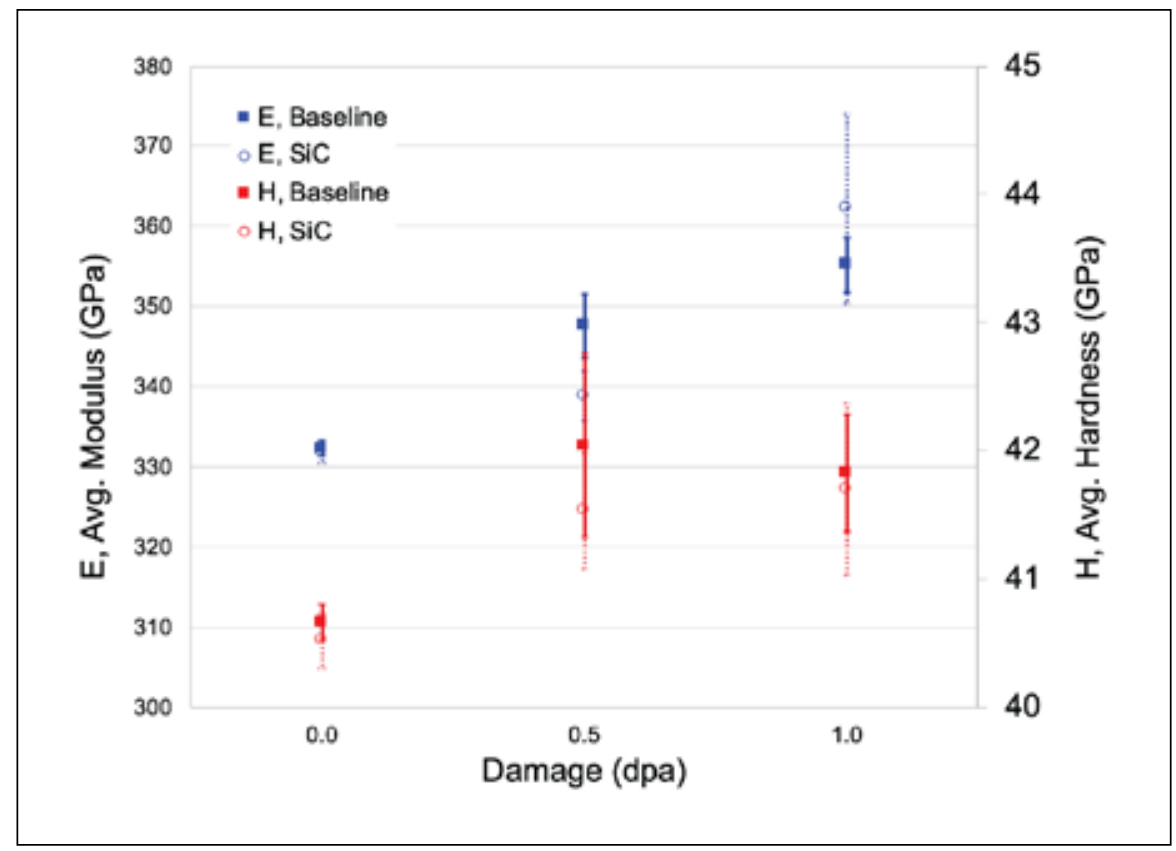

Figure 4. Comparison of ambient temperature FB-CVD SiC modulus $(E)$ and hardness $(H)$ for baseline and SiC variant samples subjected to irradiation at HTGR relevant conditions.
Layer properties such as modulus (E) and hardness $(\mathrm{H})$ and optical anisotropy factor (OPTAF) are vital inputs in multiphysics models used to predict TRISO particle failure probabilities [4]. Data from representative FB-CVD TRISO materials at representative irradiation conditions are necessary to validate the inputs used to predict performance. Figure 4 shows the change in modulus and hardness for the baseline and $\mathrm{SiC}$ variant samples. An increase in $\mathrm{SiC}$ modulus as a function of dose was observed, while there was no apparent grain size effect as both variants showed similar trends and asfabricated values. An increase in hardness as a function dose was observed with an apparent saturation above $4.4 \times 10^{24} \mathrm{n} / \mathrm{m}^{2}, \mathrm{E}>0.18 \mathrm{MeV}$ (0.5 dpa). The PyC responded similarly with an increase in modulus (12-22\%) and hardness (8-12\%) as a function of dose for both variants. Similar to the $\mathrm{SiC}$ layer, the change in hardness appeared to be saturated at
$4.4 \times 10^{24} \mathrm{n} / \mathrm{m}^{2}, \mathrm{E}>0.18 \mathrm{MeV}$. The OPTAF was measured to be $1.052 \pm 0.006$ and showed a decrease of $\sim 2 \%$ after $4.4 \times 10^{24} \mathrm{n} / \mathrm{m}^{2}, \mathrm{E}>$ $0.18 \mathrm{MeV}$ at $1027{ }^{\circ} \mathrm{C}$ and $\sim 3 \%$ after $9.0 \times 10^{24} \mathrm{n} / \mathrm{m}^{2}, \mathrm{E}>0.18 \mathrm{MeV}$ at $1051^{\circ} \mathrm{C}$.

\section{Discussion}

The findings generated through the targeted research discussed prior have enabled new insights on fission product behavior and layer property change at relevant irradiation conditions for the TRISO fuel particle system. Development of novel PyC and $\mathrm{SiC}$ samples with representative properties and variants with specifically tailored property variations allowed for the influence of single variables to be isolated. The development of the $\mathrm{PyC}$ and $\mathrm{SiC}$ samples was foundational. While the design was validated by GDOES depth profiling, the diffusion kinetics analysis proved challenging due to limitations in sensitivity and depth resolution. Supporting STEM and energy dispersive spectroscopy (EDS) analysis showed diffusion identified by depth profiling was occurring in the dilute limit. This differs from the real TRISO fuel system where segregated fission product features are found on microstructural features in the IPyC and $\mathrm{SiC}$ interface and in the SiC. The difference in behavior is hypothesized to be due to a greater diversity in fission products in the TRISO system as well as numerous temperature cycles supporting potential precipitation and possible growth of fission product precipitates. Analysis of the high-temperature, thermally exposed samples showed diffusion of silver in $\mathrm{FB}-\mathrm{CVD} \mathrm{SiC}$ active at $1700^{\circ} \mathrm{C}$ and supported a grain boundary dominant diffusion mechanism at temperatures relevant to accident scenarios. 
The 3D analysis of the $\mathrm{PyC}$ and $\mathrm{SiC}$ interfaces represents a novel approach to defining the complex $\mathrm{PyC}$ and $\mathrm{SiC}$ interfacial structures expected in TRISO fuel systems. Clear variation in the interface structure was observed between the baseline and $\mathrm{PyC}$ variant. This comparison confirmed that the nature of the interface can be impacted through processing. It is hypothesized that excess open porosity and interface tortuosity will influence how fission products and, in particular, how palladium will interact with the $\mathrm{SiC}$ layer. It is hypothesized that reducing the open porosity at the interface may limit the extent of fission product reaction with the $\mathrm{SiC}$ layer, thus limiting opportunity for failure and possible rapid throughlayer release of fission products. Under irradiation, the interface porosity was observed to increase as a function of dose. This suggests that the interface structures evolve during irradiation and may be more susceptible to fission products interaction later in life, which is relevant as a higher concentration of fission products is available to interact with the SiC layer at higher burnups.

The observed change in $\mathrm{PyC}$ and $\mathrm{SiC}$ layer properties at HTGR relevant irradiation conditions provides understanding as to how the layers evolve under irradiation. Most preexisting irradiation data are based on commercial chemical vapor deposition (CVD) SiC, which has a significantly different microstructure relative to FB-CVD $\mathrm{SiC}$ [9]. The observed changes in the FB-CVD SiC layer modulus and hardness from this work reflect similar magnitudes and trends in property changes as commercial CVD $\mathrm{SiC}$ data. This implies the large preexisting data base can be confidently leveraged to support fuel performance modeling. This is also supported by the comparison of baseline and $\mathrm{SiC}$ variant samples which, while showing an $\sim 5 \times$ difference in grain size (based on average grain area), showed no significant variation in hardness and modulus. The observed change in $\mathrm{PyC}$ properties track with radiation induced structural changes observed at the $\mathrm{PyC}$ and $\mathrm{SiC}$ interface from 3D analysis. The change in properties and interface structure should be considered when interpreting observations concerning fission product interaction and the integral response of the layers to irradiation. The general decrease in OPTAF under irradiation suggests no significant increased risk of failure probability in TRISO fuel due to anisotropy changes in the $\mathrm{PyC}$ layer based on current models [4].

\section{Conclusion}

A novel $\mathrm{PyC}$ and $\mathrm{SiC}$ sample design was established to explore separate effects testing and diffusion analysis of representative TRISO materials using an identical coating technology to that used in TRISO production. Limitations in analysis capabilities challenged the explicit diffusion analysis. New methods for defining and characterizing the complex $\mathrm{PyC}$ and $\mathrm{SiC}$ interfaces were established, and the ability to control the interface structure was demonstrated. This has a potential impact on the tailoring of interface properties in TRISO fuels to promote reduced fission product interactions with the $\mathrm{SiC}$ barrier layer. A systematic evaluation of specific layer properties across variants at HTGR relevant irradiation conditions showed variable dose dependence and interface evolution. These insights and the obtained data can be leveraged to support fuel performance modeling.

\section{Future Activities}

As this project finishes, publications are being finalized to ensure the insights and data can be accessed by others in the community. Follow on studies to explore the diffusion behavior of neutron irradiated sampels, using potentially accessible radiological SIMS facilities, are planned. Additionally, the excess $\mathrm{PyC}$ and SiC samples developed and irradiated under this project will be made available via the NSUF's Nuclear Fuels and Materials Library to support future research efforts. The PI encourages other researchers to leverage the sample inventory to explore related research goals.

This work has established a baseline for separate effects testing and TRISO coating of unique geometries. The insights and processes established under this project will be leveraged to support current and future studies and fuel development efforts. Specific examples are the techniques and analysis approaches established for 3D interface analysis that are now being leveraged to explore the accommodation of fission products at the IPyC and $\mathrm{SiC}$ interface in irradiated AGR TRISO fuel [10]. 


\section{References}

[1.] R.N. Morris, C.A. Baldwin, P.A Demkowicz, J.D. Hunn, E.L. Reber, "Performance of AGR-1 high-temperature reactor fuel during post-irradiation heating tests," Nucl. Eng. Des. 306 (2016) 24-35. doi:10.1016/j. nucengdes.2016.04.031.

[2.] P.A. Demkowicz, J.D. Hunn, R.N. Morris, I. van Rooyen, T. Gerczak, J.M. Harp, S.A. Ploger, "AGR-1 Post Irradiation Examination Final Report," INL/ EXT-15-36407 rev. 0, Idaho National Laboratory, Idaho Falls, ID (2015).

[3.] J.D. Hunn, C.A. Baldwin, T.J. Gerczak, F.C. Montgomery, R.N. Morris, C.M. Silva, P.A. Demkowicz, J.M. Harp, S.A. Ploger, Detection and analysis of particles with failed $\mathrm{SiC}$ in AGR-1 fuel compacts, Nucl. Eng. Des. 306 (2016). doi:10.1016/j.nucengdes.2015.12.011.

[4.] W.F. Skerjanc, J.T. Maki, B.P. Collin, D.A. Petti, "Evaluation of design parameters for TRISO-coated fuel particles to establish manufacturing critical limits using PARFUME," J. Nucl. Mater. 469 (2016) 99-105. doi:10.1016/j.jnucmat.2015.11.027.

[5.] T.J. Gerczak, J.D. Hunn, B.C. Jolly, A.T. Schumacher, A.A. Campbell, J.A. Dyer, X. Hu, "Development of planar $\mathrm{PyC} / \mathrm{SiC}$ diffusion couples to investigate irradiation effects and microstructural variation on fission product diffusion," Proceedings of HTR 2018, Warsaw, Poland (2018), Paper HTR 2018-0047.
[6.] T.J. Gerczak, A.A. Campbell, X. Hu, J.D. Hunn, B.C. Jolly, R.L. Seibert, A.T. Schumacher, "Preparation of Diffusion Couples for Irradiation and High-Temperature Testing of Representative TRISO PyC/SiC," ORNL/ TM-2018/1012. Oak Ridge, TN, Oak Ridge National Laboratory (2018).

[7.] C.M. Petrie, K. Smith, T.J. Gerczak, "Design and Thermal Analysis for Irradiation of Pyrolytic Carbon/Silicon Carbide Diffusion Couples in the High Flux Isotope Reactor," ORNL/ TM-2017/390. Oak Ridge, TN, Oak Ridge National Laboratory (2017).

[8.] J.D. Arregui-Mena, T. J. Gerczak, R. L. Seibert, "Characterization of SiC/PyC Interfaces by FIB-SEM Tomography," Under Review, J. Nucl. Mater. Submitted 2020 .

[9.] L.L. Snead, T. Nozawa, Y. Katoh, T.S. Byun, S. Kondo, D.A. Petti, "Handbook of $\mathrm{SiC}$ properties for fuel performance modeling," J. Nucl. Mater. 371 (2007) 329-377, https:// doi.org/10.1016/j.jnucmat.2007.05.016.

[10.] R.L. Seibert, J.D. Arregui-Mena, C. McKinney, T.J. Gerczak, G. Helmreich, K.A. Terrani, "Focused ion beam serial sectioning and 3D-reconstruction of nuclear fuel," Micro. Microanal. 25, S2 (2019), Cambridge University Press: 1580-1581, https://doi.org/10.1017/ S1431927619008638. 


\section{Publications}

[1.] C.M. Petrie, K. Smith, T.J. Gerczak, Design and Thermal Analysis for Irradiation of Pyrolytic Carbon/Silicon Carbide Diffusion Couples in the High Flux Isotope Reactor, ORNL/ TM-2017/390-R0. Oak Ridge, TN, Oak Ridge National Laboratory (2017).

[2.] T.J. Gerczak, A.A. Campbell, J.D. Hunn, B.C. Jolly, A.T. Schumacher, Progress on Fabrication of Planar Representative PyC/ SiC Diffusion Couples, ORNL/ TM-2017/704-R0. Oak Ridge, TN, Oak Ridge National Laboratory (2017).

[3.] A.G. le Coq, K.D. Linton, R.C. Gallagher, T.J. Gerczak, K.A. Terrani, C.M. Petrie, Assembly of Rabbit Capsules for Irradiation of Pyrolytic Carbon/Silicon Carbide Diffusion Couples in the High Flux Isotope Reactor, ORNL/SPR-2018/876-R0, Oak Ridge, TN, Oak Ridge National Laboratory (2018).

[4.] T. J. Gerczak, A. A. Campbell, X. Hu, J. D. Hunn, B. C. Jolly, R. L. Seibert, and A. T. Schumacher, Preparation of Diffusion Couples for Irradiation and High-Temperature testing of Representative TRISO PyC/SiC. ORNL/ TM-2018/1012. Oak Ridge, TN, Oak Ridge National Laboratory (2018).
[5.] T.J. Gerczak, J.D. Hunn, B.C. Jolly, A.T. Schumacher, A.A. Campbell, J.A. Dyer, X. Hu, Development of Planar PyC/SiC Diffusion Couples to Investigate Irradiation Effects and Microstructural Variation on Fission Product Diffusion, Proceedings of HTR 2018, Warsaw, Poland (2018), Paper HTR 2018-0047.

[6.] R.L. Seibert, J.D. Arregui-Mena, C. McKinney, T.J. Gerczak, G. Helmreich, K.A. Terrani, Focused Ion Beam Serial Sectioning and 3D-reconstruction of Nuclear Fuel, Micro. Microanal. 25, S2 (2019), 1580-1581.

[7.] J.D. Arregui-Mena, T. J. Gerczak, R. L. Seibert. Characterization of $\mathrm{SiC} / \mathrm{PyC}$ Interfaces by FIB-SEM Tomography, Under Review, J. Nucl. Mater. Submitted 2020.

\begin{tabular}{|l|l|}
\hline \multicolumn{2}{|l|}{ Distributed Partnership at a Glance } \\
\hline NSUF Institution & Facilities and Capabilities \\
\hline $\begin{array}{l}\text { Oak Ridge National } \\
\text { Laboratory }\end{array}$ & $\begin{array}{l}\text { High Flux Isotope Reactor, Irradiated Materials } \\
\text { Examination and Testing Facility Hot Cells, } \\
\text { Low Activation Materials Design and Analysis } \\
\text { Laboratory }\end{array}$ \\
\hline Collaborators & $\begin{array}{l}\text { Anne Campbell (co-principal investigator), } \\
\text { Austin Schumacher (collaborator), Brian Jolly } \\
\text { (collaborator), J. David Arregui-Mena } \\
\text { (collaborator), John Hunn (collaborator), } \\
\text { Rachel Seibert (collaborator) }\end{array}$ \\
\hline University of Michigan & Ovidiu Toader (collaborator) \\
\hline University of Tennessee & Austin Schumacher (collaborator) \\
\hline $\begin{array}{l}\text { Virginia Polytechnic } \\
\text { Institute and State University }\end{array}$ & Natalie Sievers (collaborator) \\
\hline
\end{tabular}




\title{
HPC Access to Advance Understanding of Fission Gas Behavior in Nuclear Fuel
}

\author{
Brian Wirth - University of Tennessee, Knoxville - bdwirth@utk.edu
}

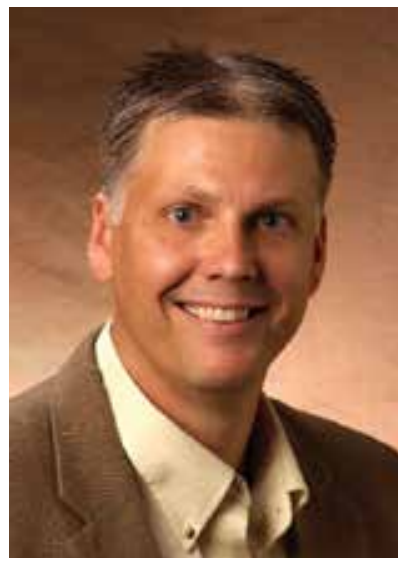

$\mathrm{T}$ his report describes the strategy implemented to couple the Xolotl cluster dynamics code to the MARMOT phase-field model to assess the long standing and important problem of fission gas induced bubble swelling and fission gas release from $\mathrm{UO}_{2}$ nuclear fuel. This hybrid model couples Xolotl to MARMOT using the MultiApp and Transfer systems in the Multiphysics Object Oriented Simulation Environment (MOOSE) framework. Xolotl predicts the production, diffusion, clustering, and re-solution of fission gas atoms within the grains, ultimately predicting intragranular bubble induced swelling. Furthermore, Xolotl passes the rate at which gas atoms arrive at grain boundaries to MARMOT. MARMOT models the growth and coalescence of the intergranular bubbles, as well as grain boundary migration, and can pass the resulting modified grain boundary (GB) locations back to Xolotl. The coupled model performs well, producing similar results to the standard phase-field model when Xolotl does not include clustering or re-solution. Including clustering and intragranular xenon bubble evolution significantly reduces the flux of xenon to the grain boundaries, as expected, thereby decreasing the growth rate of the intergranular gas bubbles. Including an atomistically informed re-solution model leads to a significant increase in the xenon monomer concentration, which notably increases both the growth of intragranular bubbles (swelling) and increases the flux of xenon to the grain boundaries that also produces a small increase in the intergranular bubble fraction. An assessment of the computational performance of the coupled Xolotl and MARMOT simulations indicates nearly ideal scaling up to 128 processors in the strong scaling regime, and the computational cost of the data transfer between the codes is negligible.

However, the computational assessment does reveal that Xolotl scales better for larger problems than MARMOT; thus, future computational optimization will be focused on improving the scaling of MARMOT, in addition to a computational physics exercise to experimentally benchmark the predictions of the coupled codes prior to performing a three dimensional demonstration.

\section{Introduction}

Fission gas behavior in uranium dioxide fuels is a key factor in determining fuel performance because the diffusion and precipitation of xenon and krypton in fission gas bubbles influences both fuel swelling and the quantity of fission gas released to the fuel plenum $[1,2]$. Fission gas bubbles within the fuel significantly contribute to intragranular swelling in addition to decreasing a fuel's thermal conduc- 
This project improves the ability to predict fission gas release, instrumental in addressing problems with

extending the burnup and utilization of nuclear fuel in light water reactors.

tivity [3]. This, in turn, increases temperature gradients and thermalmechanical stresses, increasing crack probability [4], and impeding other microstructure evolution, such as grain growth [5]. Coarse intragranular bubbles are responsible for the majority of the fuel swelling [6] and, in combination with the much larger intergranular bubbles, determine the rate of fission gas release [7]. Once fission gas is released from the fuel, it lowers gap conductivity and raises cladding pressure $[1,2]$.

Most fission gas behavior models used for fuel performance calculations trace back to the 1957 formulation by Booth [8], the mid-to-late 1960s formulation by Speight and co-workers [9,10]; or the slightly more recent work by Turnbull [11], White and Tucker [12], and Forsberg and Massih [13,14]. These models typically rely on a small number of spatially independent partial differential equations, or even a single partial differential equation, along with the concept of an effective diffusivity to account for the effect of intragranular fission gas bubbles on the bulk diffusion rate [14]. More recently, additional physically based fission gas bubble models have been developed by Pastore and co-workers [16-18], based on a cluster-dynamics framework. In these reduced models, fission gas release from the fuel pellets into the fuel rod free volume is modeled as a simple percolation threshold for the gas that has reached grain boundaries. These models are clearly oversimplifications of the actual behavior of noble gas within the fuel. Indeed, the dynamics of fission gas bubbles, which form both within the grains (intragranular) and on grain boundaries (intergranular), affect the rate of fission gas diffusion and release and also determine swelling due to fission gas accumulation $[1,19,20]$. Despite being a key determinant of fission gas effects, accurate physical based models of intragranular bubble evolution are still lacking in current codes. Rather, the characteristics (number density, mean size) of the bubble population are given as constant parameters or calculated through simplistic, empiric based 


\section{"The ease of MOOSE}

multi-app, in addition

to the access to the high

performance computing

capability at INL, has

been instrumental to us

in making progress on

coupling MARMOT to

Xolotl and advancing our

ability to predict fission gas

evolution in nuclear fuel."

- Brian Wirth functions of temperature $[12,13,16]$.

As the complex bubble evolution strongly depends on the specific fuel irradiation conditions and reactor operating history $[7,19,21]$, this gap in current modeling significantly limits the accuracy and transferability of available treatments. Therefore, developing effective modeling capabilities for fission gas bubble evolution, both within grain interiors (intragranular) and on grain boundaries (intergranular) is a key issue in achieving higher standards of accuracy for fission gas swelling and release calculations in fuel performance analysis.

Fission gas behavior leading to release may be categorized in three stages (all of which occur simultaneously) according to the location of the dominating physics. The first stage is intragranular fission gas behavior, including the generation, diffusion, clustering, and re-solution of fission gas atoms in the fuel matrix. In this stage, fission gas clustering with vacancies results in the creation of intragranular bubbles. The second stage is the intergranular fission gas behavior on GBs or grain faces. Fission gas bubbles nucleate on GBs and then grow and interconnect. As a percolated network of bubbles form, more and more of the grain face bubbles come in contact with the grain edges, or GB triple junctions. The third stage is the fission gas behavior along the grain edges. Bubbles on the grain edges quickly connect to form networks of grain edge tunnels that eventually contact free surfaces, allowing fission gas to escape the fuel and enter the gap between the fuel and cladding and the plenum.

As mentioned earlier, fission gas behavior in $\mathrm{UO}_{2}$ has been modeled for many years. Initially, these models were mean-field approximations of the overall fission gas release that initially only considered the first stage of release [8]. These were later extended to include the other stages [12-16]. More recently, physicalbased models of fission gas evolution [16-18] have been grounded in a mean-field cluster-dynamics approach in which gas atom and vacancy cluster complexes evolve over time, including the transfer of gas atoms and vacancies between clusters. Our cluster-dynamics model has evolved over time. Initially developed for the simulation of radiation defects in solids and gas behavior in solids for fusion plasma facing components, it includes the ability to spatially resolve the solid domain in multiple dimensions [22-25]. The strength of the cluster-dynamics method is that it directly models the nucleation and growth of noble gas bubbles and naturally incorporates very small clusters (bubble nuclei) that are continually forming and dissolving. The limitations of cluster-dynamics are associated with the computational expense of modeling large bubbles (e.g., assuming a xenon density of $10^{28} \mathrm{~m}^{-3}$ within a fission gas bubble, then a 10 $\mathrm{nm}$ radius bubble contains around 45,000 xenon atoms), which requires at least 45,000 degrees of freedom. 
Also, cluster-dynamics based on finite different meshing can be a challenge in modeling the grain faces and edges of a polycrystalline spatial domain.

The phase-field method is another computational approach that has been used to model fission gas bubble behavior [14-15,26-28]. In phasefield models of fission gas [29-31], conserved thermodynamic variable fields are used to represent defects, including fission gas atoms and vacancies. Non-conserved variable fields are used to represent bubbles and grains. These variable fields smoothly transition between values, such that bubble surfaces and GBs have a diffuse interface with a finite width. These variables are evolved over time to minimize the free energy of the system. Source terms are used to add defects due to fission and radiation damage. The strength of phase-field models is that they naturally represent the co-evolution of all bubbles and GBs over time. Thus, they are well suited to investigate the interconnection of grain face and edge bubbles [30,31]. Limitations include that they cannot naturally model nucleation and that they cannot efficiently model small bubbles and large bubbles in the same simulation. For example, a polycrystal simulation with a 10-micron average grain size could efficiently model GB bubbles with radii of $50 \mathrm{~nm}$ and greater, but they could not feasibly include small intragranular bubbles with a radius of a few nanometers.

Here, we present a hybrid model in which a spatially resolved cluster- dynamics model is directly coupled to a phase-field fission gas model such that the growth and interconnection of grain face and edge bubbles can be modeled while also resolving the nucleation, growth, and re-solution of intragranular gas bubbles. Thus, the combined model can represent all three stages of fission gas release and provide a powerful means of investigating fission gas behavior

\section{Experimental or Technical Approach}

\section{Xolotl cluster-dynamics code}

Intragranular fission gas behavior is modeled by Xolotl, a cluster-dynamic code originally developed to simulate irradiated material in fusion reactors [22-25,32]. To simplify the model, it assumes that all fission gas atoms are xenon, the most common component of the noble gas atoms produced by fission. Xolotl evolves the concentrations of clusters of increasing numbers of Xe atoms. The evolution of each cluster size is determined by solving a partial differential equation generally described as:

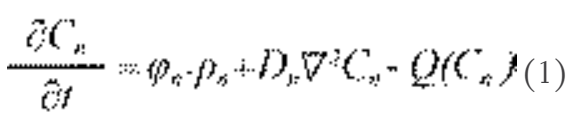

where $C_{n}$ is the concentration of a cluster containing $\mathrm{n}$ Xe atoms; the first right hand term corresponds to the production of new xenon, related to the neutron flux that sets the fission rate; the second term is the diffusion term; and the third term accounts for reactions 
between clusters. Xenon production is computed using a fission yield of 0.25 and only generates single Xe atoms $\left(\mathrm{C}_{1}\right)$. For this demonstration of the coupled Xolotl and MARMOT code, $\mathrm{UO}_{2}$ vacancies are not explicitly modeled and only Xe atoms and Xe clusters/bubbles are modeled. The single Xe atom is the sole cluster considered mobile, with a diffusion coefficient following the Turnbull model [11]; thus, two types of reactions are allowed: self-clustering to form larger Xe bubbles $\mathrm{Xe}_{1}+$ $\mathrm{Xe}_{\mathrm{n}} \rightarrow \mathrm{Xe}_{\mathrm{n}+1}$ and single $\mathrm{Xe}$ atom emission $\mathrm{Xe}_{\mathrm{n}} \rightarrow \mathrm{Xe}_{1}+\mathrm{Xe}_{\mathrm{n}-1}$. The general form of the reaction term for clusters of size $n \geq 2$ is:

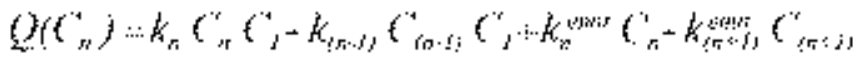

with reaction rates:

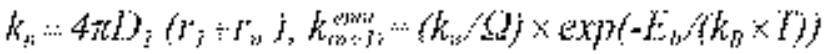

where $D_{1}$ is the single Xe diffusion coefficient, $r_{n}$ is the reaction radius for the bubble made of $\mathrm{n}$ Xe atoms, $\Omega$ the atomic volume, $\mathrm{E}_{\mathrm{b}}$ the binding energy of $\mathrm{Xe}_{\mathrm{n}+1}, \mathrm{k}_{\mathrm{B}}$ the Boltzmann constant, and $\mathrm{T}$ the temperature. The reaction radius for the single Xe atom is set to $0.3 \mathrm{~nm}$ and a Xe density of $10.16 \mathrm{~nm}^{-3}$ is used to describe the bubble size based on the number of xenon atoms in a cluster/ bubble. The binding energy of $\mathrm{Xe}_{2}$ is set to $1.85 \mathrm{eV}$ and energies increase progressively to reach a constant value of $7 \mathrm{eV}$ for $\mathrm{n}>30$. The reaction term for the single xenon atom sums the contribution from each reaction:

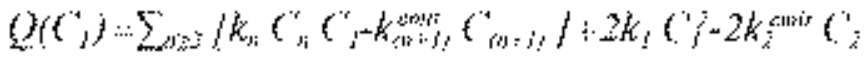

Additionally, a model for heterogeneous re-solution of Xe bubble, described in [34], has been incorporated.

The partial differential equations are solved using the finite difference method (FDM) and implicit time integration with Portable, Extensible Toolkit for Scientific Computation (PETSc) [35]. Xolotl uses a uniform grid to model the spatial domain with periodic boundary conditions. The grid points corresponding to interface locations are treated like free surfaces, meaning that the concentration vectors at these grid points are forced to 0.0 at all times. At each grid point, Xolotl can compute the current single Xe concentration and the

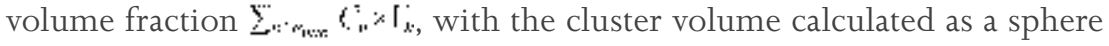
whose radius is the reaction radius and $\mathrm{n}_{\min }$ an optional minimum size. On each grid point located in an interface, Xolotl also computes the single Xe rate from Xe diffusing from nearby grid points. 


\section{MARMOT phase-field model}

The phase-field method is a common numerical approach used to predict spatially resolved microstructure evolution. In the phase-field method, microstructural features are represented by the values of continuous variable fields. The fields smoothly transition between values at interfaces, such as grain boundaries or bubble surfaces, giving the interfaces a finite width. The phase-field method has been used to simulate and investigate various physical phenomena [36-38], including radiation damage and nuclear materials [26-28]. It has been applied to model fission gas bubbles in $\mathrm{UO}_{2}$ by various researchers, with various assumptions and approximations depending on the phenomena of interest $[30,31,39,40]$. In this work, we use the model from Aagesen et al. [31] that was developed to investigate the evolution of intergranular gas bubbles in polycrystalline $\mathrm{UO}_{2}$. While we refer the reader to Ref. [31] for a complete description of the model, we summarize it below.

In this model, the material microstructure is represented by various continuous variable fields. Non-conserved order parameters are used to distinguish voids $\left(\varphi_{0}\right)$ and the various $\mathrm{UO}_{2}$ grains $\left(\varphi_{\mathrm{i}}, \mathrm{i}=1, \ldots \mathrm{N}\right.$, where $\mathrm{N}$ is the number of grains) where the order parameters are equal to one in their corresponding region and zero in the other regions. The interfaces between these regions (bubble surfaces for transitions from void to grains and GBs for transitions from one grain to another) have a finite width of $l_{\mathrm{i}}$. The model explicitly represents fission gas atoms (treated as Xe atoms) and uranium lattice vacancies (the oxygen lattice is neglected, as the uranium lattice is rate limiting). Rather than directly solving for the concentrations of gas atoms and vacancies, we solve for their chemical potentials $\mu_{\mathrm{g}}$ and $\mu_{\mathrm{v}}$. The concentrations $c_{\mathrm{g}}$ and $c_{\mathrm{v}}$ can then be determined from the chemical potentials. The order parameters and chemical potentials are evolved with time to minimize the free energy of the system according to the equations:

$$
\begin{aligned}
& \frac{\partial \phi_{i}}{\partial t} \cdots-\frac{\delta g}{\partial \phi_{i}}
\end{aligned}
$$

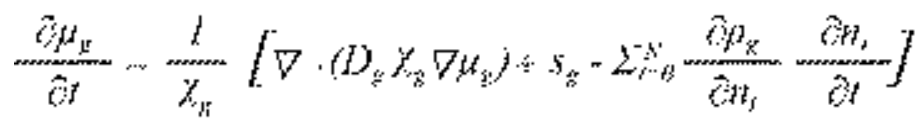

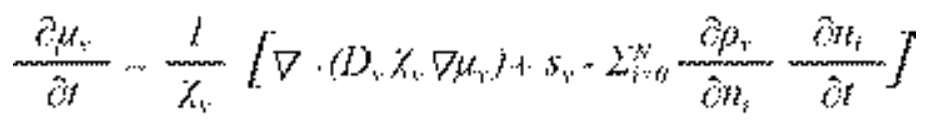

where $\mathrm{L}$ is the order parameter mobility and $\Omega$ is the total grand potential, for $j$ either $v$ or $g$; $D_{j}$ is the diffusion coefficient, $\chi_{j}$ is the susceptibility, $s_{j}$ is the 
spatially varying source term, and $\rho_{\mathrm{j}}$ is the defect density. The density is $\rho_{\mathrm{j}}=\mathrm{c}_{\mathrm{j}} / \mathrm{V}_{\mathrm{a}}$, where $\mathrm{V}_{\mathrm{a}}$ is the atomic volume of $\mathrm{UO}_{2}$.

The total grand potential, $\Omega$, is formulated from approximations of the grand. potential density in the bubbles and grains as well as numerical functions that provide an energetic driving force for only one order parameter to be equal to one at a given spatial location:

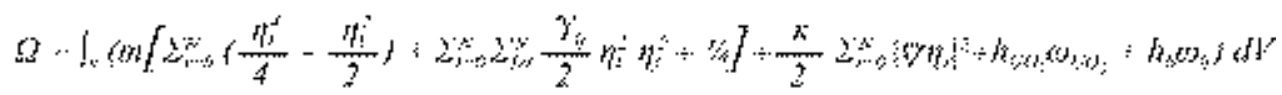

where $\mathrm{m}$ is a scalar weight, $\gamma_{\mathrm{ij}}$ allows for the adjustment between GB and surface energies, $\kappa$ is the gradient energy coefficient, $\omega_{\mathrm{UO}_{2}}$ and $\omega_{\mathrm{b}}$ are the grand potential densities for $\mathrm{UO}_{2}$ and bubbles respectively, and $\mathrm{h}_{\mathrm{UO}_{2}}$ and $\mathrm{h}_{\mathrm{b}}$ are the corresponding switching functions. The switching functions interpolate between the properties of the $\mathrm{UO}_{2}$ and bubbles phases and are defined as:

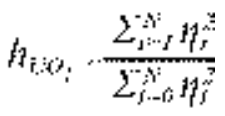

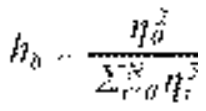

The grand potential densities are:

$\omega_{\mathrm{UO}_{2}}=\mathrm{f}_{\mathrm{UO}_{2}}-\mu_{\mathrm{v}} \rho_{\mathrm{v}}-\mu_{\mathrm{g}} \rho_{\mathrm{g}}$

$\omega_{\mathrm{b}}=\mathrm{f}_{\mathrm{b}}-\mu_{\mathrm{v}} \rho_{\mathrm{v}}-\mu_{\mathrm{g}} \rho_{\mathrm{g}}$

where $\mathrm{f}_{\mathrm{UO}_{2}}$ and $\mathrm{f}_{\mathrm{b}}$ are the Helmholtz free energies of $\mathrm{UO}_{2}$ and the bubbles respectively. Both free energies are approximated as parabolic functions of the vacancy and gas atom concentrations, as:

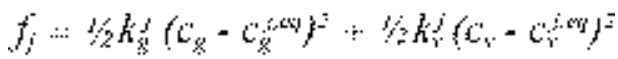

where $\mathrm{j}$ is either $\mathrm{UO}_{2}$ or $b, \mathrm{k}_{\mathrm{g}}^{\mathrm{j}}$ and $\mathrm{k}_{\mathrm{v}}^{\mathrm{j}}$ are the polynomial coefficients, and $\mathrm{c}_{\mathrm{g}}^{\mathrm{j}, \mathrm{eq}}$ and $\mathrm{C}_{\mathrm{v}}^{\mathrm{j}, \mathrm{eq}}$ are the equilibrium concentrations. 
The susceptibilities are calculated as:

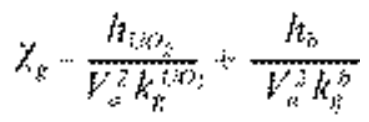

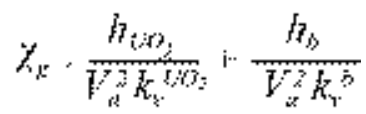

The model parameters that impact the interface can be defined in terms of the interfacial width and the GB energy as:

$\gamma_{i j}=1.5$, where $i \neq j, i>0, j>0$

$\gamma_{0 \mathrm{i}}=\gamma_{\mathrm{i} 0}=0.922$, where $\mathrm{i}>0$

$k \therefore 1 / \hbar \sigma_{(j)} l ;$

H) $:=\frac{b t_{r, d s}}{t_{j}}$

Table 1 lists the parameter values used in all of the simulations in this work.

Note that we currently assume that the diffusion coefficient of vacancies is equal to that of fission gas, to simplify the model. The partial differential equations (PDEs) defining the evolution of the order parameters and chemical potentials are solved using implicit time integration and the finite element method (FEM) in the MARMOT mesoscale fuel performance code [41]. MARMOT is based on the MOOSE $[42,43]$, which uses the PETSc library [35] for solving the system of nonlinear equations.
Table 1. Parameters used in the MARMOT simulations, including the reference citations(s)

\begin{tabular}{|c|c|c|}
\hline Parameter & Value & Reference \\
\hline $\mathrm{T}$ & $1800 \mathrm{~K}$ & \\
\hline $\mathrm{V}_{\mathrm{a}}$ & $0.409 \mathrm{~nm} 2$ & {$[30]$} \\
\hline $\mathrm{C}_{\mathrm{g}}^{\mathrm{UO}_{2} \text {,eq }}$ & $\operatorname{erp}\left(\frac{-3 e V}{k_{h} I}\right)$ & {$[30]$} \\
\hline $\mathrm{C}_{\mathrm{v}}^{\mathrm{UO}}, \mathrm{eq}$ & $\exp \left(\frac{-3 e V}{k_{i} I}\right)$ & {$[30]$} \\
\hline$c_{g}^{b, e q}$ & 0.454 & {$[30]$} \\
\hline $\mathrm{C}_{\mathrm{v}}^{\mathrm{b}, \mathrm{eq}}$ & 0.546 & {$[30]$} \\
\hline $\mathrm{k}_{\mathrm{g}}^{\mathrm{UO}_{2}}=\mathrm{k}_{\mathrm{v}}^{\mathrm{UO}_{2}}$ & $2.57 \times 10^{8} \mathrm{~J} / \mathrm{m}^{3}$ & {$[30]$} \\
\hline $\mathrm{k}_{\mathrm{g}}^{\mathrm{b}}=\mathrm{k}_{\mathrm{v}}^{\mathrm{b}}$ & $4.8 \times 10^{9} \mathrm{~J} / \mathrm{m}^{3}$ & \\
\hline$\sigma_{\mathrm{GB}}$ & $1.5 \mathrm{~J} / \mathrm{m}^{2}$ & {$[31]$} \\
\hline$l_{\mathrm{i}}$ & $480 \mathrm{~nm}$ & {$[30]$} \\
\hline $\mathrm{D}_{\mathrm{g}}$ & $2.3 \mathrm{~nm}^{2} / \mathrm{s}$ & {$[44]$} \\
\hline$D_{v}=D_{g}$ & $2.3 \mathrm{~nm}^{2} / \mathrm{s}$ & \\
\hline $\mathrm{L}$ & $1.56 \times 10^{-10} \mathrm{~m} /(\mathrm{J} \mathrm{s})$ & \\
\hline$S_{\mathrm{v}}$ & $8.0 \times 10^{-9}$ vacancies $/\left(\mathrm{nm}^{3} \mathrm{~s}\right)$ & \\
\hline
\end{tabular}




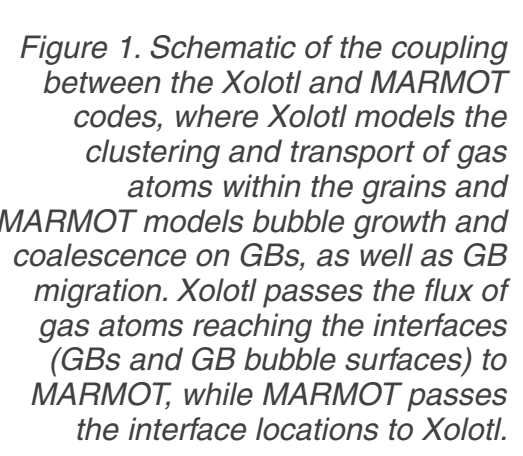

Figure 1. Schematic of the coupling ween the Xolotl and MARMOT codes, where Xolotl models the clustering and transport of gas atoms within the grains and migration. Xolot passes the flux of gas atoms reaching the interfaces GBs and GB bubble surfaces) to the interface locations to Xolot

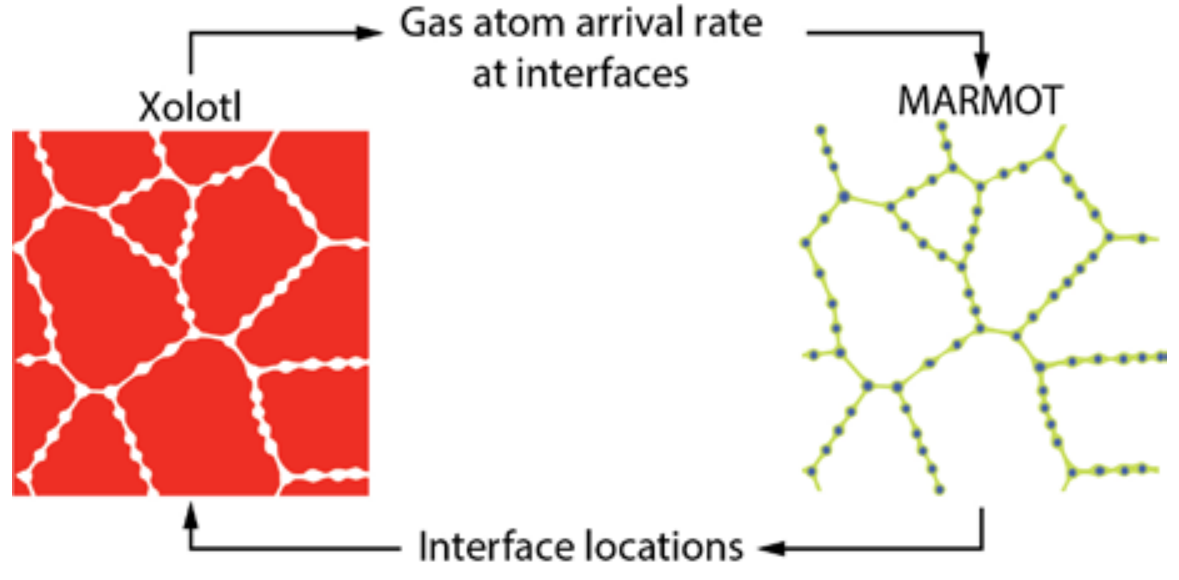

Numerical code coupling of Xolotl (cluster-dynamics) and MARMOT (phase-field)

We couple Xolotl and MARMOT to create a hybrid mesoscale fission gas model that uses cluster-dynamics to represent the behavior of fission gas within the grains and MARMOT to represent the behavior of fission gas on GBs, as depicted in Figure 1. Xolotl includes the generation of gas atoms due to fission, their diffusion through the $\mathrm{UO}_{2}$ matrix, the clustering of the gas atoms, and their re-solution due to radiation damage. When gas atoms reach the locations of GBs or intergranular bubble surfaces, Xolotl passes the gas atom concentrations to MARMOT. The only source of gas atoms in MARMOT is the atoms passed by Xolotl at these interfaces, such that they are the only locations at which the gas source term $\mathrm{s}_{\mathrm{g}} \neq 0$. MARMOT models the evolution of the interfaces due to GB migration as well as the growth and coalescence of the GB bubbles. It passes the evolving locations of these interfaces to Xolotl.
Both codes solve systems of PDEs using implicit time integration and both codes use PETSc to solve the resultant systems of nonlinear equations. Xolotl uses FDM to discretize the simulation domain while MARMOT uses FEM. Thus, both codes discretize the simulation domain with a grid of points; however, Xolotl directly evaluates residuals at these points, while MARMOT evaluates residuals at the integration points in order to determine the nodal quantities. Thus, directly coupling the solutions of the two codes would be difficult. For this reason, we employ a weak coupling in which, at a given time step, MARMOT solves its system of equations and passes the new interface locations to Xolotl. Xolotl then solves its system of equations and passes the rate at which gas atoms arrive at the interfaces $S_{g}$ to MARMOT. Both codes then move on to the next time step.

The communication between the two codes is managed using the MultiApp and Transfer systems from the MOOSE framework [44]. In the coupled code, MARMOT is the master 


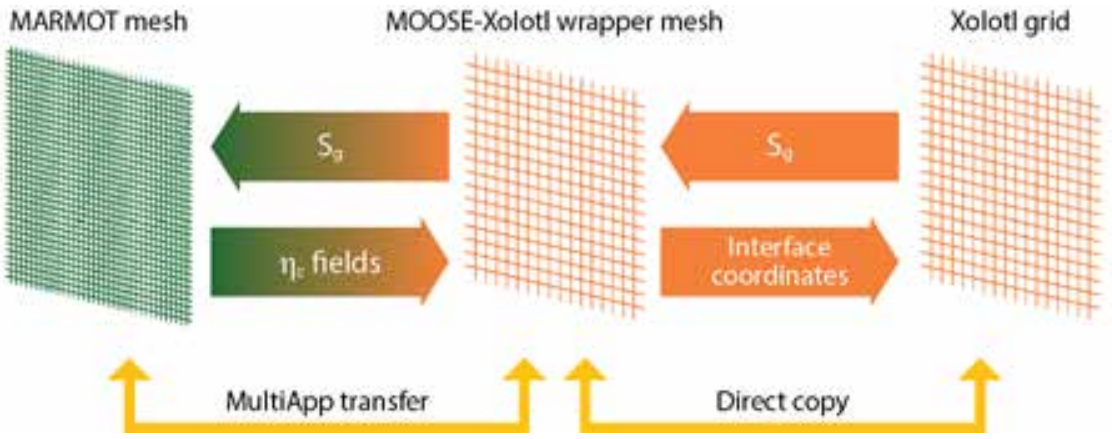

application that couples to Xolotl as a subapplication, as illustrated in Figure 2. However, an intermediate mesh is required to couple to the external Xolotl code and transfer its data from the FDM grid points. Thus, the MOOSE-Xolotl wrapper mesh is a MOOSE application with a FEM mesh that has nodes in the same locations as the Xoltol grid points. The fission gas arrival rate at the interfaces $\mathrm{S}_{\mathrm{g}}$ is directly copied from the Xolotl grid to the wrapper mesh and the interface coordinates are directly copied from the wrapper mesh to the Xolotl grid. A multiapp transfer is used between the wrapper and MARMOT mesh in which the data from the wrapper mesh nodes are interpolated using the FEM basis functions to the nodes in the MARMOT mesh; $\mathrm{S}_{\mathrm{g}}$ is transferred from the wrapper mesh to the MARMOT mesh and the order parameter fields, $\varphi_{\mathrm{i}}$, are transferred from the MARMOT mesh to the wrapper mesh. The MARMOT and the wrapper mesh can be different, allowing the MARMOT phase-field calculations to take advantage of mesh adaptivity and have a finer mesh resolution at the interfaces. Note that the MARMOT mesh is never coarser than the wrapper mesh. This approach also works with a distributed mesh for large parallel computations.

The MARMOT and Xolotl time steps also do not have to be identical, although the MARMOT time steps must always be larger than or equal to the Xolotl times steps. When the Xolotl time steps are smaller than the MARMOT time steps, Xolotl takes multiple time steps without passing data and then takes a small timestep to sync to the MARMOT time and pass data. Currently, Xolotl only includes gas atom clusters; therefore, it can only pass the atom arrival rate at the interfaces $\mathrm{S}_{\mathrm{g}}$. However, MARMOT evolves both gas atoms and uranium vacancies. Thus, the production rate of vacancies $\mathrm{S}_{\mathrm{v}}=4 \mathrm{~S}_{\mathrm{g}}$ throughout the solid regions of the MARMOT domain, ensuring an excess number of vacancies in the simulation. In the future, Xolotl will be expanded to consider clustering of vacancies and gas atoms and both $\mathrm{S}_{\mathrm{g}}$ and $\mathrm{S}_{\mathrm{v}}$ will be passed from Xolotl to MARMOT.

\section{Results}

We demonstrate our hybrid mesoscale model of fission gas behavior using a two dimensional (2D) simulation of intergranular bubble growth in a small polycrystalline domain. First, we
Figure 2. Schematic of the data transfer approach used in the hybrid code. 


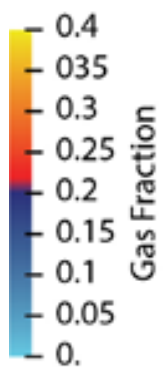

Figure 3. Comparison of standalone MARMOT to a coupled Xolotl

- MARMOT simulation. (a) Initial GB bubble microstructure. (b) and

(c) show final $G B$ gas fractions from stand alone MARMOT versus coupled simulation respectively. (d) Intragranular bubble fraction with increasing time for stand alone MARMOT (black) versus the coupled simulation (red).

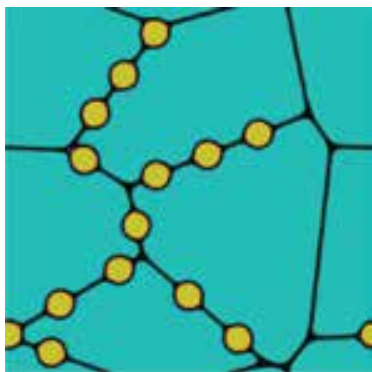

(a)

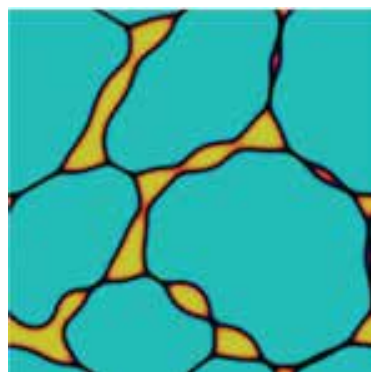

(b)

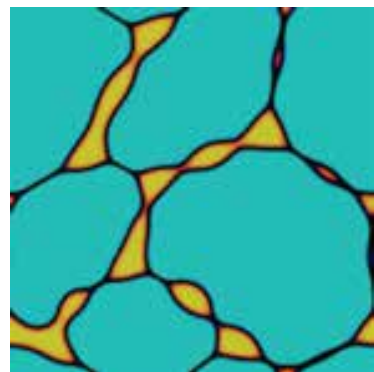

(c)

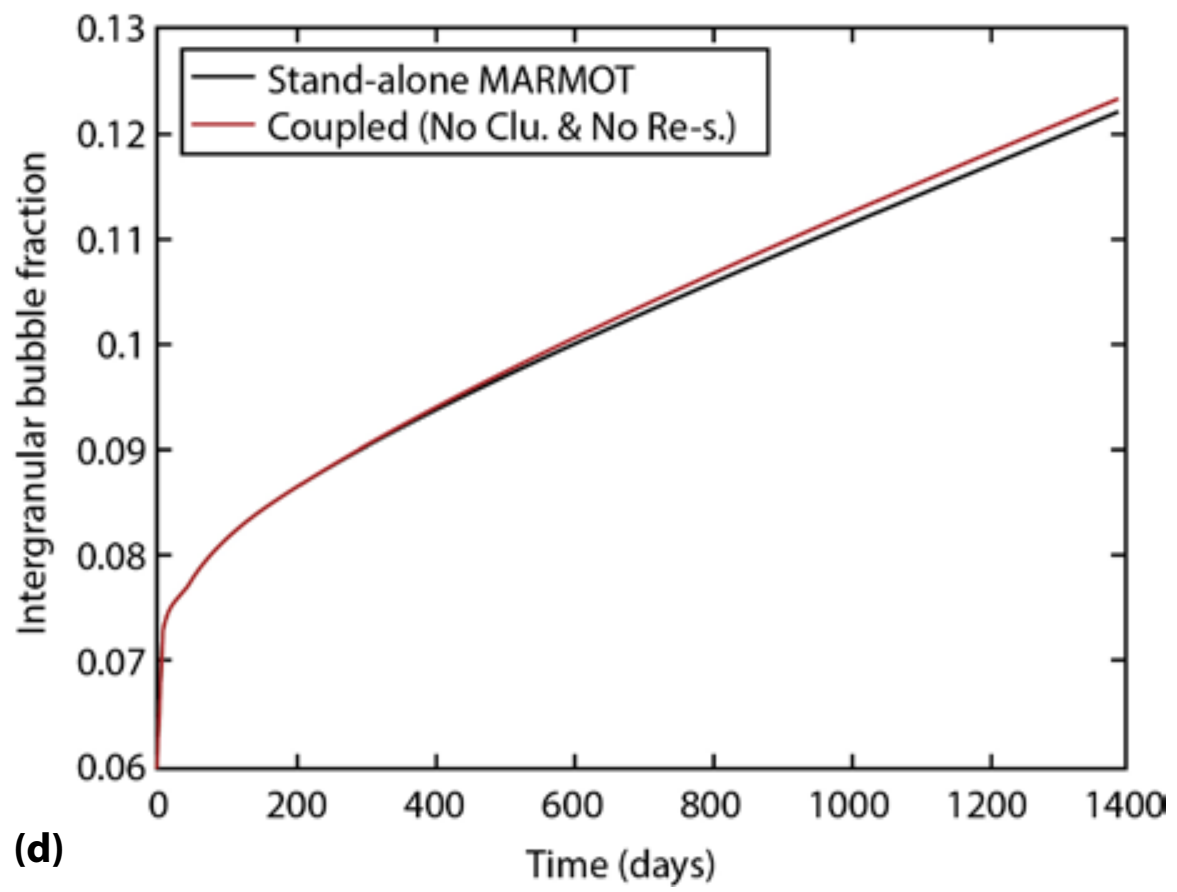

verify the performance of the coupled code by comparing the hybrid model (intragranular clustering or re-solution) to a stand alone MARMOT simulation. We then compare the impact of clustering and re-solution on the bubble growth in the simulation. Finally, we assess the numerical performance of the hybrid model, including the parallel scalability.

\section{Model Verification}

We test to show the coupling between MARMOT and Xolotl is functioning correctly by comparing a coupled simulation to a simulation that uses only the MARMOT phase-field model. If clustering and re-solution of gas atoms are not included in Xolotl, then the spatially resolved cluster-dynamics model becomes just a solution of the diffusion equation. Thus, a simulation of the hybrid model without clustering or re-solution should result in results similar to a stand alone MARMOT simulation in which fission gas is produced uniformly throughout the domain.

For the verification, we simulate a $20 \mu \mathrm{m} \times 20 \mu \mathrm{m}$ domain with periodic boundary conditions containing 
five grains. There are 14 initial bubbles with a radius of $0.73 \mu \mathrm{m}$, positioned randomly along the GBs. The simulations are carried out with a fission rate of $1.09 \times 10^{19}$ fissions $\mathrm{m}^{-3} \mathrm{~s}^{-1}$ and a yield of $\sim 0.22$ fission gas atoms per fission. The MARMOT phase-field model in both simulations used the values previously listed in Table 1 . The simulations are carried out for $1.2 \times 10^{8} \mathrm{~s}(1389$ days) at $1800 \mathrm{~K}$. The mesh used in both codes is identical and consisted of $126 \times 126$ nodes. Figures 3(b) and 3(c) compare the results predicted from the stand alone and coupled version of MARMOT respectively and indicate a similar qualitative result in which the bubbl fraction evolution deviates slightly over time (Figure 3d).

Having verified that the hybrid model is performing qualitatively as expected, we can use this coupled model to demonstrate the temporal evolution of the microstructure predicted by the model and the information provided by two coupled codes. Figure 4 shows snapshots in time of the intergranular gas fraction computed by Xolotl, the gas atom arrival rate at the interfaces is computed by Xolotl and passed to MARMOT, and the GB gas fraction is evolved by MARMOT. The three panes in Figure 4 (top to bottom) are at a time of 20,127 and 1389 days respectively. Figure 4(a) shows the impact of grain size on the intragranular gas fraction in which the larger grains have a higher concentration of monomer xenon atoms due to the longer diffusion distance to the GB. Figure 4(b) shows the effective flux of xenon (arrival rate) to the grain boundaries, which are passed from Xolotl to MARMOT, while Figure 4(c) provides snapshots of the GB

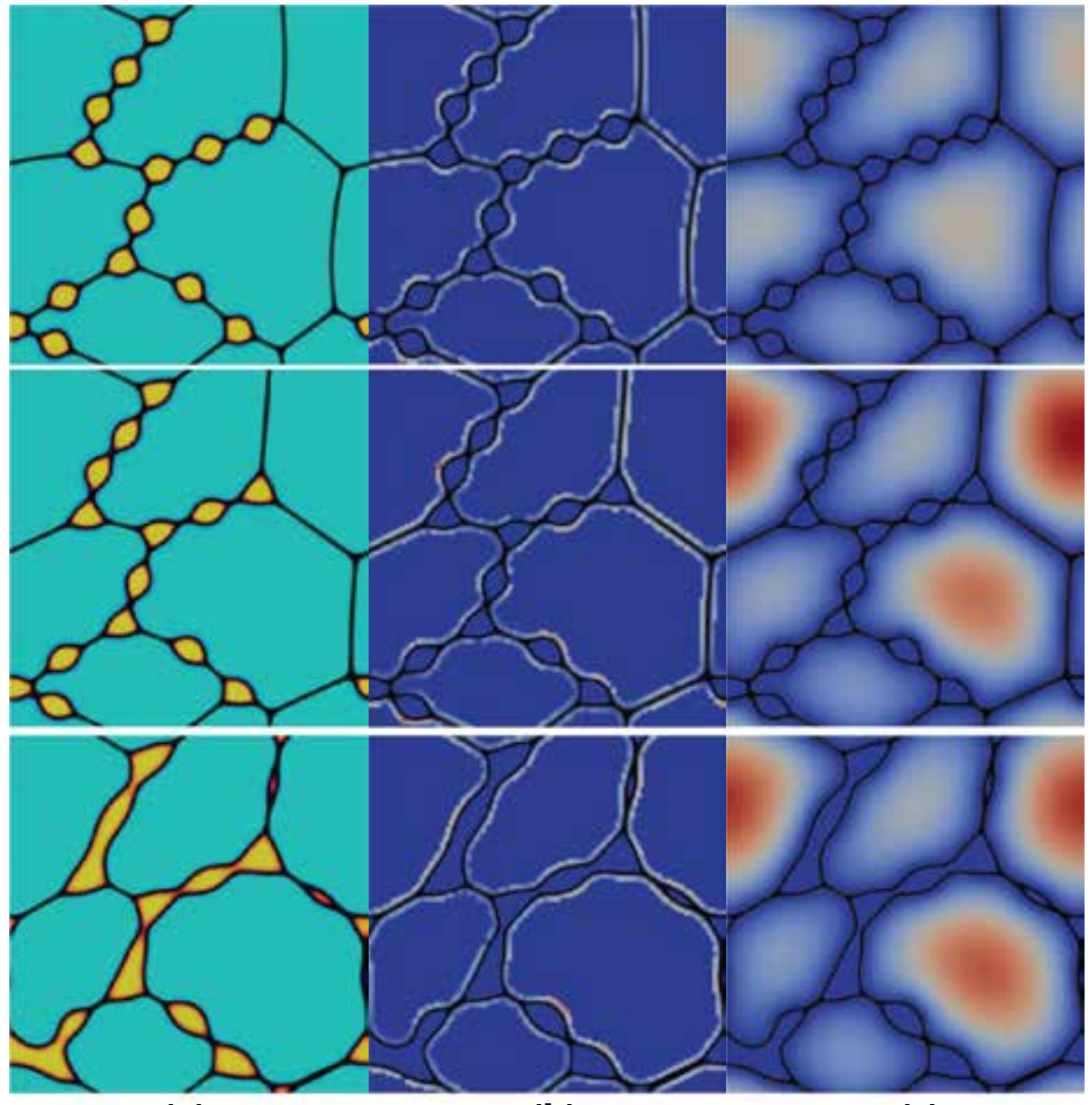

(a)

GB Gas Fraction $\begin{array}{llll}0.1 & 0.2 & 0.3 & 0.4\end{array}$ (b)

S, $2 \mathrm{e}-8$, se-8 $4.7 \mathrm{e}-08$ (c)

Intragranular Gas fraction
$0.0 \mathrm{e} 400 \quad 0.0003$ s.9e- 04 10 .
Figure 4. Snapshots showing representative microstructure with (a) xenon intragranular gas, (b) effective flux of xenon to the GB, and (c) the GB gas fraction as a function of time. The top image is after 20 days, the middle after 127 days, and the bottom image after 1389 days.

fission gas fraction at the times of 20, 127 and 1389 days respectively. Notably, this simulation demonstrates significant GB bubble growth and coalescence, even though the effective xenon flux to the GB is non-physically large since the Xolotl simulations are only diffusing xenon without any clustering or intragranular bubble formation. Thus, the intragranular gas fraction increases at early simulated time, but eventually reaches a steady 
state value once the production is balanced by the rate of gas diffusing to the grain boundaries. The intergranular bubble gas fractions stay at the equilibrium concentration in each of the bubbles, but as more and more fission gas is passed from Xolotl to MARMOT, the bubbles grow and eventually interconnect.

\section{Incorporation of Clustering and Re-solution on Intergranular Bubble Growth}

The simple example shown in Figures 3 and 4 essentially includes no physics within the Xolotl code, using it only as a diffusional solver to demonstrate that the two codes are effectively exchanging the gas flux at the boundaries. But this simplified simulation does not take advantage of the capability of Xolotl to predict intragranular bubble growth and, hence, fission gas swelling.

Here, we demonstrate the impact of considering additional physics in Xolotl. The simulation conditions have again been repeated, but now selectively increasing the physical fidelity of the Xolotl prediction by incorporating intragranular xenon clustering and finally a simulation in which both clustering and re-solution of xenon from intragranular bubbles is included, and representative results are shown in Figure 5. As expected, the simulations with xenon clustering and bubble formation have a much larger amount of gas trapped within the grains (as shown in Figures $5[\mathrm{a}-\mathrm{c}])$ resulting in a large decrease in the intergranular bubble growth over time (Figure 5[d]). As expected, the impact of re-solution is to increase the xenon monomer concentration within the grain interior. Notably, as a result of the size dependence of the Setyawan et al. re-solution model [34] implemented into Xolotl, the smaller bubbles shrink at faster rates than the larger bubbles. The increased monomer population then reacts with the remaining large bubbles to produce more extensive intragranular bubble growth at lower bubble density, which correspondingly increases intragranular swelling, and also results in an increase in the flux of xenon monomers to the GB. This increased arrival rate of xenon to the grain boundaries resulting from heterogeneous re-solution leads to a slightly larger intragranular bubble fraction, as indicated in Figure 5(e).

\section{Computational Performance}

The computational performance of the coupled codes has been assessed by investigating the wall clock time required for the completion of the simulations from the previous two sections. Specifically, we compare the portion of the total wall time taken 

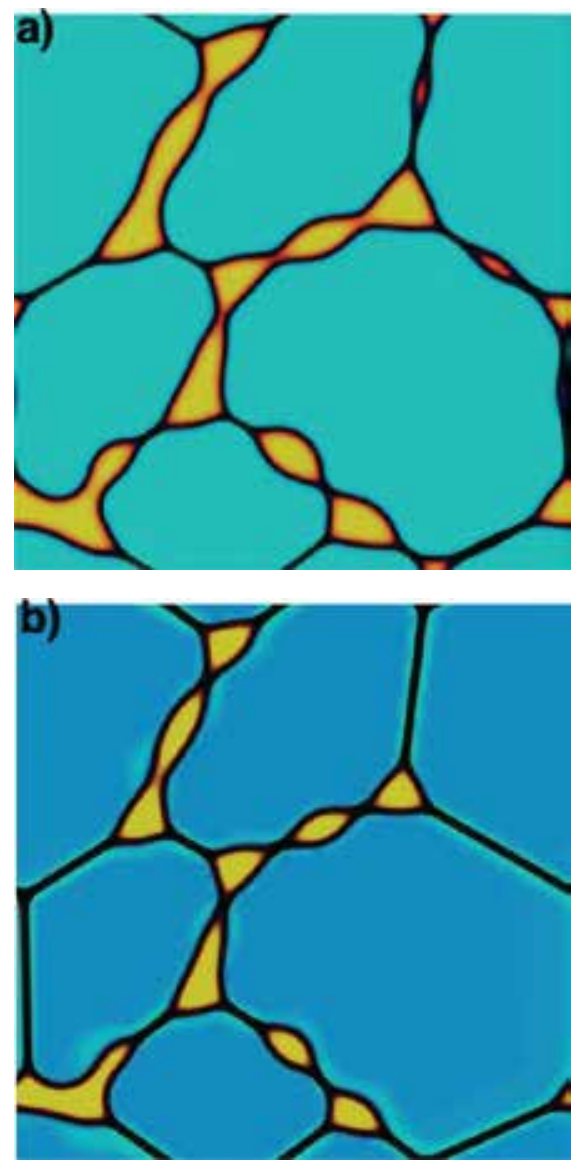

(d) 0.13
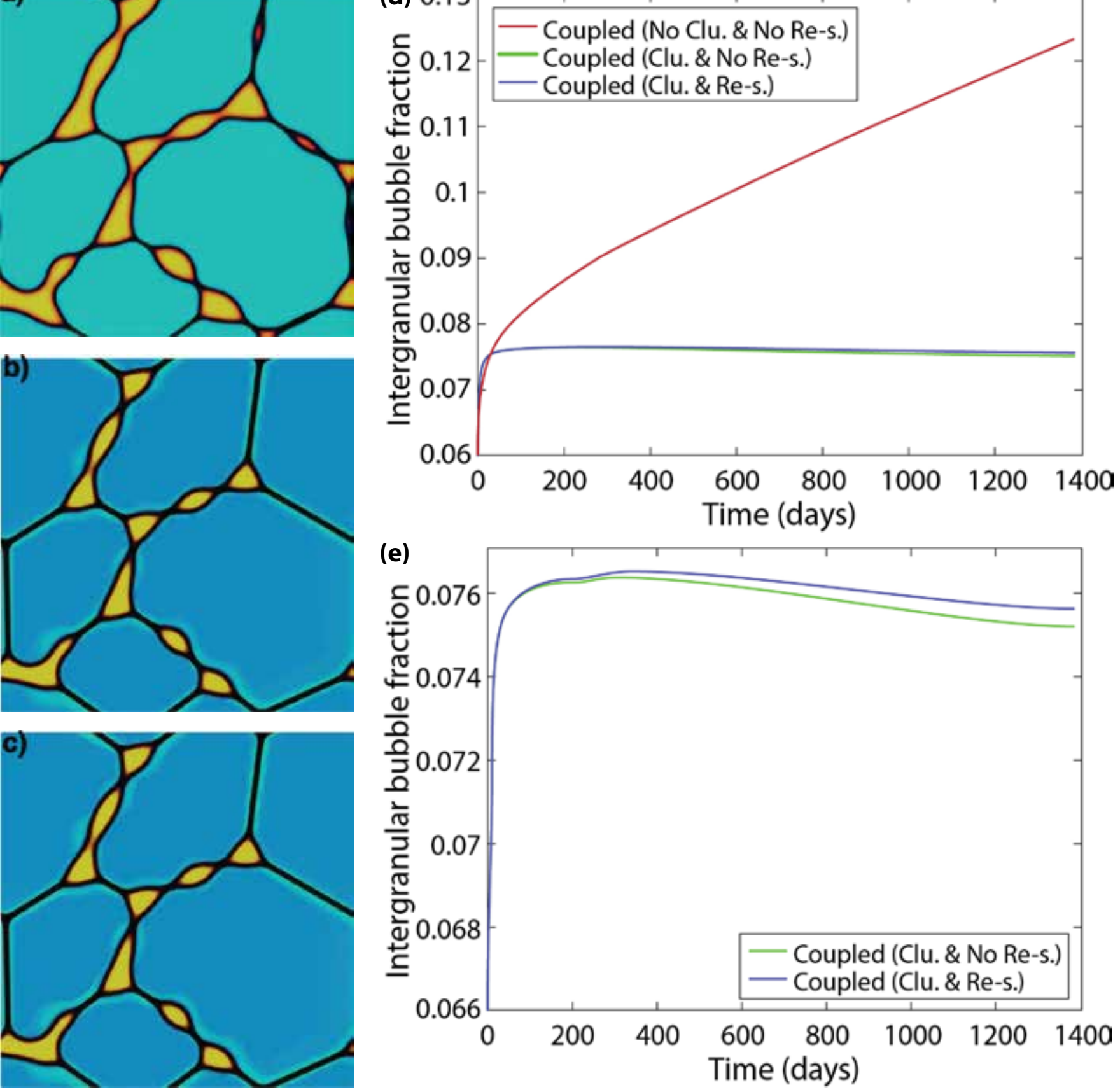

GB Gas Fraction

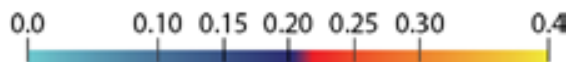

Figure 5. Snapshots of the GB xenon gas fraction at a time of 1389 days as a result of selective incorporation of clustering and re-solution in the coupled Xolotl-MARMOT simulation in which Xolotl incorporated (a) no clustering, (b) clustering but no-re-solution, and (c) clustering and re-solution. (d) Intergranular bubble fraction with time, comparing the three physical models while (e) plots the intergranular bubble fraction to demonstrate the impact of re-solution. 

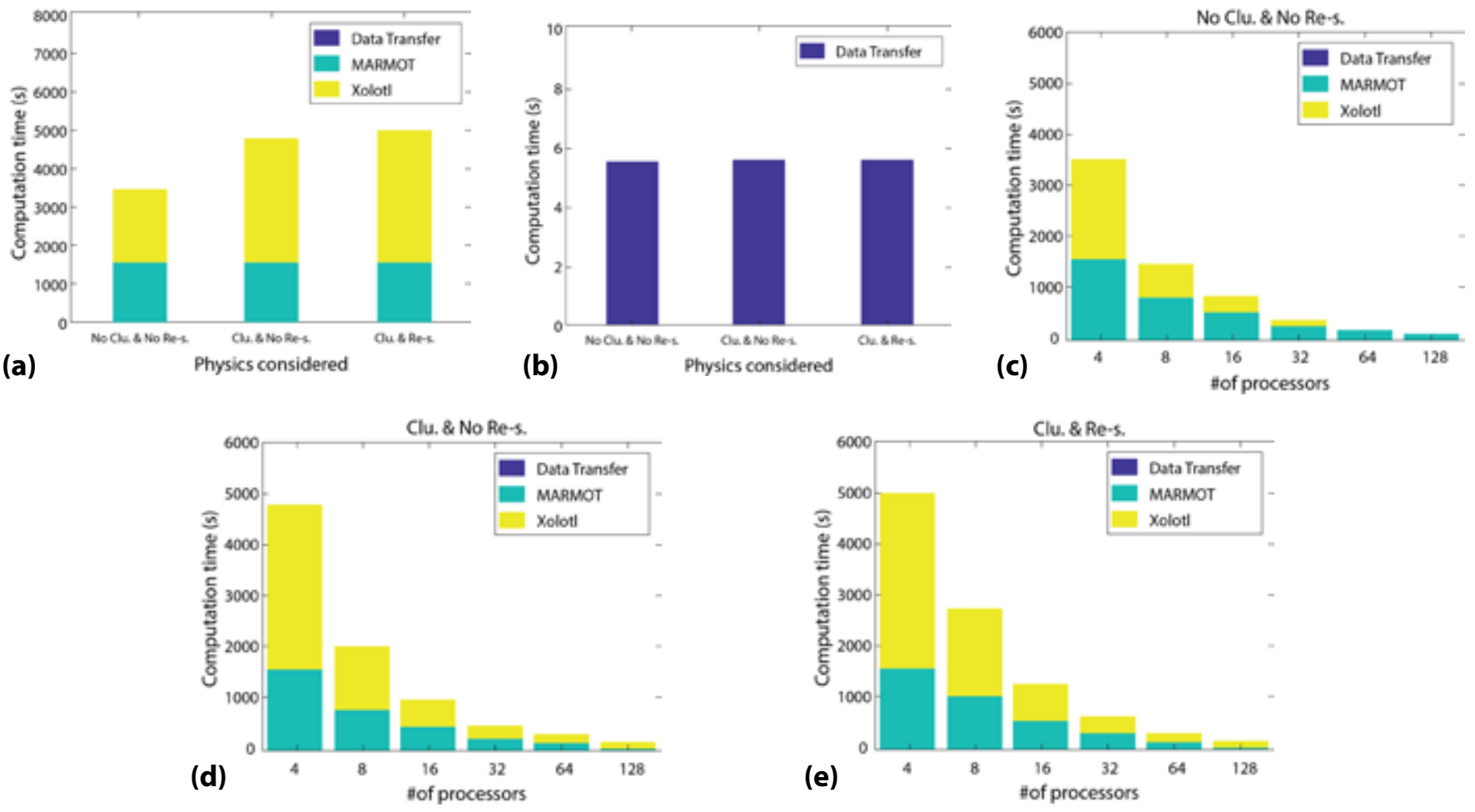

Figure 6. Computational wall clock time for the coupled Xolotl-MARMOT simulations involving a two dimensional, five grain model demonstrating (a) time using four processors and resolving the time used by Xolotl (yellow), MARMOT (green), and data transfer (blue) for selective physics incorporation in

Xolotl; (b) the data transfer time and the computational time and the relative time used by Xolotl versus MARMOT as a function of the number of processors for (c) no clustering in Xolotl, (d) xenon clustering but no re-solution, and (e) xenon clustering and heterogeneous fission gas re-solution. up by MARMOT, Xolotl, and the data transfer between the codes. We also compare the wall time as a function of the number of processors used for the computation. The results are shown in Figure 6. The computation time for the MARMOT portion of the simulations is independent of whether clustering or re-solution is included, though the Xolotl computation time and, thus, the total wall time increases with implementing more realistic physics containing both clustering and re-solution. When neither clustering or re-solution is used, the computational cost of the two codes is approximately equal when using four processors (Figure 6[a]), though Xolotl requires a larger portion of the cost when clustering and re-solution are included. The cost of the data transfer between the codes is negligible for any number of processors. However, as the number of processors increases, MARMOT takes a larger and larger portion of the overall computation cost, indicating that Xolotl has better computational performance and scaling to larger size problems than MARMOT at present. Thus, we anticipate future effort to further optimize the computational performance of MARMOT and the coupled Xolotl-MARMOT simulations.

\section{MARMOT Simulations}

To more accurately assess the parallel scalability of the coupled code, we performed a strong scaling study. For the strong scaling study, the same problem was used as described in the previous sections; however, we used a finer mesh in both codes (201 $\times 201$ nodes). In this strong scaling study, the time step was fixed to 0.5 seconds and 20 total time steps were simulated (10 seconds). The simulations were performed with 


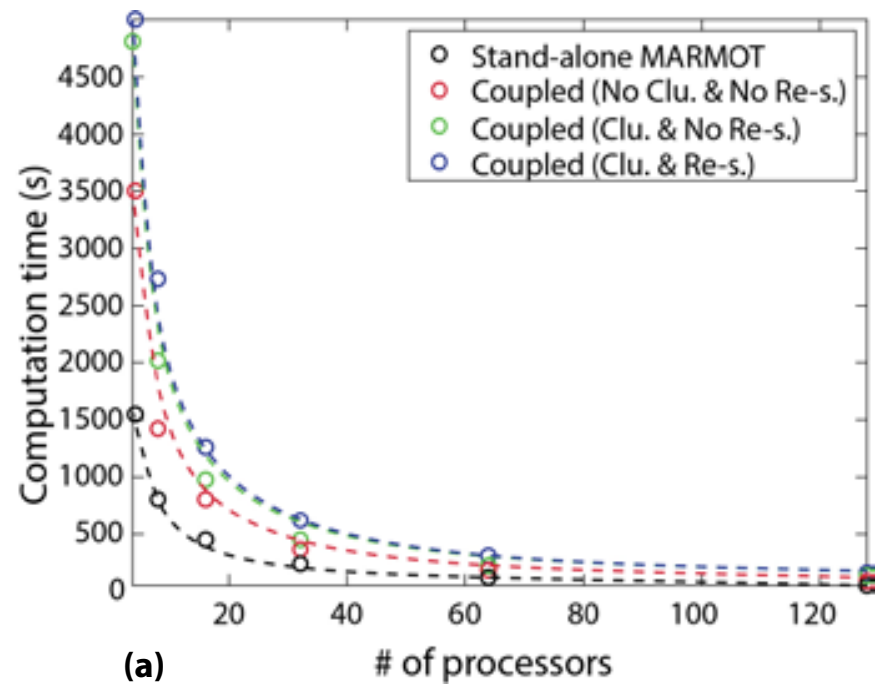

six independent processor combinations and used between four and 128 processors. Figure 7 presents the results of the scaling study, both for the total computational time for the 20 timesteps (Figure 7[a]) and the speedup with respect to the time required using four processors (Figure 7[b]). The scaling for a stand alone MARMOT simulation is shown for reference. In the strong scaling study, the coupled code scales quite well, demonstrating nearly ideal scaling up to 128 processors. The coupled code scales slightly better than the stand alone MARMOT simulation.

\section{Discussion}

Fission gas behavior in uranium dioxide fuels is a key factor in determining fuel performance because the diffusion and precipitation of xenon and krypton in fission gas bubbles influences both fuel swelling and the quantity of fission gas released to the fuel plenum. Thus, this project is important to the mission of DOE in assisting the nuclear industry to increase the burnup and utilization of nuclear fuel.

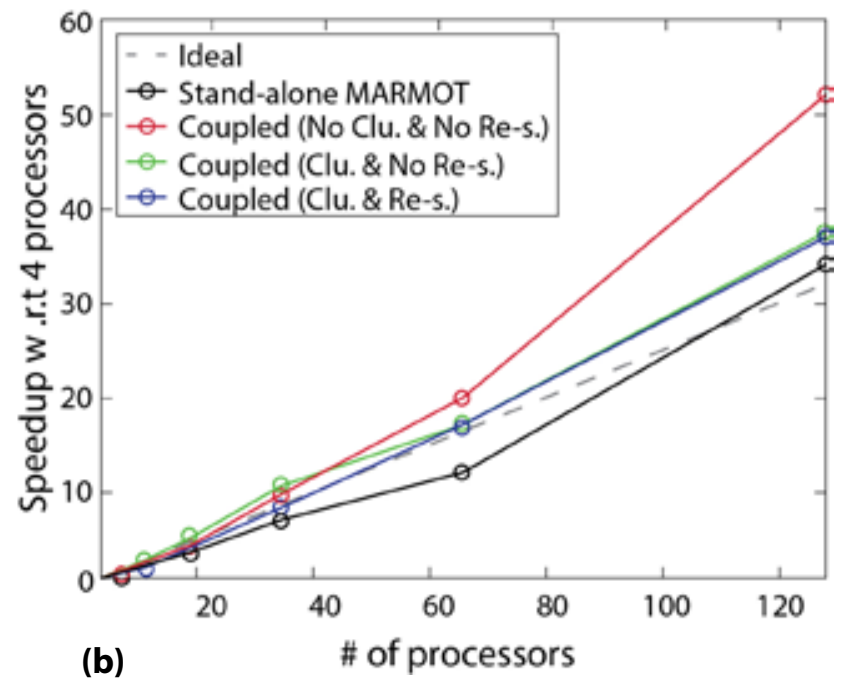

Figure 7. Strong scaling computational performance assessment of the coupled Xolotl-MARMOT code with a variation from four to 128 processors, showing (a) total computational time and (b) speedup with respect to four processors for various physics implementations of the cluster dynamics model versus standalone MARMOT. 
xenon to the grain boundaries, as expected, and thereby decreases the growth rate of the intergranular gas bubbles. Including an atomistically informed re-solution model leads to a significant increase in the xenon monomer concentration, which notably increases both the growth of intragranular bubbles (swelling) and increases the flux of xenon to the grain boundaries that also produces a small increase in the intergranular bubble fraction. An assessment of the computational performance of the coupled Xolotl and MARMOT simulations indicates nearly ideal scaling up to 128 processors in the strong scaling regime and that the computational cost of the data transfer between the codes is negligible. However, the computational assessment does reveal that Xolotl scales better for larger problems than MARMOT; thus, future computational optimization will be focused on improving the scaling of MARMOT in addition to a computational physics exercise to experimentally benchmarking the predictions of the coupled codes prior to performing a three dimensional demonstration.

\section{Future Activities}

The project will continue to extend the coupled MARMOT and Xolotl simulations to three dimensions, and assess fuel swelling and fission gas release for normal and transient operating conditions.

\section{References}

[1.] D.R. Olander, Fundamental Aspects of Nuclear Reactor Fuel Elements, TID-26711-P1, National Technical Information Services (1976).

[2.] J. Rest, M.W.D. Cooper, J. Spino, J.A. Turnbull, P. Van Uffelen, C.T. Walker, "Fission gas release from UO2 nuclear fuel: A review," J. Nucl. Mater. 513 (2019) 310-345, https:// doi.org/10.1016/j.jnucmat.2018.08.019.

[3.] M.R. Tonks, X.-Y. Liu, D. Andersson, D. Perez, A. Chernatynskiy, G. Pastore, C.R. Stanek, R. Williamson, "Development of a multiscale thermal conductivity model for fission gas in UO2," J. Nucl. Mater. 469 (2016) 89-98, https://doi.org/10.1016/j. jnucmat.2015.11.042.

[4.] M. Oguma "Microstructure Effects on Fracture Strength of $\mathrm{UO}_{2}$ Fuel Pellets," J. Nucl. Sci. Technol. 19 (1982) 1005-1014, https://doi.org/10.1080/1881 1248.1982.9734249.

[5.] J.B. Ainscough, B.W. Oldfield, J.O. Ware, "Isothermal grain growth kinetics in sintered $\mathrm{UO}_{2}$, , J. Nucl. Mater. 49 (1973) 117-128, https:// doi.org/10.1016/00223115(73)90001-9. 
[6.] R.J. White, R.C. Corcoran and J.P. Barnes, "A Summary of Swelling Data Obtained from the AGR/Halden Ramp Test Programme," Report R\&T/NG/ EXT/REP/0206/02 (2006).

[7.] P. Lösönen, “On the behaviour of intragranular fission gas in $\mathrm{UO}_{2}$ fuel," J. Nucl. Mater 280 (2000) 56-72, https:// doi.org/ 10.1016/S00223115(00)00028-3.

[8.] A.H. Booth, "A method of calculating fission gas diffusion from $\mathrm{UO}_{2}$ fuel and its application to the X-2-f loop test", Canadian Report CRDC-721, September 1957.

[9.] M.V. Speight, “A Calculation on the Migration of Fission Gas in Material Exhibiting Precipitation and Re-solution of Gas Atoms Under Irradiation," Nuclear Science \& Engineering 37 (1969) 180, https://doi.org/ 10.13182/ NSE69-A20676.

[10.] R.M. Cornell, M.V. Speight and B.C. Masters, "The role of bubbles in fission gas release from uranium dioxide," J. Nucl. Mater 30 (1969) 170-178, https:// doi.org/10.1016/00223115(69)90178-0.

[11.] J.A. Turnbull, C.A. Friskney, J.R. Findlay, F.A. Johnson and A.J. Walter, "The diffusion coef- ficients of gaseous and volatile species during the irradiation of uranium dioxide," J. Nucl. Mater 107 (1982) 168-184, https:// doi.org/10.1016/00223115(82)90419-6.

[12.] R.J. White and M.O.Tucker, "A New Fission-Gas Release Model," J. Nucl. Mater 118 (1983) 1-38.

[13.] K. Forsberg and A.R. Massih, "Diffusion theory of fission gas migration in irradiated nuclear fuel $\mathrm{UO}_{2}$," J. Nucl. Mater 135 (1985) 140-148, https:// doi.org/10.1016/00223115(85)90071-6.

[14.] A.R. Massih and K. Forsberg, "Calculation of grain boundary gaseous swelling in $\mathrm{UO}_{2}$, , J. Nucl. Mater 377 (2008) 406-408, https://doi.org/10.1016/j. jnucmat.2008.03.011.

[15.] R.J. White, “The development of grain-face porosity in irradiated oxide fuel," J. Nucl. Mater 325 (2004) 61. https:// doi.org/10.1016/j.jnucmat.2003.10.008.

[16.] G. Pastore, L. Luzzi, V. Di Marcello, P. van Uffelen, "Physics-based modelling of fission gas swelling and release in UO2 applied to integral fuel rod analysis," Nuclear Engineering and Design 256 (2013) 75, https://doi.org/10.1016/j. nucengdes.2012.12.002. 
[17.] G. Pastore, D. Pizzocri, C. Rabiti, T. Barani, P. van Uffelen, and L. Luzzi, “An effective numerical algorithm for intra-granular fission gas release during nonequilibrium trapping and resolution," J. Nucl. Mater 509 (2018) 687-699, https:// doi.org/10.1016/j.jnucmat.2018.07.030.

[18.] D. Pizzocri, G. Pastore, T. Barani, A. Magni, L. Luzzi, P. van Uffelen, S.A. Pitts, A. Alfonsi, and J.D. Hales, "A model describing intra-granular fission gas behaviour in oxide fuel for advanced engineering tools," $\mathrm{J}$. Nucl. Mater 502 (2018) 323-330, https://doi.org/10.1016/j. jnucmat.2018.02.024.

[19.] S. Kashibe, K. Une and K. Nogita, "Formation and growth of intragranular fission gas bubbles in UO2 fuels with burnup of 6-83 GWd/t," J. Nucl. Mater 206 (1993) 22-34, https:// doi.org/10.1016/00223115(93)90229-R.

[20.] P. Lösönen, "Modelling intragranular fission gas release in irradiation of sintered LWR UO2," J. Nucl. Mater 304 (2002) 29-49.
[21.] C. Baker, “The fission gas bubble distribution in uranium dioxide from high temperature irradiated sghwr fuel pins," J. Nucl. Mater 66 (1977) 283-291, https:// doi.org/10.1016/00223115(77)90117-9.

[22.] B.D. Wirth, X. Hu, A. Kohnert, and D. Xu, "Modeling defect cluster evolution in irradiated structural materials: Focus on comparing to high-resolution experimental characterization studies," J. of Materials Research 30 (2015) 1440-1455, https:// doi.org/10.1557/jmr.2015.25.

[23.] D. Maroudas, S. Blondel, L. Hu, K.D. Hammond, and B.D. Wirth, "Helium segregation on surfaces of plasma-exposed tungsten," J. of Physics: Condensed Matter 28 (2016) 064004.

[24.] S. Blondel, D.E. Bernholdt, K.D. Hammond, and B.D. Wirth, "Continuum-scale modeling of helium bubble bursting under plasma-exposed tungsten surfaces," Nuclear Fusion 58 (2018) 126034.

[25.] D. Xu and B.D. Wirth, "Modeling spatially dependent kinetics of helium desorption in BCC iron following He ion implantation," J. Nucl. Mater 403 (2010) 184-190, https:// doi.org/10.1016/j.jnucmat.2010.06.025. 
[26.] P.C. Millett, M. Tonks, “Application of phase-field modeling to irradiation effects in materials," Curr. Opin. Solid State Mater. Sci. 15 (2011) 125-133, https://doi.org/10.1016/j. cossms.2010.10.002.

[27.] Y. Li, S. Hu, X. Sun, M. Stan, "A review: applications of the phase field method in predicting microstructure and property evolution of irradiated nuclear materials," Npj Comput. Mater. 3 (2017) 16.

[28.] M.R. Tonks, A. Cheniour, L. Aagesen, "How to apply the phase field method to model radiation damage," Comput. Mater. Sci. 147 (2018) 353-362, https:// doi.org/10.1016/j.commatsci.2018.02.007.

[29.] P.C. Millett, A. El-Azab, D. Wolf, "Phase-field simulation of irradiated metals: Part II: Gas bubble kinetics," Comput. Mater. Sci. 50 (2011) 960-970, https://doi.org/10.1016/j. commatsci.2010.10.032.

[30.] P.C. Millett, M.R. Tonks, S.B. Biner, L. Zhang, K. Chockalingam, Y. Zhang, "Phase-field simulation of intergranular bubble growth and percolation in bicrystals," J. Nucl. Mater. 425 (2012) 130-135, https:// doi.org/10.1016/j.jnucmat.2011.07.034.
[31.] L.K. Aagesen, D. Schwen, M.R. Tonks, Y. Zhang, "Phase-field modeling of fission gas bubble growth on grain boundaries and triple junctions in $\mathrm{UO}_{2}$ nuclear fuel," Comput. Mater. Sci. 161 (2019) 35-45, https:// doi.org/10.1016/j.commatsci.2019.01.019.

[32.] S. Blondel, D. E. Bernholdt, K. D. Hammond, L. Hu, D. Maroudas, and B. D. Wirth, "Modeling Helium Segregation to the Surfaces of Plasma-Exposed Tungsten as a Function of Temperature and Surface Orientation," Fusion Science and Technology 71 (2017) 8492, https://doi.org/10.13182/ FST16-110.

[33.] W. Setyawan, M.W.D. Cooper, K.J. Roche, R.J. Kurtz, B.P. Uberuaga, D.A. Andersson, B.D. Wirth, "Atomistic model of xenon gas bubble re-solution rate due to thermal spike in uranium oxide," J. Appl. Phys. 124 (2018) 075107, https://doi. org/10.1063/1.5042770.

[34.] S. Balay, S. Abhyankar, M.F. Adams, J. Brown, P. Brune, K. Buschelman, L. Dalcin, V. Eijkhout, W.D. Gropp, D. Kaushik, M.G. Knepley, D.A. May, L.C. McInnes, R.T. Mills, T. Munson, K. Rupp, P. Sanan, B.F. Smith, S. Zampini, H. Zhang, H. Zhang, PETSc Users Manual, Argonne National Laboratory, 2020. 
[35.] L.-Q. Chen, “Phase-Field Models for Microstructure Evolution,” Annu. Rev. Mater. Res. 32 (2002) 113-140. https:// doi.org/10.1146/annurev. matsci.32.112001.132041.

[36.] N. Moelans, B. Blanpain, P. Wollants, “An Introduction to Phase-Field Modeling of Microstructure Evolution," Calphad. 32 (2008) 268-294, https://doi.org/10.1016/j. calphad.2007.11.003.

[37.] M.R. Tonks and L.K. Aagesen, "The phase field method: mesoscale simulation aiding material discovery," Annu. Rev. Mater. Res. 49 (2019) 79-102, https:// doi.org/10.1146/annurevmatsci-070218-010151.

[38.] Y. Li, S. Hu, R. Montgomery, F. Gao, and X. Sun, "Phase-field simulations of intragranular fission gas bubble evolution in $\mathrm{UO}_{2}$ under post-irradiation thermal annealing," Nucl. Instrum. Methods Phys. Res. Sect. B Beam Interact. Mater. 303 (2013) 62-67, https://doi.org/10.1016/j. nimb.2012.11.028.
[39.] Y. Zhu and H. Hallberg, "Investigation of faceted void morphologies in UO2 by phase field modelling," J. Nucl. Mater. 467 (2015) 113-120, https:// doi.org/10.1016/j.jnucmat.2015.09.024.

[40.] M.R. Tonks, D. Gaston, P.C. Millett, D. Andrs, P. Talbot, “An object-oriented finite element framework for multiphysics phase field simulations," Comput. Mater. Sci. 51 (2012) 20-29, https://doi.org/10.1016/j. commatsci.2011.07.028.

[41.] D. Gaston, C. Newman, G. Hansen, D. Lebrun-Grandié, “MOOSE: A parallel computational framework for coupled systems of nonlinear equations," Nucl. Eng. Des. 239 (2009) 1768-1778, https:// doi.org/10.1016/j.nucengdes.2009.05.021.

[42.] D. Schwen, L.K. Aagesen, J.W. Peterson, M.R. Tonks, "Rapid multiphase-field model development using a modular free energy based approach with automatic differentiation in MOOSE/MARMOT," Comput. Mater. Sci. 132 (2017) 36-45, https://doi.org/10.1016/j. commatsci.2017.02.017. 
[43.] P.V. Nerikar, K. Rudman, T.G. Desai, D. Byler, C. Unal, K.J. McClellan, S.R. Phillpot, S.B. Sinnott, P. Peralta, B.P. Uberuaga, C.R. Stanek, "Grain boundaries in uranium dioxide: scanning electron microscopy experiments and atomistic simulations," J. Am. Ceram. Soc. 94 (2011) 1893-1900, https:// doi.org/10.1111/j.15512916.2010.04295.x.
[44.] D.R. Gaston, C.J. Permann, J.W. Peterson, A.E. Slaughter, D. Andrš, Y. Wang, M.P. Short, D.M. Perez, M.R. Tonks, J. Ortensi, L. Zou, R.C. Martineau, "Physicsbased multiscale coupling for full core nuclear reactor simulation," Ann. Nucl. Energy. 84 (2015) 45-54, https:// doi.org/10.1016/j.anucene.2014.09.060.

\section{Distributed Partnership at a Glance}

\begin{tabular}{|l|l|}
\hline NSUF Institution & Facilities and Capabilities \\
\hline Idaho National Laboratory & High Performance Computing \\
\hline Collaborators & $\begin{array}{l}\text { David Andersson (co-principal investigator) } \\
\text { Laboratory }\end{array}$ \\
\hline University of Florida & $\begin{array}{l}\text { Dong-Uk Kim (collaborator), Mike Tonks } \\
\text { (collaborator) }\end{array}$ \\
\hline $\begin{array}{l}\text { University of Tennessee, } \\
\text { Knoxville }\end{array}$ & Sophie Blondel (collaborator) \\
\hline
\end{tabular}




\section{Short Communications}

Editor's note: This short communications report is a compilation of three separate NSUF projects all centering on oxidedispersion strengthened steels.

\section{Microstructural Characterization of the Radiation Tolerance of Advanced Joining Techniques for Oxide Dispersion Strengthened Steels under Ion Irradiation}

Elizabeth Getto - United States Naval Academy - getto@usna.edu

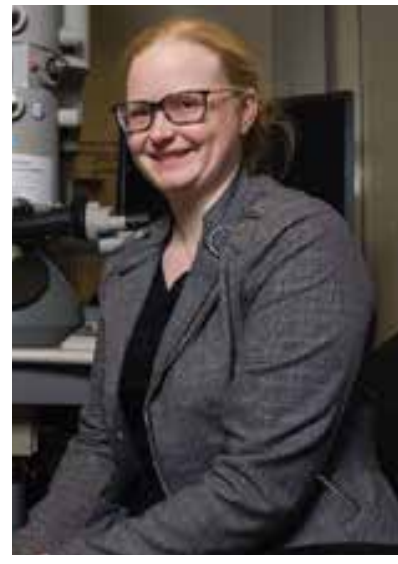

The objective of this work is to examine the effect of high damage levels of radiation on oxide dispersion strengthened (ODS) steels that have been subjected to advanced joining techniques.

ODS steels have been suggested as a candidate material for reactor structural components expected to be subject to high radiation damage measured in displacements per atom (dpa). The behavior of reactor components under extreme environments of temperature, radiation damage, and pressure is a key challenge facing both Navy and civilian reactor fleets. Recently, self-ion $\left(\mathrm{Fe}^{2+}\right)$ irradiation has been the chosen surrogate for in-reactor irradiations for accelerated irradiation testing because of the accelerated damage rate, superior temperature control, and quick turnaround times. This project examined irradiated friction stir welded MA956 (nominal composition: Fe-20Cr-5Al-0.4Ti-0.51 $\mathrm{Y}_{2} \mathrm{O}_{3}$ ) with two fully consolidated welding conditions (medium and high heat input).

The outcome of this project is the systematic/parametric understanding of irradiation evolution of multiple welding conditions, which can more broadly help guide the design of ODS weldments for future nuclear reactors.

\section{Results}

Prior to irradiation, coarsening of the grain and dispersoids were observed, with the weld process causing softening relative to the as-received base material [1]. The irradiation conditions were $50 \mathrm{dpa}$ at 400 and $500^{\circ} \mathrm{C}$ and $100 \mathrm{dpa}$ at 400,450 , and $500^{\circ} \mathrm{C}$, with $5 \mathrm{MeV}$ $\mathrm{Fe}^{2+}$ at the Michigan Ion Beam Laboratory. The dispersoid, dislocation, and void microstructure was examined using STEM atom probe tomography, and composition scans using a SuperX EDS system (ChemiSTEM). Increasing diameter and decreasing number density of the dispersoids were observed at all temperatures with increased dose. In general, the dispersoid diameter increased weakly with temperature and number density decreased. Dislocation loops formed at all temperatures and were larger at higher temperatures. The dislocation loop and network density tended to increase with dose. Voids formed only at the highest doses in the base material $\left(450^{\circ} \mathrm{C}, 200 \mathrm{dpa}\right)$ and nucleated on the dispersoids (Figure 1).

\section{Conclusion}

The microstructure evolution observed after welding and irradiation is promising for radiation tolerance in actual advanced reactor conditions. The reprecipitation of the dispersoids during irradiation after welding is especially surprising and promising in terms of mechanical property recovery after softening from the welding process. The superior swelling resistance of MA956 was demonstrated by the small fraction of voids in both the base material and, to a lesser extent, the welded material. Despite the formation of voids in the weld, this work demonstrates the suitability of both MA956 and friction stir welding in future reactor designs. 


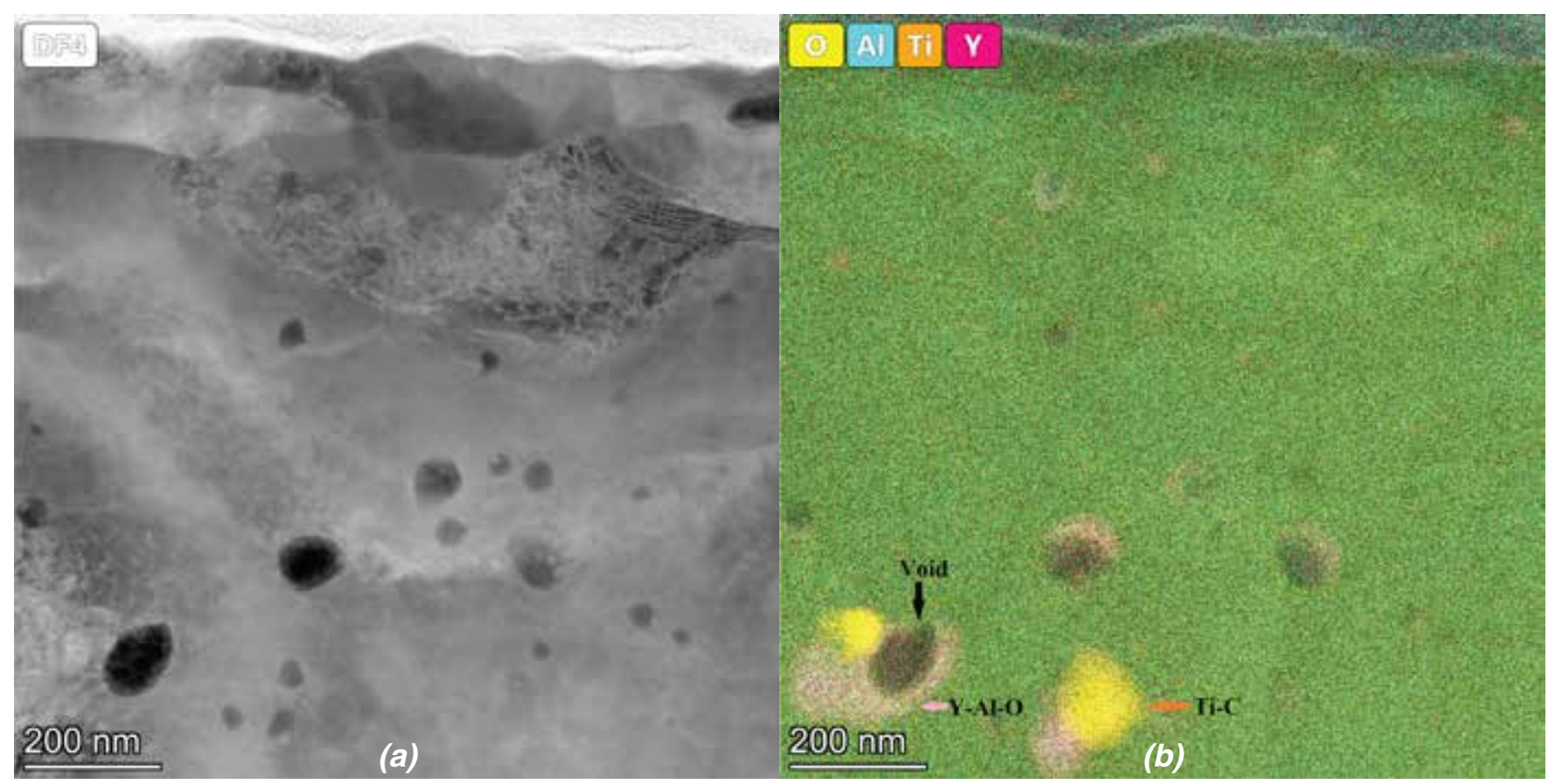

Figure 1. (a) High-angle annular dark-field imaging and (b) composition map (O-Al-Y-Ti) of the stir zone of friction stir welded MA956 irradiated with $5 \mathrm{MeV} \mathrm{Fe++} \mathrm{at} 450^{\circ} \mathrm{C}$ up to $200 \mathrm{dpa}$.

\section{References}

[1.] E. Getto, B. Baker, B. Tobie, S. Briggs, K. Hattar, K. Knipling, Effect of friction stir welding and self-ion irradiation on dispersoid evolution in oxide dispersion strengthened steel MA956 up to $25 \mathrm{dpa}$, J. Nucl. Mater. 515 (2019) 407-419. https://doi.org/10.1016/j.jnucmat.2018.12.040.

\section{Publications}

[1.] E. Getto, B. Baker, B. Tobie, S. Briggs, K. Hattar, K. Knipling, Effect of friction stir welding and self-ion irradiation on dispersoid evolution in oxide dispersion strengthened steel MA956 up to $25 \mathrm{dpa}$, J. Nucl. Mater. 515 (2019) 407-419. https://doi.org/10.1016/j.jnucmat.2018.12.040.
[2.] E. Getto, N. Nathan, J. McMahan, B. Baker, Effect of temperature and dose on the microstructure of 5 MeV Fe++-irradiated MA956," J. Nucl. Mater. submitted.

\section{Distributed Partnership at a Glance}

\begin{tabular}{|l|l|}
\hline NSUF Institution & Facilities and Capabilities \\
\hline $\begin{array}{l}\text { Center for Advanced } \\
\text { Energy Studies }\end{array}$ & Microscopy and Characterization Suite \\
\hline Idaho National Laboratory & $\begin{array}{l}\text { Electron Microscopy Laboratory, Irradiated } \\
\text { Materials Characterization Laboratory }\end{array}$ \\
\hline University of Michigan & Michigan Ion Beam Laboratory \\
\hline Collaborators & \multicolumn{2}{|l|}{ Dr. Mukesh Bachhav (collaborator) } \\
\hline Idaho National Laboratory & $\begin{array}{l}\text { CAPT Brad Baker, Ph.D. (co-principal } \\
\text { investigator), ENS J. McMahan (collaborator), } \\
\text { ENS Nicholas Nathan (collaborator) }\end{array}$ \\
\hline United States Naval Academy
\end{tabular}




\section{In Situ Ion Irradiation of Second Phase Particles in Zirconium Fuel Cladding}

Chris Grovenor - University of Oxford - Chris.grovenor@materials.ox.ac.uk

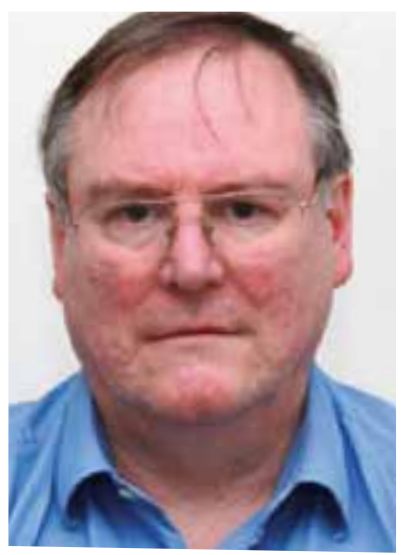

Z irconium alloys are universally utilized as fuel cladding and support structures in pressurized water reactors (PWRs). However, these alloys often experience aqueous corrosion while in use, which can result in a shortening of the operating lifetime and the efficient burnup of the uranium fuel. The oxides on $\mathrm{Zr}$ alloys corroded in-reactor are generally less textured and have more equiaxed grains, and more macro cracks than samples corroded in an autoclave [1]. Because of the key role of the oxide layer in the corrosion kinetics, it is important to understand the processes by which the oxide grains are damaged by irradiation. The distribution of alloying elements in the metal matrix is also crucial to controlling the corrosion kinetics [2]. These elements are initially found in second phase particles (SPPs) 50-500 nm in size, but these SPPs are damaged by neutron irradiation and release alloying elements to the metal matrix and further affect the overall corrosion performance. To provide better understanding on radiation effects in the surface oxides and SPPs in Zr alloys, we have investigated their microstructural evolution under ion irradiation using in situ transmission electron microscopy
(TEM) in combination with postirradiation analysis using a series of advanced analytical microscopies.

TEM foils were prepared using the focused ion beam (FIB) lift-out method from as-received and autoclaved $\mathrm{Zr}-\mathrm{Nb}$ alloys provided by Westinghouse. In situ irradiation was carried out utilizing the Intermediate Voltage Electron Microscope (IVEM) at Argonne National Laboratory using $1 \mathrm{MeV} \mathrm{Kr}{ }^{2+}$ ions at four temperatures (e.g., $50 \mathrm{~K}, 293 \mathrm{~K}$, $623 \mathrm{~K}$, and $873 \mathrm{~K}$ ) and a dose rate of $\sim 10^{-3} \mathrm{dpa} / \mathrm{s}$ up to $20 \mathrm{dpa}$. Pre- and post-irradiation specimens have also been analysed using a combination of analytical microscopies, high-resolution transmission electron microscopy (HRTEM), aberration-corrected scanning transmission electron microscopy (STEM), and energy-dispersive X-ray spectroscopy (EDX) to provide correlative information to understand the radiation damage mechanisms.

\section{Results}

Figure 1(a) and (b) show typical post-irradiation HRTEM images from the oxide/metal interface region in an autoclave corroded $\mathrm{Zr}-\mathrm{Nb}$ alloy in situ irradiated at $50 \mathrm{~K}$ up to $4 \times 10^{15}$ ions $/ \mathrm{cm}^{-2}$ (13 dpa). The $\mathrm{ZrO}$ 

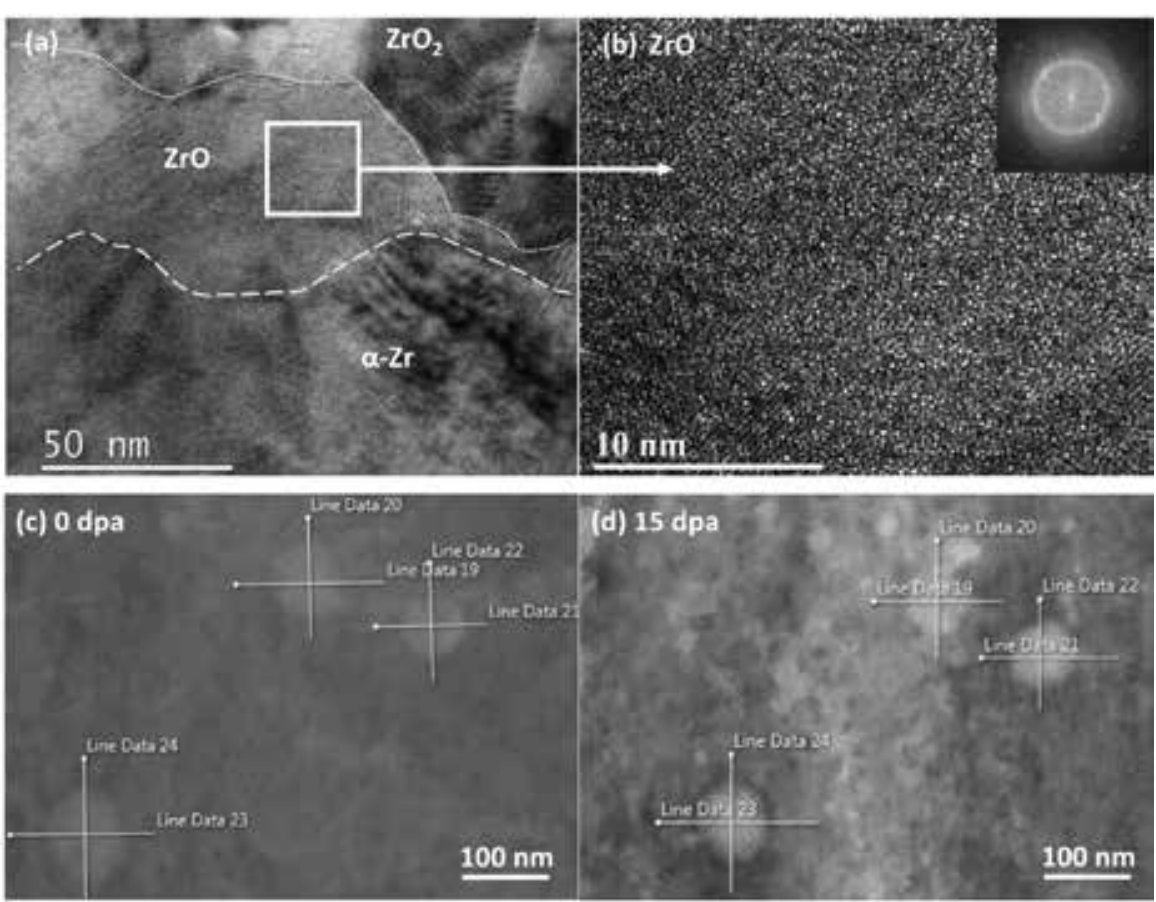

(e) Nb SPP size after irradiation at different temperatures

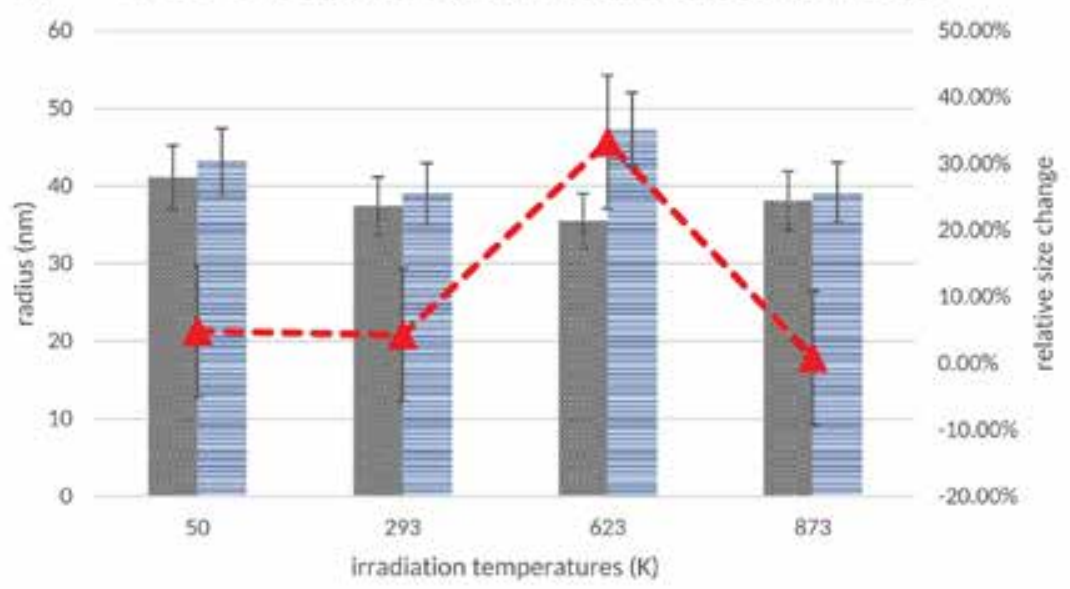

IIIIII before $=$ after - - relative size change
Figure 1. (a) TEM Bright Field image showing the metal/oxide interface region after in situ irradiation at cryogenic temperature (50K) and 13 dpa. (b) HRTEM images showing the amorphization of the sub-oxide ( $\mathrm{ZrO})$ region. (c) STEM HAADF images showing the same SPPs before and (d) after irradiation of $15 \mathrm{dpa}$ at room temperature. (e) averaged values of the size of $\beta-N b$ SPPs before and after irradiation of $15 \mathrm{dpa}$ at 4 different temperatures, and the percentage size changes. 
suboxide grain shows complete amorphization after irradiation indicating a huge amount of irradiation defects accumulating in the suboxide grains, whereas the surrounding $\mathrm{ZrO}_{2}$ and metal matrix are crystalline. These results suggest the interfacial suboxide is more susceptible to irradiation damage compared to the surrounding $\mathrm{ZrO}_{2}$ and metal matrix.

STEM images of the typical morphology of SPPs before and after irradiation are shown in Figure 1(c) and (d). The average size of $\beta-\mathrm{Nb}$ SPPs irradiated to $15 \mathrm{dpa}$ at different irradiation temperatures are measured and plotted in Figure $1(\mathrm{e})$. The $\beta-\mathrm{Nb}$ SPPs retain a bcc crystalline structure at all four temperatures. The apparent size of the SPPs increased only at $623 \mathrm{~K}$. EDX measurement suggest that this apparent size increase is caused by the redistribution of the $\mathrm{Nb}$ atoms from the SPPs to the metal matrix.

\section{Conclusion}

In situ ion irradiation experiments reveal the susceptible nature of the zirconium suboxide to radiation damage, which can generate high concentrations of defects at the oxide/metal interface that can then affect the nucleation and growth processes of new oxide grains, and lead to an increase of porosity and reduced cohesion between grains. As a result, oxides formed in-reactor are more porous, less columnar, and less textured-all of which can lead to enhanced in-reactor corrosion rates.

Under the in situ irradiation conditions used in this study, the $\beta-\mathrm{Nb}$ SPPs have shown remarkable stability against irradiation up to $20 \mathrm{dpa}$; however, $\mathrm{Nb}$ redistribution between the SPPs and Zr matrix under irradiation is observed at elevated temperature at $\sim 623 \mathrm{~K}$ radiationinduced redistribution of a small amount of $\mathrm{Nb}$ from the SPPs into the surrounding metal matrix is observed. The change in solid solution $\mathrm{Nb}$ will further affect the overall corrosion and hydrogen pick-up kinetics of $\mathrm{Zr}$ alloys in-service.

\section{References}

[1.] A. Garner, F. Baxter, P. Frankel, M. Topping, A. Harte, T. Slater, P. Tejland, J. Romero, E. C Darby, A. Cole-Baker, M. Gass, M. Preuss, Investigating the effect of zirconium oxide microstructure on corrosion performance: A comparison between neutron, proton, and 
non-irradiated oxides, Zirconium in the Nuclear Industry: 18th International Symposium, ASTM International (2018) 491-523.

[2.] A.T. Motta, A. Couet, R.J. Comstock, Corrosion of Zirconium Alloys Used for Nuclear Fuel Cladding, Annual Review of Materials Research 45 (2015) 311-343.

\section{Publications}

[1.] Liu, J., He, G., Hu, J., Shen, Z., Kirk, M., Li, M., Ryan, E., Baldo, P., Lozano-Perez, S. and Grovenor, C., Irradiation-induced amorphization in the zirconium suboxide on $\mathrm{Zr}-0.5 \mathrm{Nb}$ alloys. Journal of Nuclear Materials, 513 (2019), p.226-231.
[2.] He, G., Liu, J., Li, K., Hu, J., Mir, A.H., Lozano-Perez, S. and Grovenor, C. Investigating the stability of second phase particles in Zr-Nb alloys under irradiation. Journal of Nuclear Materials, 526 (2019), p. 151738 .

\section{Distributed Partnership at a Glance}

\begin{tabular}{|l|l|}
\hline NSUF Institution & Facilities and Capabilities \\
\hline $\begin{array}{l}\text { Argonne National } \\
\text { Laboratory }\end{array}$ & $\begin{array}{l}\text { The Intermediate Voltage Electron Microscopy } \\
\text {-Tandem Facility }\end{array}$ \\
\hline Collaborators & $\begin{array}{l}\text { Jing Hu (collaborator) } \\
\text { Laboratory }\end{array}$ \\
\hline University of Oxford & $\begin{array}{l}\text { Guanze He (collaborator), Junliang Liu } \\
\text { (collaborator) }\end{array}$ \\
\hline
\end{tabular}




\title{
Hydrogen Analysis and Oxide Characterization of Reactor Irradiated Zr-Nb Alloy
}

\author{
Jacqueline Stevens - Framatome - Jacqueline.stevens@framatome.com
}

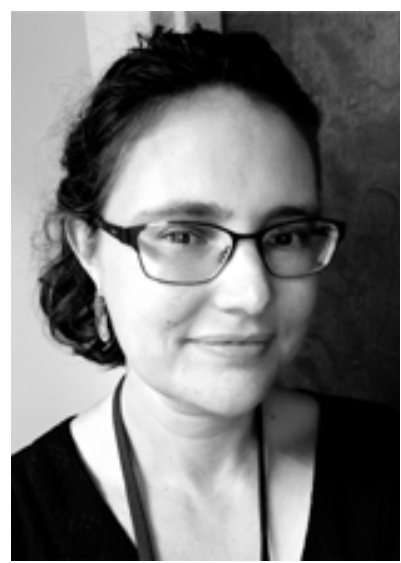

Z rconium-Niobium (Zr-Nb)

alloys have been used as

structural materials for pressurized water reactors (PWRs) since the early 2000s. These alloys were developed to provide improved corrosion resistance when compared to traditional Zircaloy-4 material [1]. While the improved corrosion resistance and corresponding low hydrogen pickup are well known for $\mathrm{Zr}-\mathrm{Nb}$ alloys, the mechanisms for reduced corrosion kinetics are less understood.

Fuel assemblies utilizing Zr-Nb alloys for guide tube components were irradiated in two separate PWRs, reactors B44 and B62, for two 24-month cycles. Following irradiation, samples were cut from the $\mathrm{Zr}$-Nb guide tubes. The samples from B44 were transmitted to Oak Ridge National Laboratory (ORNL) in 2007 and from B62 in 2009. The initial examination of these samples, focusing on the underlying Zr-Nb metal, was completed in 2010.

In 2017, five remaining segments of these irradiated samples were brought into the Low Activation Materials Development and Analysis (LAMDA) facility at ORNL. These segments reached fluence values of approximately 2 to $7 \times 10^{21} \mathrm{n} / \mathrm{cm}^{2}$. The focus of this work was to extend the earlier studies with an evaluation of the hydrogen and oxygen content of these segments as well as a study of the microstructure of the oxide layer formed on the segments.

\section{Results}

Inert gas fusion techniques were used to measure the quantity of hydrogen and oxygen in the $\mathrm{Zr}-\mathrm{Nb}$ specimens (metal plus oxide) by using a LECO ONH836 instrument, while additional segments of the samples were prepared for metallurgical examination. Focused ion beam-scanning electron microscopy (FIB-SEM) was used to extract samples from the oxide scale for further characterization using TEM. Final thinning of samples was performed at cryogenic temperatures to mitigate hydride formation. Imaging was conducted on an FEI Talos TEM operating at $200 \mathrm{keV}$ through a combination of bright field and dark field images and chemical (elemental) mapping using Scanning Transmission Electron Microscopy - Energy Dispersive X-Ray Analysis (STEM-EDS) techniques on select sites.

Hydrogen and oxygen measurement results were found to be consistent with the hot cell examinations conducted over the period from 2007 to 2010 , confirming continuity from older instruments to those currently available.

The metal, oxide, and interface were characterized via TEM and EDS on the FIB samples from each segment. Microstructure and precipitates were confirmed to be as expected for each of the segments investigated with insignificant differences found between segments. See Figure 1 for oxide characterization of one segment. 


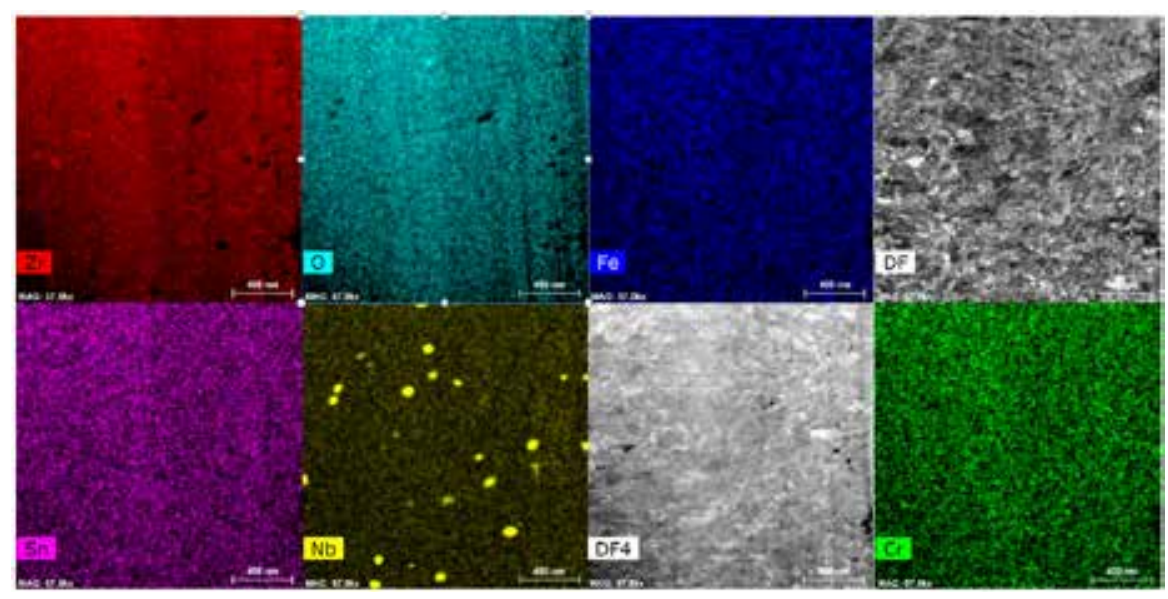

\section{Conclusion}

The results of this work were compared to results previously obtained from the original samples from 2007 to 2010. While different evaluation techniques and instruments were utilized, results were consistent with those previously obtained. The hydrogen contents of the irradiated samples were consistent with expectations for Zr-Nb materials following 48 months of irradiation in commercial PWRs. The microscopy efforts in this work focused on the oxide layer present on the irradiated material segments. TEM and elemental line scans of the samples demonstrated a consistent microstructure between samples, and the results were aligned with previous results.

\section{References}

[1.] Mardon, J.-P., D. Charquet, and J. Senevat, "Influence of Composition and Fabrication Process on Out-of-Pile and In-Pile Properties of M5 Alloy," Zirconium in the Nuclear Industry: Twelfth International Symposium, STP-1354, (1998), 505-522.
Figure 1. EDS map of oxide region of irradiated segment from reactor $B 44$.

\section{Distributed Partnership at a Glance}

\begin{tabular}{|l|l|}
\hline NSUF Institution & Facilities and Capabilities \\
$\begin{array}{l}\text { Oak Ridge National } \\
\text { Laboratory }\end{array}$ & $\begin{array}{l}\text { Low Activation Materials Design } \\
\text { and Analysis Laboratory }\end{array}$ \\
\hline Collaborators & \multicolumn{2}{|l|}{$\begin{array}{l}\text { Keith Leonard (co-principal investigator), } \\
\text { Laboratory }\end{array}$} & $\begin{array}{l}\text { Philip Edmondson (co-principal investigator), } \\
\text { Xunxiang Hu (co-principal investigator) }\end{array}$ \\
\hline
\end{tabular}




\title{
APT and TEM Study of Redistribution of Alloying Elements in ZrNb Alloys Following Proton Irradiation: Effects on In-reactor Corrosion Kinetics
}

\author{
Adrien Couet - University of Wisconsin, Madison - couet@wisc.edu
}

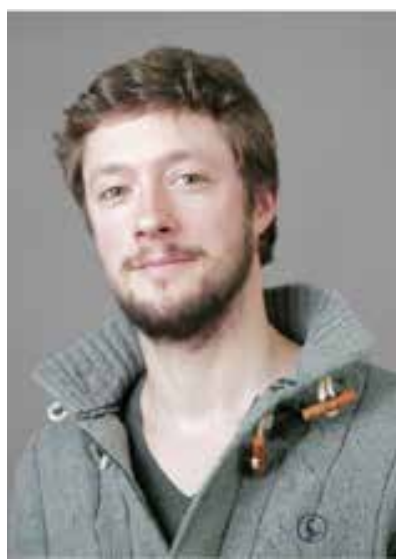

U nderstanding the coupled effect of irradiation and corrosion is critical to developing advanced fuel claddings for safe and economical deployment in light-water reactors (LWRs), as well as for the development of advanced tools for predictive modeling and simulation of fuel-cladding integrity in reactors. A perfect example of how irradiation may result in different corrosion rates is the case of $\mathrm{ZrNb}$ alloys and Zircalloy in LWR environments. Nb-containing alloys do not show the sudden increase in oxidation kinetics at relatively high burnup that is observed in Zircalloys [1], although both alloys have comparable out-of-reactor corrosion rates. This specific feature has led to the replacement of Zircaloys by ZrNb alloys; however, the significant difference in oxidation kinetics between the two alloy families is still not understood even though it is well known that the corrosion rates of $\mathrm{ZrNb}$ fuel claddings are controlled by $\mathrm{Nb}$ distribution in the base metal $[2,3]$, and there is extensive literature on the effect of neutron irradiation on $\mathrm{Nb}$ redistribution in $\mathrm{ZrNb}$ alloys with the precipitation of Nb-rich platelet-like precipitates after several cycles [4].

The main hypothesis of this research program is that the formation of platelet-like precipitates under irradiation is responsible for the low corrosion rates experienced by $\mathrm{ZrNb}$ alloys even at high burnup. This study aims at precisely characterizing the microstructure and microchemistry at the nanoscale of proton irradiated $\mathrm{Zr}-\mathrm{Nb}$ alloys with different $\mathrm{Nb}$ contents, below and above the theoretical solid solubility limit, using atom probe tomography (APT) and STEM equipped with Super-X Energy Dispersive Spectroscopy (EDS).

\section{Results}

Zr-xNb binary model alloys $(\mathrm{x}=0.2$, $0.4,0.5,1.0 \mathrm{wt} \%)$ have been irradiated by $2 \mathrm{MeV}$ protons up to $1 \mathrm{dpa}$ (in the flat region of the damage-depth curve) at $350^{\circ} \mathrm{C}$ at the University of Wisconsin's Ion Beam Laboratory. The unirradiated microstructure and microchemistry of these alloys have already been extensively characterized, and native precipitate densities, compositions, and sizes have been determined in multiple grains for all compositions. The focused ion beam technique was employed to prepare samples for STEM and APT analysis from the proton irradiated specimen. The main results of the study are:

- Proton irradiation induces a redistribution of $\mathrm{Nb}$ in the alloy with the formation of:

Figure $1: \beta-\mathrm{Nb}$ platelets approximately $20-100 \mathrm{~nm}$ in length, containing 10-40 at.\% $\mathrm{Nb}$ in $\mathrm{Zr}-0.5 \mathrm{Nb}$ and $\mathrm{Zr}-1.0 \mathrm{Nb}$ irradiated at $1.0 \mathrm{dpa}$. Particle densities measured by STEM/EDS show a reduction of total particle density after proton irradiation, implying that incoherent native SPPs have dissolved in the matrix.

Figure 2: Nb-rich and Fe-rich nanoclusters (few nanometers in diameter) in $\mathrm{ZrNb}$ alloys at doses as small as $0.55 \mathrm{dpa}$.

- After careful APT cluster analysis, it is clearly shown that the $\mathrm{Nb}$ concentration in the solid solution decreases with irradiation dose.

\section{Conclusion}

These results are consistent with the hypothesis that a reduction of $\mathrm{Nb}$ concentration in solid solution, to some extent, enhances corrosion resistance of $\mathrm{ZrNb}$ alloys. Using the unique results presented in the study, a $\mathrm{ZrNb}$ corrosion mechanism has been presented in the framework of the Couple Current Charge Compensation (C4) model, which explains the impact of irradiation induced variations in $\mathrm{Nb}$ concentration in 

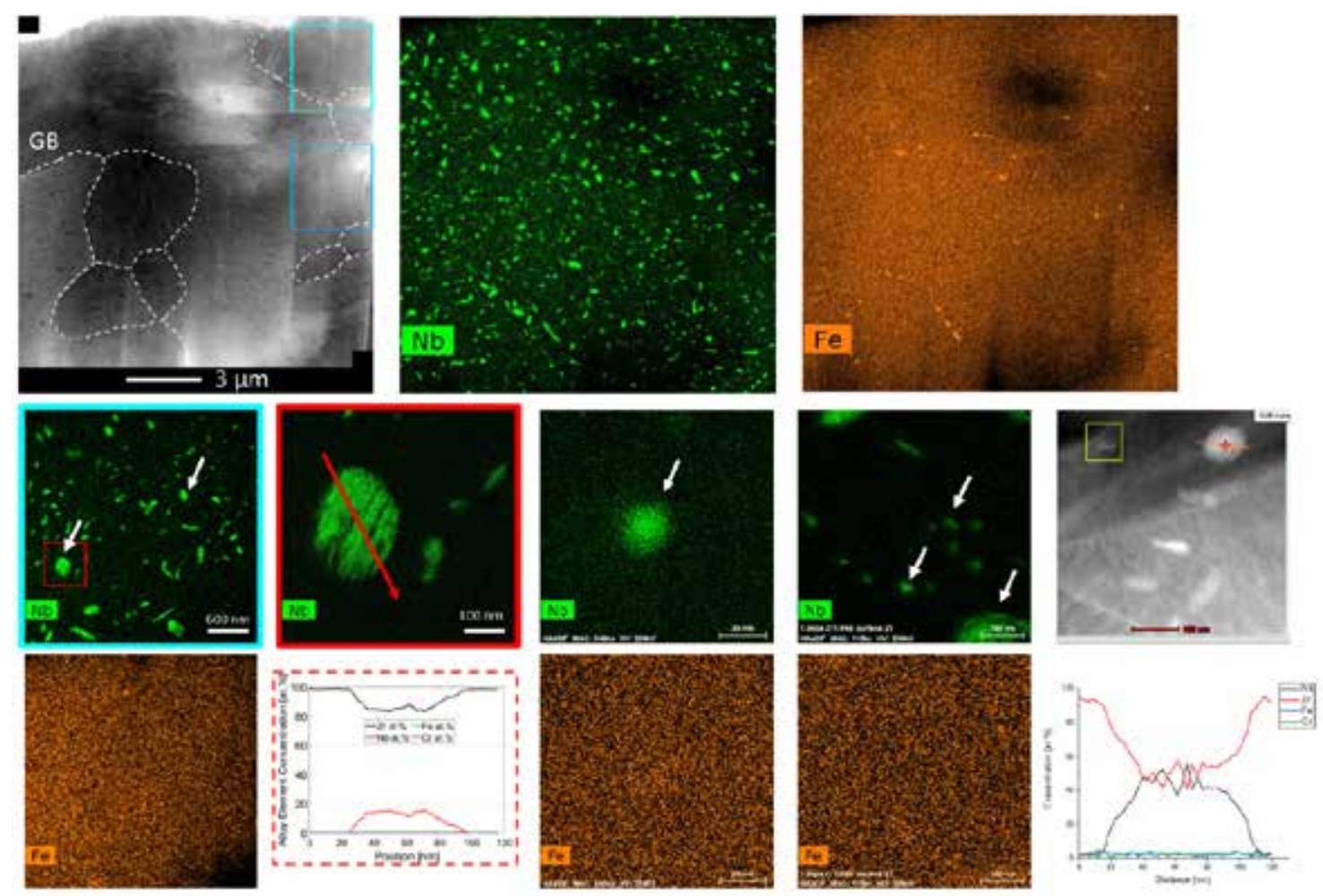

Figure 1. STEM/EDS images and line scan of platelet like $\mathrm{Nb}$-rich irradiation induced precipitates in focus ion beam lamella from $1 \mathrm{dpa}$ protonir radiated $\mathrm{Zr}$-1.0Nb. The white arrows point to large rod shaped precipitates, which are likely the native precipitates under dissolution.

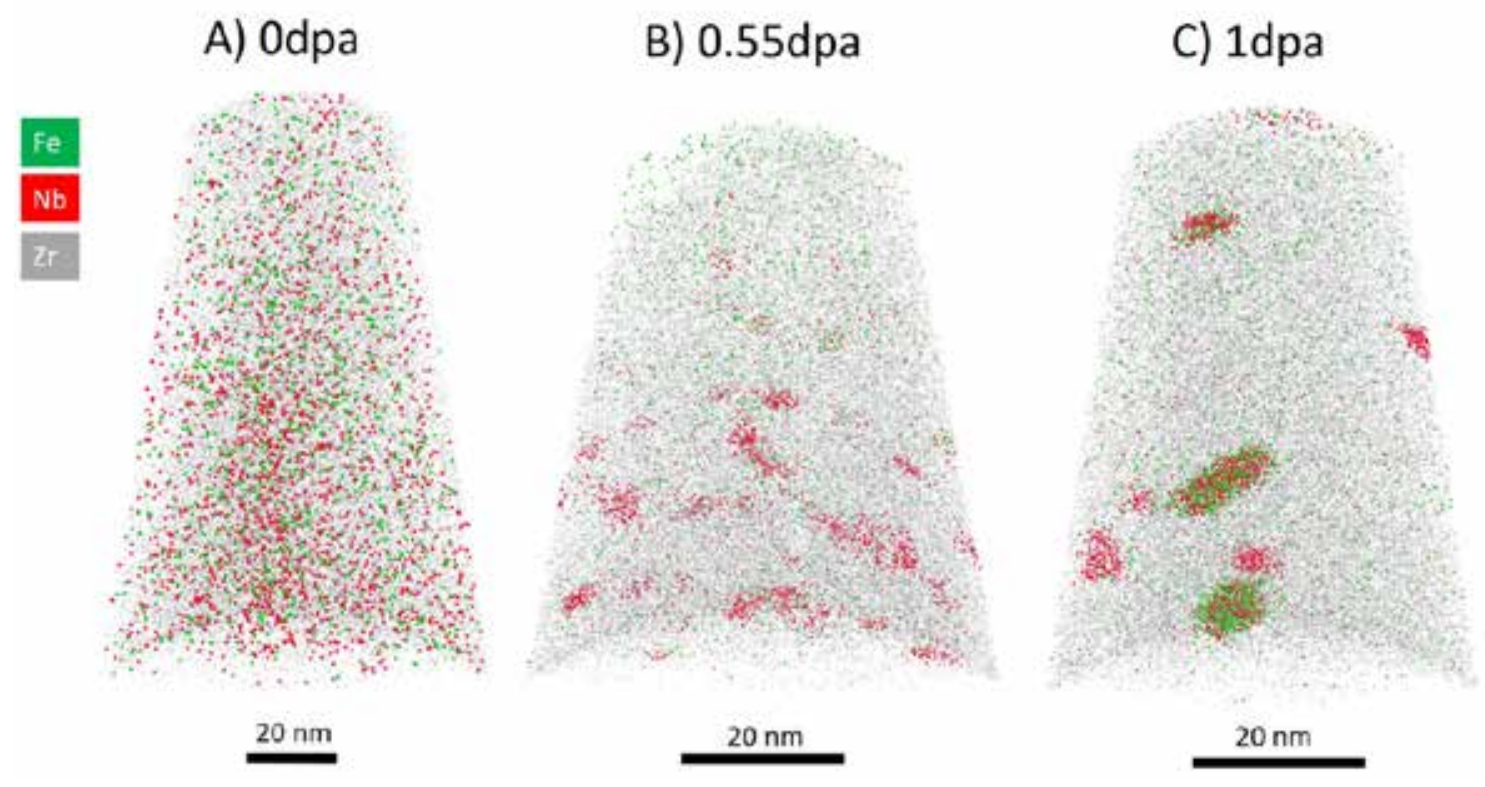

Figure 2. Reconstruction examples of APT needle on $\mathrm{Zr}$-1.0Nb at A) $0 \mathrm{dpa}$ B) proton irradiated to $0.55 \mathrm{dpa}$ C) proton irradiated to $1 \mathrm{dpa}$, clearly showing the $\mathrm{Nb}$ - and Fe-rich clustering after irradiation. 
solid solution on corrosion kinetics.

The mechanism, based on oxide space charge compensation, explains why irradiated $\mathrm{ZrNb}$ alloys have better corrosion resistance than unirradiated $\mathrm{ZrNb}$ alloys.

Relatively smaller, but similar precipitates/nanoclusters are observed in neutron irradiated samples as in proton irradiated samples, suggesting that proton irradiation is a good surrogate for neutron irradiation if one wishes to study the effect of $\mathrm{Nb}$ redistribution on corrosion and mechanical properties.

\section{References}

[1.] A.T. Motta, A. Couet, R.J. Comstock, Corrosion of zirconium alloys used for nuclear fuel cladding, Annual Review of Materials Research, 45 (2015) 311-343, ttps://doi.org/10.1146/annurevmatsci-070214-020951.

[2.] Y.H. Jeong, H. G. Kim, D. J. Kim, B. K. Choi, J. H. Kim, Influence of $\mathrm{Nb}$ concentration in the $\alpha$-matrix on the corrosion behavior of $\mathrm{Zr}-$ $\mathrm{xNb}$ binary alloys, Journal of $\mathrm{Nu}-$ clear Materials, 323 (2003) 7280, https://doi.org/10.1016/j. jnucmat.2003.08.031.

[3.] A. Couet, A. T. Motta, A. Ambard, The coupled current charge compensation model for zirconium alloy fuel cladding oxidation: I. Parabolic oxidation of zirconium alloys, Corrosion Science, 100 (2015) 73-84, https://doi.org/10.1016/j. corsci.2015.07.003.
[4.] S. Doriot, et al., Zirconium in the Nuclear Industry: 14th International Symposium, 2005, pp. 175-201.

\section{Publications}

\section{Journal Publications}

[1.] Z. Yu, T. Kim, M. Bachhav, X. Liu, L. He and A. Couet "Effect of proton pre-irradiation on corrosion of $\mathrm{Zr}-0.5 \mathrm{Nb}$ model alloys with different Nb distributions" Corrosion Science, Vol. 173, 108790 , August. 2020.

[2.] Z. Yu, M. Moorehead, L. Borrel, M. Bachhav, J. Hu, A. Couet, Fundamental understanding of $\mathrm{Nb}$ effect on corrosion mechanisms of $\mathrm{ZrNb}$ alloys in and out of reactor, Proceedings of the Zirconium in the Nuclear Industry: 19th International Symposium, ASTM, Manchester, UK, 2020.

[3.] Z. Yu, C. Zhang, P.M. Voyles, L. He, X. Liu, K. Nygren, A. Couet, Microstructure and microchemistry study of irradiation-induced precipitates in proton irradiated ZrNb alloys, Acta Materialia 178 (2019) 228-240.

[4.] Z. Yu, A. Couet, Nb redistribution in proton irradiated $\mathrm{Zr} 1.0 \mathrm{Nb}$, American Nuclear Society 120 (2019) 335-338.

[5.] Z. Yu, M. Bachhav, A. Couet, Irradiation-induced $\mathrm{Nb}$ redistribution of ZrNb alloy: An APT study, Journal of Nuclear Materials 516 (2019) 100-110. 


\section{Conference Presentations}

[1.] A. Couet, Z. Yu, M. Bachhav, L. $\mathrm{He}$, "Fundamental Understanding of Coupled Irradiation and Corrosion Effects on ZrNb Fuel Cladding”, MiNES Conference, Baltimore, MD, 2019.

[2.] Z. Yu, M. Moorehead, L. Borrel, A. Couet, "Fundamental understanding of $\mathrm{Nb}$ effect on corrosion mechanisms of $\mathrm{Zr}-\mathrm{Nb}$ alloys in and out of reactor", 19th International Symposium on Zirconium in the Nuclear Industry, May 2019, Manchester, UK.

[3.] Z.Yu, M.B. Bachhav, A. Couet, "Precipitation mechanism of irradiation induced Nb-rich particles in ZrNb alloys", The Minerals, Metals, \& Materials Society Conference; 2019 March 10-14; San Antonio, TX.

[4.] Z. Yu, A. Couet, M.B. Bachhav, "Irradiation induced $\mathrm{Nb}$ redistribution in $\mathrm{ZrNb}$ alloys and its effect on corrosion kinetics: an Atom Probe Tomography study", The 5th Nuclear Materials Conference; 2018 October 14-18; Seattle, WA.

[5.] Z. Yu, A. Couet, M. Bachhav, "Atom probe tomography study on irradiation induced $\mathrm{Nb}$ redistribution in $\mathrm{ZrNb}$ alloys", Conference on Application of Accelerators in Research and Industry (CAARI), Grapevine, Texas, USA from August 12th - 17th, 2018.
[6.] A. Couet, Z. Yu, M. Moorehead, L. Borrel, "Fundamental and Holistic Approach to Nuclear Fuel Cladding Corrosion and Hydrogen Pickup Under Irradiation in Normal and Accidental Conditions", Materials Research Society, Symposium on "Fundamental Materials Science to Enable the Performance and Safety of Nuclear Technologies", March 2018, Phoenix, AZ.

[7.] A. Couet, Z. Yu, M. Moorehead, L. Borrel, "Fundamental Understanding of Corrosion of Nuclear Materials: Holistic Approach to Fuel Cladding Corrosion under Irradiation", The Minerals, Metals, \& Materials Society, Symposium on "Computational Materials Science and Engineering for Nuclear Energy - Nuclear Fuels and Cladding", February 2018 , Phoenix, AZ.

\section{Distributed Partnership at a Glance}

\section{NSUF Institution}

Center for Advanced Energy Studies

Idaho National Laboratory Collaborators

Idaho National Laboratory

University of

Wisconsin, Madison

\section{Facilities and Capabilities}

Microscopy and Characterization Suite

Irradiated Materials Characterization Laboratory

Lingfeng He (co-principal investigator), Mukesh Bachhav (co-principal investigator)

Kelly Nygren (collaborator), Zefeng Yu

(collaborator) 


\title{
Irradiation Responses of Ultrastrong Nano Precipitation Martensite Steel
}

\author{
Steven Zinkle - University of Tennessee, Knoxville - szinkle@utk.edu
}

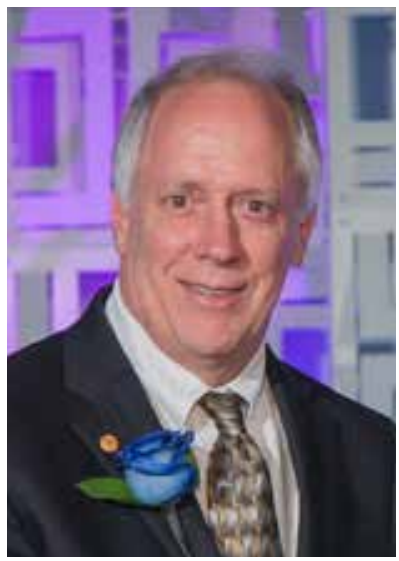

amples of three $\mathrm{Fe}-\mathrm{Cr}$ alloys,

S $\mathrm{Fe}-9 \mathrm{Cr}, \mathrm{Fe}-9 \mathrm{Cr}-0.3 \mathrm{Y}$ and $\mathrm{a}$ nanoprecipitation steel (Fe-18Ni$3 \mathrm{Al}-4 \mathrm{Mo}-0.8 \mathrm{Nb}-0.08 \mathrm{C}-0.01 \mathrm{~B}$ [wt $\%])$ were prepared (FIB with EDS/electron backscatter diffraction [EBSD]/ Omniprobe) and characterized by local-electrode APT in the Microscopy and Characterization Suite at the Center for Advanced Energy Studies. Our characterization focused on the precipitate nanostructures in $\mathrm{Fe}-9 \mathrm{Cr}$ $0.3 \mathrm{Y}$ and the nanoprecipitation steel. High density yttrium enriched oxides in Fe-9Cr-0.3Y and (Ni, Al) enriched nanoparticles in the nanopreciptation steel were expected to be observed. After characterization of the as-prepared samples, ion irradiation experiments were performed at the University of Tennessee, Knoxville using $5 \mathrm{MeV}$ Fe ions at 250, 350, 500, and $650^{\circ} \mathrm{C}$ with an irradiation fluence of $4 \times 10^{16} \mathrm{~cm}^{-2}$. The samples irradiated at the four different temperatures were then characterized by APT and TEM in order to study irradiation responses in the three different kinds of alloy at different temperatures, especially the evolution of nanoprecipitates with irradiation temperature. FIB with EDS/ EBSD/Omniprobe was employed to prepare the APT tips, concentrating on irradiation depths from the sample surface to $\sim 400 \mathrm{~nm}$.

\section{Results}

No precipitates were observed in Fe-9Cr-0.3Y by APT, i.e., the concentration of yttrium in precipitates is lower than the APT detection limit (Figure 1). TEM results show that both $\mathrm{Fe}-9 \mathrm{Cr}$ and $\mathrm{Fe}-9 \mathrm{Cr}-0.3 \mathrm{Y}$ have comparable void swelling after ion irradiation at $500^{\circ} \mathrm{C}$. The distributions of voids are quite inhomogeneous. Five tips from the same region were analyzed for Fe-9Cr-0.3Y and Fe-9Cr to obtain good statistics. For nanoprecipitation steels, a high density of ( $\mathrm{Ni}, \mathrm{Al})$ enriched precipitates was detected; the average size was $\sim 5 \mathrm{~nm}$. TEM characterization show that these nanoprecipitates have a B2 structure and are coherent with the matrix. No voids were observed in the nanoprecipitation steels irradiated at four different temperatures. However, significant precipitate coarsening was observed. The average size of the precipitates was $100 \mathrm{~nm}$ after high temperature irradiations. Besides the precipitates enriched with $\mathrm{Ni}$ and Al, precipitates enriched with Mo were also observed. The two irradiated Fe-9Cr and Fe-9Cr-0.3Y alloys exhibited relatively minimal void swelling after the ion irradiation.

\section{Conclusion}

APT characterizations surprisingly did not show any precipitates in Fe-9Cr-0.3Y. One possibility is that yttrium has not been well distributed in the sample preparation process, leading to an inhomogeneous spatial distribution of yttrium. This would result in an inhomogeneous distribution of precipitates, which is consis- 
(a)

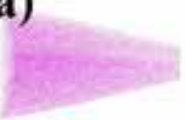

$\mathrm{Fe}$

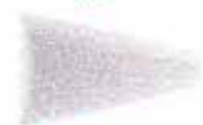

w

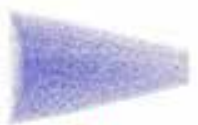

$\mathrm{Cr}$

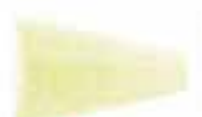

Mn

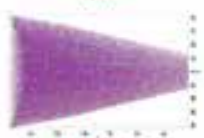

All ions (b)

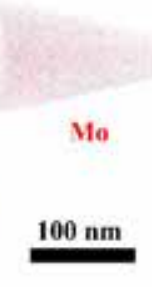

v

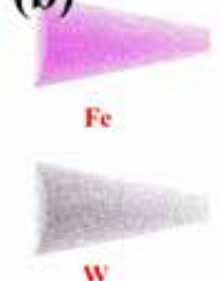

W

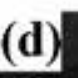

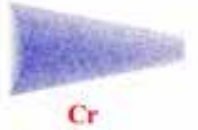

$\mathrm{Cr}$

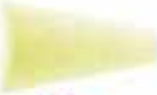

Mn

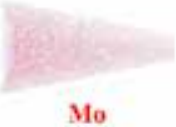

Mo

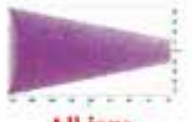

All ions

\section{(c)}
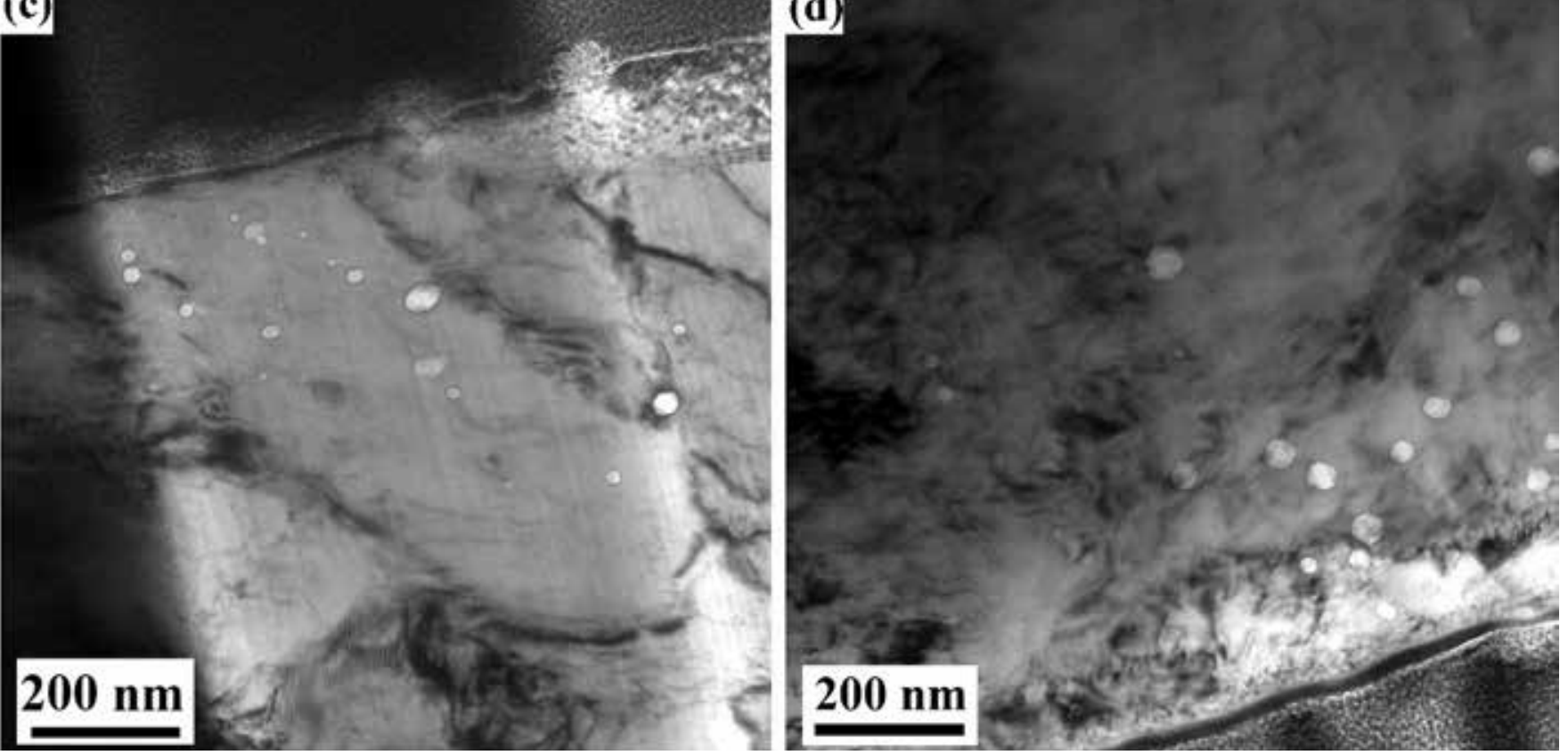

tent with the experimental observations of an inhomogeneous distribution of voids. For the nanoprecipitation steel, the significant coarsening observed at high temperatures would degrade the steel's mechanical properties. Thus, it is crucial to suppress the coarsening for the application of nanoprecipitation steels in advanced nuclear energy system.
Figure 1. Atom maps of pristine (a) Fe-9Cr-0.3Y and (b) Fe9Cr-OY, BF TEM images of as-irradiated (c) Fe-9Cr-0.3Y and (d) Fe-9Cr. No yttrium was detected in $\mathrm{Fe}-9 \mathrm{Cr}-0.3 \mathrm{Y}$.

\begin{tabular}{|c|c|}
\hline \multicolumn{2}{|c|}{ Distributed Partnership at a Glance } \\
\hline NSUF Institution & Facilities and Capabilities \\
\hline $\begin{array}{l}\text { Center for Advanced } \\
\text { Energy Studies }\end{array}$ & Microscopy and Characterization Suite \\
\hline \multicolumn{2}{|l|}{ Collaborators } \\
\hline $\begin{array}{l}\text { University of Tennessee, } \\
\text { Knoxville }\end{array}$ & $\begin{array}{l}\text { Congyi Li (collaborator), Ling Wang } \\
\text { (collaborator), Tengfei Yang (collaborator) }\end{array}$ \\
\hline
\end{tabular}




\title{
Study of the Factors Affecting the Radiation Tolerance of MAX Phases for Innovative Fuel Cladding Concepts
}

\author{
Konstanza Lambrinou - SCK CEN-klambrin@sckcen.be
}

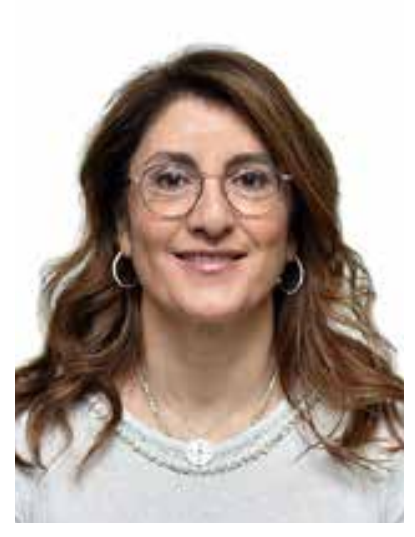

$\mathrm{D}$ ue to their liquid metal corrosion resistance [1], $\left(\mathrm{Nb}_{0.85}, \mathrm{Zr}_{0.15}\right)_{4} \mathrm{AlC}_{3}(\mathrm{NZ413})$ ceramics are considered candidate materials for Gen-IV lead fast reactors (LFRs). The NZ413 MAX phase solid solution has been found to improve appreciably the fracture toughness and thermal stability of the $\mathrm{Nb}_{4} \mathrm{AlC}_{3}$ ternary carbide [2]. Discs ( $\varnothing 3 \mathrm{~mm}$, thickness: 100-200 $\mu \mathrm{m}$ ) were prepared from both textured and non-textured $\mathrm{Nb}_{4} \mathrm{AlC}_{3}$ and $\left(\mathrm{Nb}_{0.85}, \mathrm{Zr}_{0.15}\right) 4 \mathrm{AlC}_{3}$ MAX phases. These discs were irradiated during FY 2018 at the Michigan Ion Beam Laboratory (MIBL) using $4 \mathrm{MeV} \mathrm{Al}^{++}$ and $2.18 \mathrm{MeV} \mathrm{He}^{++}$ion beams. Dual beam $\left(\mathrm{Al}^{++} / \mathrm{He}^{++}\right)$and single beam $\left(\mathrm{Al}^{++}\right)$ion irradiations were conducted on textured and non-textured $\mathrm{Nb}_{4} \mathrm{AlC}_{3}$ and $\left(\mathrm{Nb}_{0.85}, \mathrm{Zr}_{0.15}\right) 4 \mathrm{AlC}_{3}$ MAX phases at 330 and $600^{\circ} \mathrm{C}$, i.e., at the nominal operating temperatures for Gen-II/III light-water reactors (LWRs) and Gen-IV LFRs respectively. A damage dose of 40 dpa was collected at $600 \mathrm{~nm}$ depth, with a total fluence of $6.26 \times 10^{17}$ ions $/ \mathrm{cm}^{2}$ (Figure 1a). The MAX phases' irradiation temperature was controlled with thermocouples spot welded on reference MAX phase and steel disks that were not irradiated. Pressure, temperature, and beam currents were monitored and recorded during the MIBL irradiation experiments. Postirradiation examination (PIE) of the irradiated MAX phase ceramics by X-ray diffraction (XRD)/grazing incidence XRD (GIXRD), SEM EDS FIB, and TEM STEM is ongoing.

\section{Results}

PIE of the following MAX phase samples has been finalized: (i) non-textured and textured NZ413, irradiated at $330^{\circ} \mathrm{C}$ by $\mathrm{Al}^{++}$single beam; (ii) non-textured $\mathrm{NZ413}$ irradiated at $330^{\circ} \mathrm{C}$ by $\mathrm{Al}^{++} / \mathrm{He}^{++}$ dual beam; and (iii) textured NZ413 irradiated at $600^{\circ} \mathrm{C}$ by $\mathrm{Al}^{++} / \mathrm{He}^{++}$dual beam. Post-irradiation surface cracks were observed by SEM (Figure 1b) and were quantified by the line-intercept method. Surprisingly, non-textured NZ413 irradiated at $330^{\circ} \mathrm{C}$ contained fewer cracks as compared to textured NZ413 irradiated at the same temperature while textured NZ413 irradiated at $600^{\circ} \mathrm{C}$ showed the least cracking. XRD/GIXRD examinations of NZ413 irradiated at $600^{\circ} \mathrm{C}$ revealed an increase in the amounts of Al-rich ( $\mathrm{Nb}, \mathrm{Zr})_{2} \mathrm{AlC}$ MAX phase and (Nb,Zr) C on the irradiated surface, indicating an irradiation induced phase transformation that was most likely promoted by the implanted
$\mathrm{Al}$ ions. High resolution STEM imaging showed that the peak damage region in materials irradiated at $330^{\circ} \mathrm{C}$ contained twinned fcc $(\mathrm{Nb}, \mathrm{Zr}, \mathrm{Al}) \mathrm{C}$ with indistinguishable atomic contrast (Figure 1c). While the peak damage depth in NZ413 (single and dual beam) irradiated at $330^{\circ} \mathrm{C}$ contained an $\mathrm{Al}$ implantation layer, NZ413 irradiated at $600^{\circ} \mathrm{C}$ contained no such layer due to the $\mathrm{Al}$ diffusion along the material depth, which homogenized the Al profile and promoted the 413-to-211 MAX phase transition.

\section{Conclusion}

This is a pioneering study of the radiation response of MAX phase solid solutions based on the simultaneous irradiation of $\mathrm{Nb}_{4} \mathrm{AlC}_{3}$ and its derivative NZ413 solid solution. The $\mathrm{Nb}-\mathrm{Zr}$-Al-C system was selected due to the improved fracture toughness and thermal stability of NZ413 compared to $\mathrm{Nb}_{4} \mathrm{AlC}_{3}$. The irradiations $\left(\mathrm{Al}^{++} \mathrm{vs}\right.$. $\mathrm{Al}^{++} / \mathrm{He}^{++}$) were designed to investigate the effects of texture and irradiation temperature on the radiation response of quasi-phase-pure ceramics, where microcracking due to differential radiation swelling is minimized. High temperature $\left(600^{\circ} \mathrm{C}\right) \mathrm{Al}$ implantation formed the Al-rich ( $\mathrm{Nb}, \mathrm{Zr})_{2} \mathrm{AlC}$ MAX phase. Such transformations are possible when performing MAX phase irradiations with self-ions.

\section{References}

[1.] T. Lapauw, B. Tunca, J. Joris, A. Jianu, R. Fetzer, A. Weisenburger, J. Vleugels, K. Lambrinou, In- 


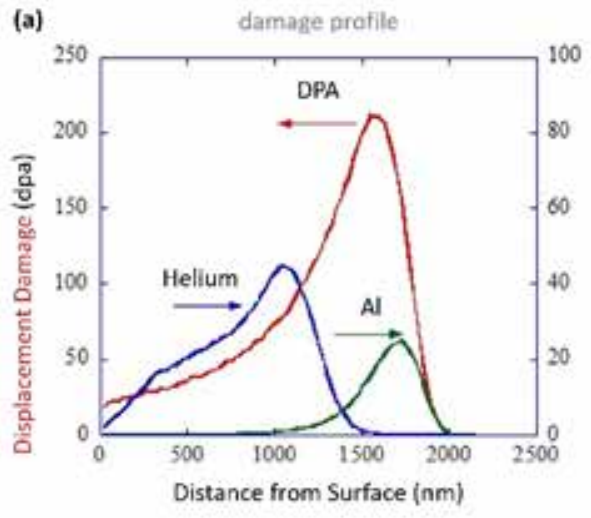

teraction of $\mathrm{M}_{\mathrm{n}+1} \mathrm{AX}_{\mathrm{n}}$ phases with oxygen-poor, static and fast-flowing liquid lead-bismuth eutectic, Journal of Nuclear Materials 520 (2019) 258-272; https://doi.org/10.1016/j.jnucmat.2019.04.010.

[2.] T. Lapauw, D. Tytko, K. Vanmeensel, S. Huang, P.-P. Choi, D. Raabe, E.N. Caspi, O. Ozeri, M. to Baben, J.M. Schneider, K. Lambrinou, J. Vleugels, $\left(\mathrm{Nb}_{\mathrm{x}}, \mathrm{Zr}_{1-\mathrm{x}}\right)_{4} \mathrm{AlC}_{3} \mathrm{MAX}$ phase solid solutions: processing, mechanical properties, and density functional 'theory calculations, Inorganic Chemistry 55 (2016) 5445-5452;

https://doi.org/10.1021/acs. inorgchem.6b00484.

\section{Publications}

[1.] B. Tunca, T. Lapauw, K. Van Loo, J. Vleugels, G.S. Was, K. Lambrinou, Ion irradiation of textured \& non-

\section{(b)}

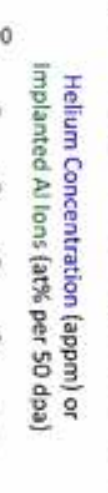

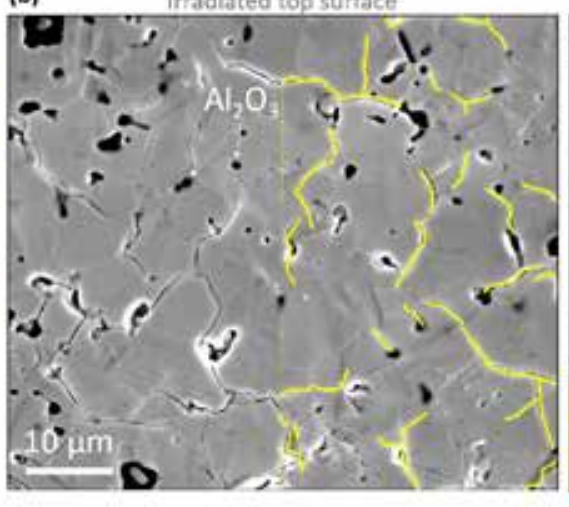

(c)

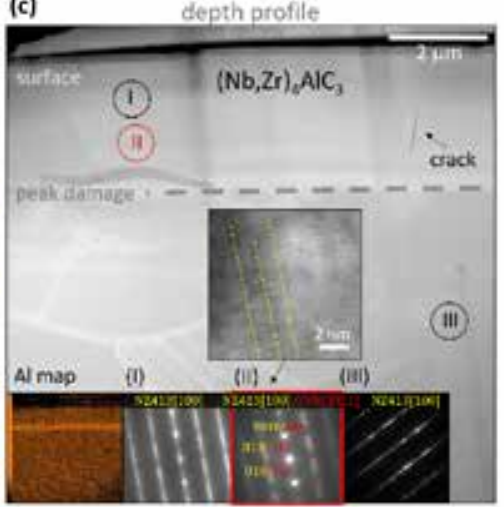

textured $\left(\mathrm{Nb}_{0.85}, \mathrm{Zr}_{0.15}\right)_{4} \mathrm{AlC}_{3} \mathrm{MAX}$ phase ceramics, poster presentation at the Advanced Accident \& Radiation-Tolerant Materials Conference, Cambridge, UK, 25-26 March 2019.
Figure 1. (a) Damage profile for the MAX phase ceramics irradiated at the MIBL. Textured NZ413 MAX phase solid solution irradiated at $330^{\circ} \mathrm{C}$ by $\mathrm{Al}++$ single beam: (b) top surface SEM image, showing cracks, and (b) cross sectional depth profile - as obtained from scanning transmission electron microscopywith selected area diffraction patterns (SADPs) and high resolution STEM images at specific damage levels.

\section{Distributed Partnership at a Glance}

\begin{tabular}{|l|l|}
\hline NSUF Institution & Facilities and Capabilities \\
\hline $\begin{array}{l}\text { The Ohio State University } \\
\text { Collaborators }\end{array}$ & Nuclear Research Laboratory \\
\hline Drexel University & Michel W. Barsoum (collaborator) \\
\hline $\begin{array}{l}\text { Katholieke Universiteit } \\
\text { Leuven }\end{array}$ & $\begin{array}{l}\text { Bensu Tunca (collaborator), Jozef Vleugels } \\
\text { (collaborator) }\end{array}$ \\
\hline SCK CEN & $\begin{array}{l}\text { Bensu Tunca (collaborator), Rémi Delville } \\
\text { (collaborator) }\end{array}$ \\
\hline University of Antwerp & Joke Hadermann (collaborator) \\
\hline University of Michigan & Gary S. Was (collaborator) \\
\hline $\begin{array}{l}\text { Westinghouse Electric } \\
\text { Company }\end{array}$ & Edward J. Lahoda (collaborator) \\
\hline
\end{tabular}




\title{
Micro-mechanical Characterization of Long Range Order in $\mathrm{Ni}-\mathrm{Cr}$ Alloys and Their Response to Radiation Damage
}

\author{
Julie D. Tucker - Oregon State University - Julie.Tucker@oregonstate.edu
}

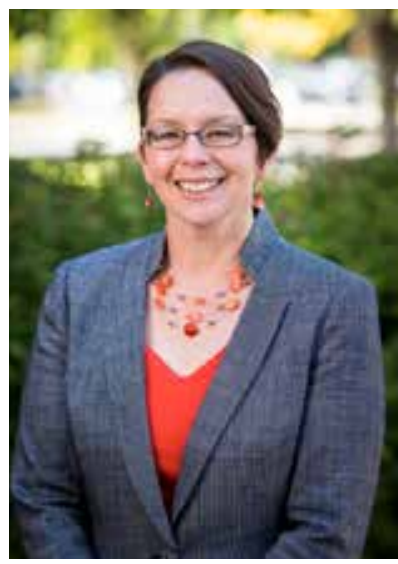

$\mathrm{T}$ his project addressed the effect of long range order phase formation of $\mathrm{Ni}_{2} \mathrm{Cr}$ precipitates in $\mathrm{Ni}-\mathrm{Cr}$ alloys using small scale mechanical testing capability performed at the Nuclear Materials Laboratory at the University of California, Berkeley. Ni-33at.\%Cr model alloys were fabricated and isothermally aged or irradiated with protons. Micropillars were fabricated using a focus ion beam (FIB) qualbeam microscope from as-fabricated thermally aged and irradiated samples. Micropillar compression to generate load-displacement plots and live scanning electron microscopy (SEM) videos was performed with an in situ Bruker Hysitron PI-88 picoindenter in a SEM instrument. The data provided information to analyze the change of failure behavior of $\mathrm{Ni}-\mathrm{Cr}$ model alloys under the effect of long range ordering induced either by isothermal aging or irradiation.

\section{Results}

For each single crystal micropillar, Young's modulus and yield strength were determined from a stress-strain plot, and the failure behavior was recorded on video. The effect of long range ordering on failure mode and plasticity was found to be significant. As shown in the accompanying figure, pillars from as-fabricated samples (with no ordered structure) failed by a lattice slipping mode that is the standard mode of failure for fcc structured materials. Meanwhile, in thermally aged or irradiated samples (with an ordered structure) failure by deformation twinning was observed in some grain orientations.

\section{Conclusion}

The results obtained suggest a potentially novel approach for material design, involving the manipulation of coherent precipitates' structure to control failure behavior. The use of in situ small scale mechanical testing to characterize the effect of coherent precipitates on deformation mode has provided a step towards the fundamental understanding of how a material's failure mode is affected by coherent precipitates. This research can be extended to other alloy systems and offers a new direction for future material research.

\section{Publications}

[1.] H.T.Vo, K.Q. Dang, F.Teng, M. Schneider, B.P. Eftink, S.A. Maloy, J.D. Tucker, L. Capolungo, P. Hosemann, "Understanding the Influence of Long Range Ordered Precipitates on Plastic Stability and Deformation Mode in $\mathrm{FCC} \mathrm{Ni}_{2} \mathrm{Cr}$ Alloy," submitted to Acta Materialia. 


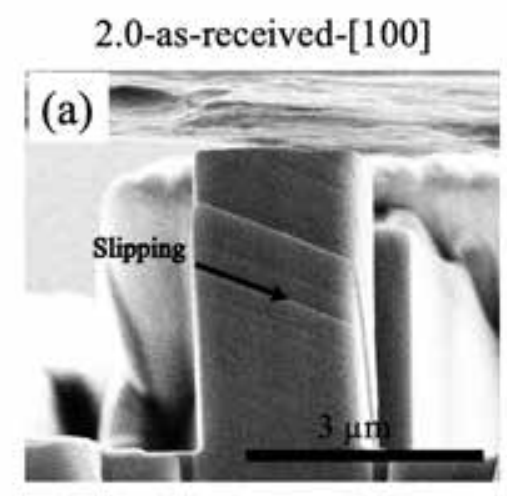

$2.0-475-10,000-[111]$

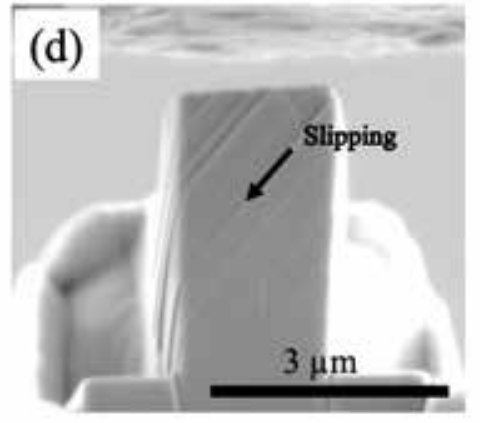

2.0-as-received-[111]

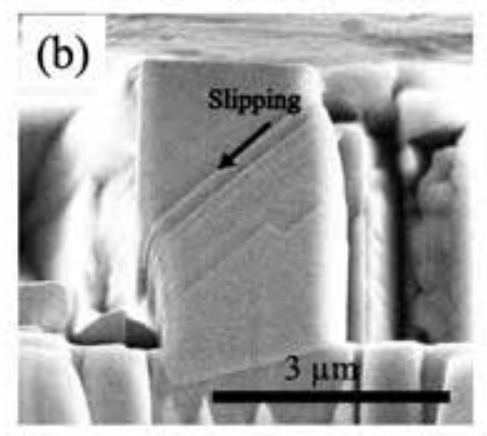

2.0-300C-6dpa proton-[001]

(e)

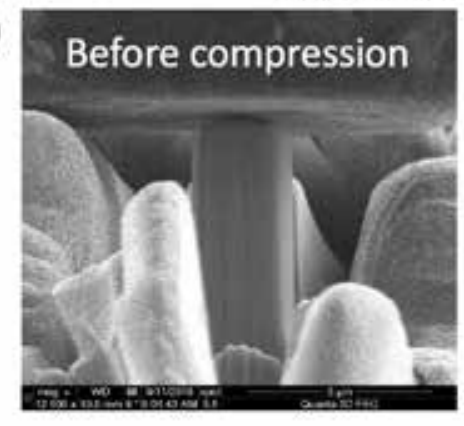

$2.0-475-10,000-[100]$

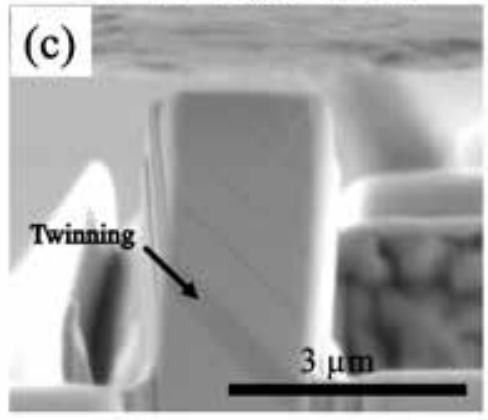

(f)

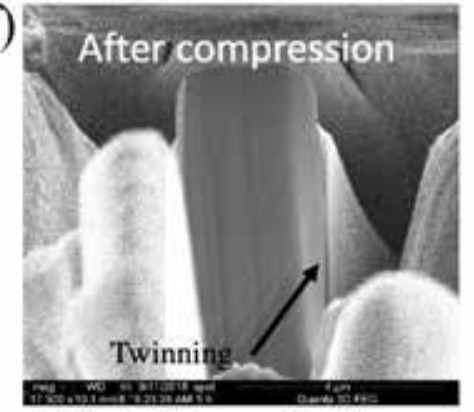

\begin{tabular}{|l|l|}
\hline \multicolumn{2}{|l|}{ Distributed Partnership at a Glance } \\
\hline NSUF Institution & Facilities and Capabilities \\
\hline $\begin{array}{l}\text { University of California, } \\
\text { Berkeley }\end{array}$ & Nuclear Materials Laboratory \\
\hline Collaborators & \\
\hline Oregon State University & Fei Teng (collaborator) \\
\hline
\end{tabular}

Figure 1. Compressed micropillars for model $\mathrm{Ni}-\mathrm{Cr}$ alloys with $\mathrm{Ni}$ to $\mathrm{Cr}$ ratio of 2.0. As-fabricated samples failed by a slipping mechanism when compressed in the [100] or the [111] direction, slides (a) and (b) respectively. Samples that were isothermally aged at $475^{\circ} \mathrm{C}$ for 10,000 hours failed by a twinning mode when compressed along the [100] direction, slide (c), and a slip mode when compressed in the [111] direction, slide (d). Irradiated samples also show twinning when compressed along the [001] direction, slides (e) and (f). 


\title{
Mechanical Characterization of Three Heats (ORNL, LANL and EBR II) of HT-9 after Side-by-side Neutron Irradiation at LWR and Fast Reactor Relevant Temperatures
}

\author{
Ramprashad Prabhakaran - Pacific Northwest National Laboratory - ramprashad.prabhakaran@pnnl.gov
}

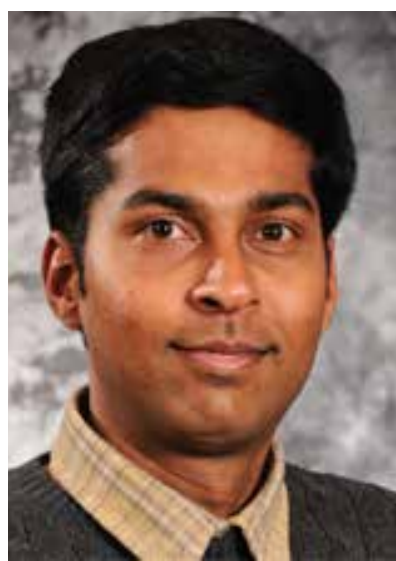

$\mathrm{H}$ T-9 is being considered as a candidate in-core structural material for fast and advanced light water reactors due to its superior resistance to radiation induced void swelling, good irradiation creep properties, microstructural stability, and thermal conductivity [1]. The extreme hardening and low fracture toughness that occur for irradiation temperatures below $425^{\circ} \mathrm{C}$ are serious issues because many reactor concepts call for core components to see lower temperatures. To address this issue, systematic investigations on the mechanical behavior of HT-9 are needed over a wide range of doses and temperatures. As part of a University of Wisconsin, Madison NSUF Irradiation Experiment, three heats (Oak Ridge National Laboratory, Los Alamos National Laboratory, and EBR-II) of HT-9 with variations in manufacturing process, chemical composition, and heat treatment were neutron irradiated in the Advanced Test Reactor at $291^{\circ} \mathrm{C}$, $360^{\circ} \mathrm{C}$, and $431^{\circ} \mathrm{C}$ to doses in the range of 3 to $8 \mathrm{dpa}$. The objective of our work is to evaluate the mechanical properties of these HT-9 heats as a function of processing conditions, irradiation temperatures, and dose. Tensile testing of control and neutron irradiated specimens (RTE 1156) was performed at nominal strain rate of 6E-4/s using an Instron Frame with an elevated temperature testing capability at the modular hot cell in the Radiochemical Processing Laboratory at Pacific Northwest National Laboratory.

\section{Results}

Tensile testing of higher dose (6-8 dpa) irradiated HT-9 heats was performed at irradiation temperatures. Engineering stress-strain curves were generated by using load-displacement data recorded during testing along with initial specimen gauge width, thickness, and reduced length. These curves were used to determine $0.2 \%$ offset yield stress (YS), ultimate tensile strength (UTS), uniform elongation (UE), and total elongation (TE). The results indicated the effect of test temperature and irradiation hardening on the mechanical properties. At $292^{\circ} \mathrm{C}$, it was found that the LANL and ORNL heats of HT-9 increased only slightly in strength compared to the unirradiated material while the EBR-II heat increased in strength considerably. YS (Figure 1) and UTS were both found to increase with temperature. Microstructure examinations will be conducted to determine the reason for this behavior. Uniform elongation after irradiation was lower than measured for the unirradiated material but was still at acceptable levels and was relatively invariant with irradiation temperature. The presence of a reasonable amount of ductility was due to conducting the tensile tests at elevated temperature where dislocation mobility is improved. If tests on the irradiated materials had been conducted 
at room temperature, the $360^{\circ} \mathrm{C}$ and $431^{\circ} \mathrm{C}$ irradiated specimens would have likely exhibited brittle fracture with little or no plastic response.

\section{Conclusion}

We recently received another RTE award (1687) to study these HT-9 heats at lower dose (3-4 dpa). Currently, efforts are ongoing to test these lower dose irradiated and control samples at irradiation temperatures. For irradiated ferritic-martensitic steels, the increase in YS is quite steep up to around $10 \mathrm{dpa}$ [2]. Extrapolation of the information learned from the 6-8 dpa irradiations is best accomplished by also examining the mechanical properties at the lower (3-4 dpa) dose because having data at two doses results in a more accurate extrapolation to higher doses. This work will benefit the Fuel Cycle Research and Development (FCR\&D) program in developing advanced structural materials with optimized chemical composition and heat treatment for greater radiation resistance, and NEAMS program by providing experimental results that would enable models to extrapolate it to the wider range of in-service conditions of future advanced reactors.

\section{References}

[1.] R. L. Klueh, A. T. Nelson, “Ferritic/Martensitic steels for next-generation reactors," J. Nucl. Mater. 371 (2007) 37-52, https://doi.org/10.1016/j.jnucmat.2007.05.005.

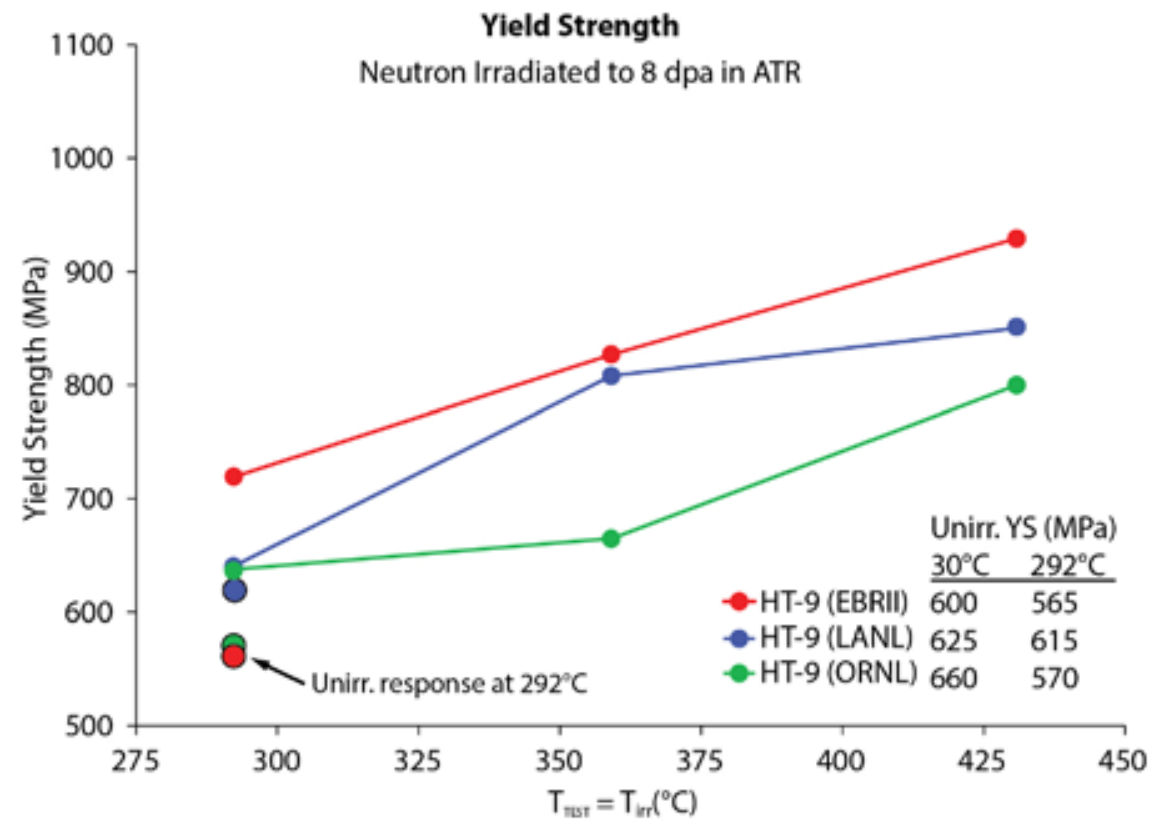

[2.] O. Anderoglu, T. S. Byun, M. Toloczko, S. A. Maloy, "Mechanical Performance of Ferritic MartensFigure 1. Effect of temperature on yield strength of three heats of neutron irradiated HT-9. itic Steels for High Dose Applications in Advanced Nuclear Reactors," Metallurgical and Materials Transactions A 44 (2013) 70-83, https://doi.org/10.1007/ s1 1661-012-1565-y.

\section{Distributed Partnership at a Glance}

\section{\begin{tabular}{l|l} 
NSUF Institution & Facilities and Capabilities
\end{tabular}}

Pacific Northwest Materials Science and Technology Laboratory, National Laboratory Radiochemical Processing Laboratory

\section{Collaborators}

Pacific Northwest National Laboratory

Danny Edwards (co-principal investigator), Mychailo Toloczko (co-principal investigator) 


\section{Synchrotron XRD Characterization of Long Range Order Phases in Ni-Cr Alloys Formed by Isothermal Aging or Irradiation}

Julie D. Tucker - Oregon State University - Julie.Tucker@oregonstate.edu

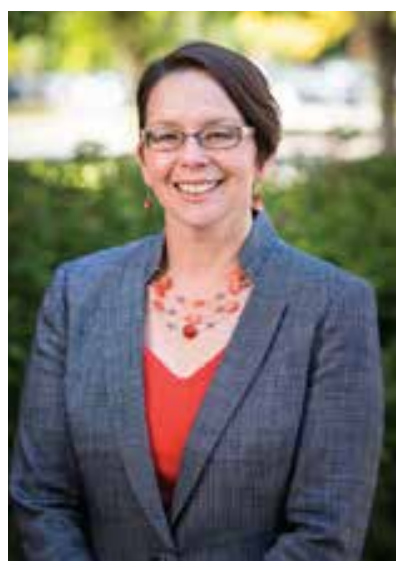

Ihe formation of long-range order in high $\mathrm{Cr}$, Ni based alloys causes several changes to the material properties, including reduced ductility, increased hardness, and lattice contraction. These changes are cause for concern about the service life of components (i.e., steam generator tubing, reactor pressure vessel heads) in pressurized water reactors. In this research, isothermal aging at temperatures between 330 and $475^{\circ} \mathrm{C}$ of model $\mathrm{Ni}-\mathrm{Cr}$, and commercial 690,625 , and $625 \mathrm{P}$ alloys has been performed up to 10,000 and 21,000 hours respectively. In model alloys, we have been able to clearly quantify the phase fraction, precipitate size, and lattice contractions associated with the $\mathrm{Ni}_{2} \mathrm{Cr}$ ordered phase as a function of aging time and temperature. Preliminary results for the commercial alloys show lattice contraction at 15,000 hours aged at $475^{\circ} \mathrm{C}$ in Alloy 690 , indicative of $\mathrm{Ni}_{2} \mathrm{Cr}$ formation as seen in model alloys.

\section{Results}

X-ray diffraction (XRD) measurements were found to be ultra-sensitive to the different phases that evolve in the model and commercial alloys with time and temperature. Figure 1 shows the XRD patterns collected for a representative selection of specimens measured as a part of the XRD characterization campaign. In Figure 1(a), the XRD patterns are shown for the commercial alloys 690, 625, and 625P, with reference to the model $\mathrm{Ni}-\mathrm{Cr}$ alloy $(\mathrm{Ni} / \mathrm{Cr}$ ratio $=2.0)$, for alloys aged at $475^{\circ} \mathrm{C}$ for $10,000 \mathrm{hrs}$. The additional peaks in the XRD patterns indicate that multiple nanoprecipitates are present-most notably, $\mathrm{Ni}_{2} \mathrm{Cr}$ in the model alloy (and potentially alloy 625P) and metal carbide peaks in alloy 625 and alloy 690. An additional nanometer sized face centered cubic (fcc) component is also observable in the alloy 625P specimen (identified as 

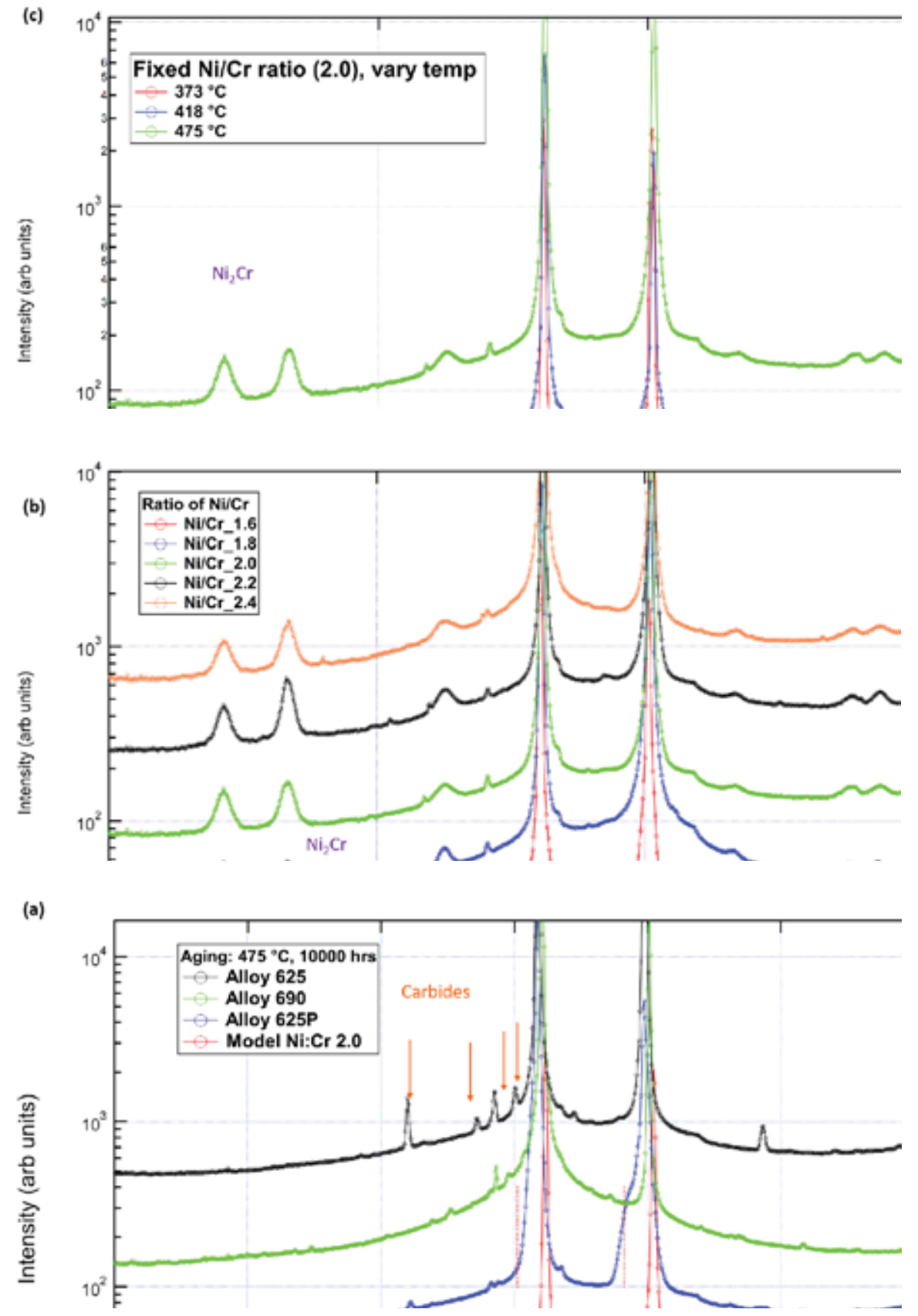

Figure 1. $X R D$ results comparing the (a) phases observable in model and commercial alloys. Peaks associated with the $\mathrm{Ni}_{2} \mathrm{Cr}$ and Metal-carbide phases are identified, (b) XRD patterns for the model alloys with varying $\mathrm{Ni} / \mathrm{Cr}$ ratios, (c), XRD patterns for model alloys $(\mathrm{Ni} / \mathrm{Cr}=2.0)$ at different temperatures. 
red broken lines). The location of the XRD peaks, at lower angles, indicates that this phase is appreciably strained relative to the fcc $\mathrm{Ni}-\mathrm{Cr}$ host phase. The evolution of the ordered $\mathrm{Ni}_{2} \mathrm{Cr}$ phase with $\mathrm{Ni} / \mathrm{Cr}$ ratio is shown in Figure 1(b). The $\mathrm{Ni}_{2} \mathrm{Cr}$ peaks are clearly visible in all patterns. Subtle differences in peak positions and intensities for the different $\mathrm{Ni} / \mathrm{Cr}$ ratio specimens indicate that the nanoprecipitates are also potentially nonstochiometric. The differences were quantified from Rietveld refining the individual XRD patterns. Finally, the effect of isothermal aging temperature on the $\mathrm{Ni}_{2} \mathrm{Cr}$ ordered phase is shown in Figure 1(c), where the XRD peaks evolve from broad diffuse peaks at low temperatures to sharper well defined peaks at elevated temperatures.

\section{Conclusion}

We have developed a method to examine and quantify minor precipitates in both model and commercial Ni-based alloys. Understanding the effects of time, temperature, and alloy chemistry on the precipitate formation is critical because they can lead to appreciable embrittlement of steamgenerating tube materials. Overall, the work in this project is intended to make power-generation technology safer, more affordable, and more reliable. The results of this work will help to guide regulations on power plants, provide guidance on component lifetimes, and direct future alloy development to create more resilient materials. 


\section{References}

[1.] L. Barnard et al., "Atomistic Modeling of the Order-Disorder Phase Transformation in the Ni2Cr Model Alloy" Acta Materialia, 81 (2014) 258-271, https://doi.org/10.1016/j. actamat.2014.08.017.

\section{Publications}

of thermally annealed longrange ordering in $\mathrm{Ni}_{\mathrm{x}} \mathrm{Cr}$ alloys, Materialia 8 (2019) 100453 https://doi.org/10.1016/j. mtla.2019.100453.

[1.] F. Teng, D.J. Sprouster, G.A. Young, J-H, Ke, J.D. Tucker, Effect of stoichiometry on the evolution

\section{Distributed Partnership at a Glance}

\begin{tabular}{|l|l|}
\hline NSUF Institution & Facilities and Capabilities \\
\hline $\begin{array}{l}\text { Brookhaven National } \\
\text { Laboratory }\end{array}$ & National Synchrotron Light Source II \\
\hline Collaborators & \multicolumn{2}{|l|}{} \\
\hline Idaho National Laboratory & Fei Teng (collaborator) \\
\hline Oregon State University & Nicholas Aerne (collaborator) \\
\hline Stony Brook University & David Sprouster (collaborator) \\
\hline
\end{tabular}




\title{
Irradiation Damage in (Zr0.25Ta0.25Nb0.25Ti0.25)C High Entropy Ceramics
}

\author{
Bai Cui - University of Nebraska-Lincoln - bcui3@unl.edu
}

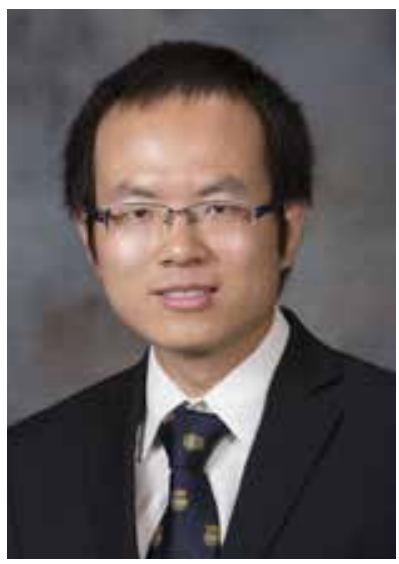

$\mathrm{T}$ he objective of this project is to examine the irradiation damage behavior of novel high entropy ceramics as potential candidate materials for the extreme environments in next generation nuclear energy systems. $\left(\mathrm{Hf}_{0.2} \mathrm{Zr}_{0.2} \mathrm{Ta}_{0.2} \mathrm{Nb}_{0.2} \mathrm{Ti}_{0.2}\right) \mathrm{C}$ was first synthesized by the spark plasma sintering process, while $\left(\mathrm{Zr}_{0.25} \mathrm{Ta}_{0.25} \mathrm{Nb}_{0.25} \mathrm{Ti}_{0.25}\right) \mathrm{C}$ was later developed as a better candidate material that removes $\mathrm{Hf}$ to reduce the neutron absorption cross section. The heavy ion irradiation experiments were conducted in the Ion Beam Laboratory at Texas A\&M University. $\left(\mathrm{Zr}_{0.25} \mathrm{Ta}_{0.25} \mathrm{Nb}_{0.25} \mathrm{Ti}_{0.25}\right) \mathrm{C}$ samples were irradiated by three $\mathrm{MeV} \mathrm{Zr}^{2+}$ to $20 \mathrm{dpa}$ at 25,300 , and $500^{\circ} \mathrm{C}$, respectively. The microstructures and mechanical properties of the irradiated $\left(\mathrm{Zr}_{0.25} \mathrm{Ta}_{0.25} \mathrm{Nb}_{0.25} \mathrm{Ti}_{0.25}\right) \mathrm{C}$ were studied. Grazing incidence X-ray diffraction was performed to analyze the irradiation induced phase transformations, while transmission electron microscopy was used to characterize the irradiation defects and radiation induced segregation at the Microscopy and Characterization Suite in the Center for Advanced Energy Studies. Nanoindentation tests were conducted to study the influence of irradiation on the hardness and elastic modulus of $\left(\mathrm{Zr}_{0.25} \mathrm{Ta}_{0.25} \mathrm{Nb}_{0.25} \mathrm{Ti}_{0.25}\right) \mathrm{C}$.

\section{Results}

Grazing incidence X-ray diffraction analysis showed that $\left(\mathrm{Zr}_{0.25} \mathrm{Ta}_{0.25} \mathrm{Nb}_{0.25} \mathrm{Ti}_{0.25}\right) \mathrm{C}$ maintained a high phase stability without phase transformation after irradiation to $20 \mathrm{dpa}$ at 25,300 , and $500^{\circ} \mathrm{C}$ respectively. However, about $0.2 \%$ lattice parameter expansion was observed. The irradiation induced microstructures were comprised of defect clusters with diameters of several nanometers. The defect clusters were characterized by transmission electron microscopy as two types of dislocation loops, including perfect loops with Burgers vectors of $\mathrm{b}=\mathrm{a} / 2<1 \quad 10>$ and faulted Frank loops with Burgers vectors of $b=a / 3<1 \quad 1 \quad 1>$. The growth of dislocation loops may be suppressed by the strong local lattice distortion caused by the compositional complexity. No void formation was observed, which may be caused by high vacancy migration barriers in carbide ceramics. No radiation induced segregation near grain boundaries was detected. Nanoindentation tests showed an irradiation induced hardness increase, which was possibly caused by dislocation loops as barriers to impede the slip during nanoindentations, as well as lattice strain. 


\section{Conclusion}

The concept of entropy stabilization has created promising opportunities for the design of new ceramic materials for advanced nuclear reactors. This research investigates the phase stability, formation of irradiation induced defect clusters, and irradiation hardening behaviors in novel high entropy carbide ceramics to provide fundamental understanding of their irradiation damage behavior. The combination of high irradiation resistance with other physical properties such as high melting temperature and hardness indicates $\left(\mathrm{Zr}_{0.25} \mathrm{Ta}_{0.25} \mathrm{Nb}_{0.25} \mathrm{Ti}_{0.25}\right) \mathrm{C}$ is a promising structural material for Generation-IV nuclear systems such as gas-cooled fast reactor and VHTR.

\section{Publications}

[1.] Fei Wang, Xueliang Yan, Tianyao Wang, Yaqiao Wu, Lin Shao, Michael Nastasi, Yongfeng Lu, Bai Cui. Irradiation damage in $\left(\mathrm{Zr}_{0.25} \mathrm{Ta}_{0.25} \mathrm{Nb}_{0.25} \mathrm{Ti}_{0.25}\right) \mathrm{C}$ high entropy ceramics. Acta Materialia, 195, 739-749 (2020).

[2.] Fei Wang, Xueliang Yan, Lin Shao, Michael Nastasi, Bai Cui. Irradiation damage behavior in novel high-entropy carbide ceramics. Transactions of the American Nuclear Society, Vol. 120, Page 327, Minneapolis, Minnesota, June 9-13, 2019.

[3.] (Invited talk) Bai Cui. Irradiation damage mechanisms in highentropy carbide ceramics. Virtual 2 Day Research Meeting on Advanced Ceramics, Institute of Materials, Minerals and Mining, UK, August 19, 2020.

\begin{tabular}{|l|l|}
\hline \multicolumn{2}{|l|}{ Distributed Partnership at a Glance } \\
\hline NSUF Institution & Facilities and Capabilities \\
\hline $\begin{array}{l}\text { Center for Advanced } \\
\text { Energy Studies }\end{array}$ & Microscopy and Characterization Suite \\
\hline Texas A\&M University & Accelerator Laboratory \\
\hline Collaborators & Yaqiao Wu (collaborator) \\
\hline $\begin{array}{l}\text { Center for Advanced } \\
\text { Energy Studies }\end{array}$ & Lin Shao (collaborator) \\
\hline Texas A\&M University & $\begin{array}{l}\text { Fei Wang (collaborator), Xueliang Yan } \\
\text { (collaborator) }\end{array}$ \\
\hline $\begin{array}{l}\text { University of } \\
\text { Nebraska-Lincoln }\end{array}$ &
\end{tabular}




\section{NSUF LIST OF ACRONYMS}

$2 D$.

3D

AGR

ANS

APT.

ATR.

BWR

C4. .. Couple Current Charge Compensation

CINR Consolidated Innovative Nuclear Research

CoMET .Combined Materials Experiment Toolkit

CPU central processing unit

CVD Chemical Vapor Deposition

DOE Department of Energy

DOE-NE......Department of Energy, Office of Nuclear Energy dpa. displacements per atom

EBSD electron backscatter diffraction

EBR-II Experimental Breeder Reactor II

EDS . energy dispersive $x$-ray spectroscopy

EDX energy dispersive $\mathbf{x}$-ray spectroscopy

EELS electron energy loss spectrometry

EML Electron Microscopy Laboratory

EPM electron probe microanalysis

EPRI. .Electric Power Research Institute

FB-CVD Fluidized Bed - Chemical Vapor Deposition

FDM. finite difference method

FEM finite element method

FIB focused ion beam
GB. grain boundary GDOES........... glow discharge optical emission spectroscopy GIXRD grazing-incidence $x$-ray diffraction GPU graphics processing unit HFIR High Flux Isotope Reactor

HPC high performance computing

HRTEM high-resolution transmission electron microscopy

HTGR high-temperature gas-cooled reactor IASCC ...............irradiation assisted stress corrosion cracking IMCL .........Irradiated Materials Characterization Laboratory IMET Irradiated Materials Examination and Testing Facility

INERI ....... International Nuclear Energy Research Initiative INI Idaho National Laboratory IPyC. inner pyrolytic carbon

LAMDA ... Low Activation Materials Design and Analysis Laboratory LANL . Los Alamos National Laboratory LWR. light water reactor

M\&S modeling and simulation

MaCS Microscopy and Characterization Suite MFC Materials and Fuels Complex MI3 Michigan In Situ Ion Irradiation MIBL Michigan Ion Beam Lab

MOOSE. Multiphysics Object-Oriented Simulation Environment

NEID. Nuclear Energy Infrastructure Database 

NSUF

INDEX

\section{NSUF \& Partner Institutions: Facilities \& Capabilities}

Argonne National Laboratory (ANL):

12, 13, 32, 34, 35, 37, 38, 39, 71, 76, $79,101,102,104$

Argonne National Laboratory: The Intermediate Voltage Electron Microscopy (IVEM) -Tandem Facility, 76, 79, 101 , 102

Brookhaven National Laboratory (BNL): 12, 37, 40, 97, 102

Brookhaven National Laboratory: National Synchrotron Light Source II, 97, 102

Center for Advanced Energy Studies (CAES): 12, 32, 33, 34, 35, 38, 39, $75,85,86,87,98,99,102,104$

Center for Advanced Energy Studies: Microscopy and Characterization Suite (MaCS), $33,75,85,86,87,98,99,100,102$

Idaho National Laboratory (INL): 2, 5, $6,7,8,12,13,14,15,16,17,20,26$, $27,28,29,30,31,32,34,35,36,37$, $38,39,50,54,73,75,85,97,100$, 102,104

Idaho National Laboratory: Advanced Test Reactor (ATR), 28, 29, 30, $31,36,92,100,102$

Idaho National Laboratory:

Collaborative Computing Center, 17, 26, 102

Idaho National Laboratory:

Electron Microscopy Laboratory (EML), 75 , 100,102
Idaho National Laboratory:

High Performance Computing (HPC), 3, 26,

$27,41,52,54,73,100,102$

Idaho National Laboratory:

High Temperature Test Laboratory, 5, 102

Idaho National Laboratory:

Irradiated Materials Characterization Laboratory

(IMCL), 2, 16, 75, 85, 100, 102

Idaho National Laboratory:

Materials \& Fuels Complex (MFC), 16, 29,

$30,100,102$

Idaho National Laboratory:

Technology Deployment Office, 15, 102

Lawrence Livermore National Laboratory (LLNL): 12, 102

Los Alamos National Laboratory (LANL): 4, 12, 13, 34, 35, 37, 38, 41, 73, 92, 100,102, 104

Massachusetts Institute of Technology (MIT): 12, 13, 32, 34, 37, 102

North Carolina State University (NCSU) : 12, 13, 32, 37, 39, 102

Oak Ridge National Laboratory (ORNL): 4, 12, 13, 24, 32, 34, 35, $38,39,41,42,50,51,80,81,92$, $101,102,104$

Oak Ridge National Laboratory: High Flux Isotope Reactor (HFIR), 24, 34, $42,50,51,100,102$
Oak Ridge National Laboratory: Irradiated Materials Examination and Testing Facility (IMET) Hot Cells, 51, 100, 102

Oak Ridge National Laboratory: Low Activation Materials Design and Analysis Laboratory (LAMDA), 51, 80, 81, 100, 102

The Ohio State University (OSU): 12 , $13,14,34,35,37,89,102$

The Ohio State University:

The Ohio State University Nuclear Research Laboratory, 89, 102

Pacific Northwest National Laboratory (PNNL): 12, 13, 22, 23, 32, 35, 38, 92, 93, 102, 104

Pacific Northwest National Laboratory: Materials Science \& Technology Laboratory

(MSTL), 93, 102

Pacific Northwest National Laboratory: Radiochemical Processing Laboratory (RPL), 92, 93, 101, 102

Purdue University: 12, 13, 21, 34, 35, 38,102

Sandia National Laboratories (SNL): 2, $12,32,38,102,103$

Sandia National Laboratories: Annular Core Research Reactor, 2, 102

Sandia National Laboratories: Ion Beam Laboratory, 103 


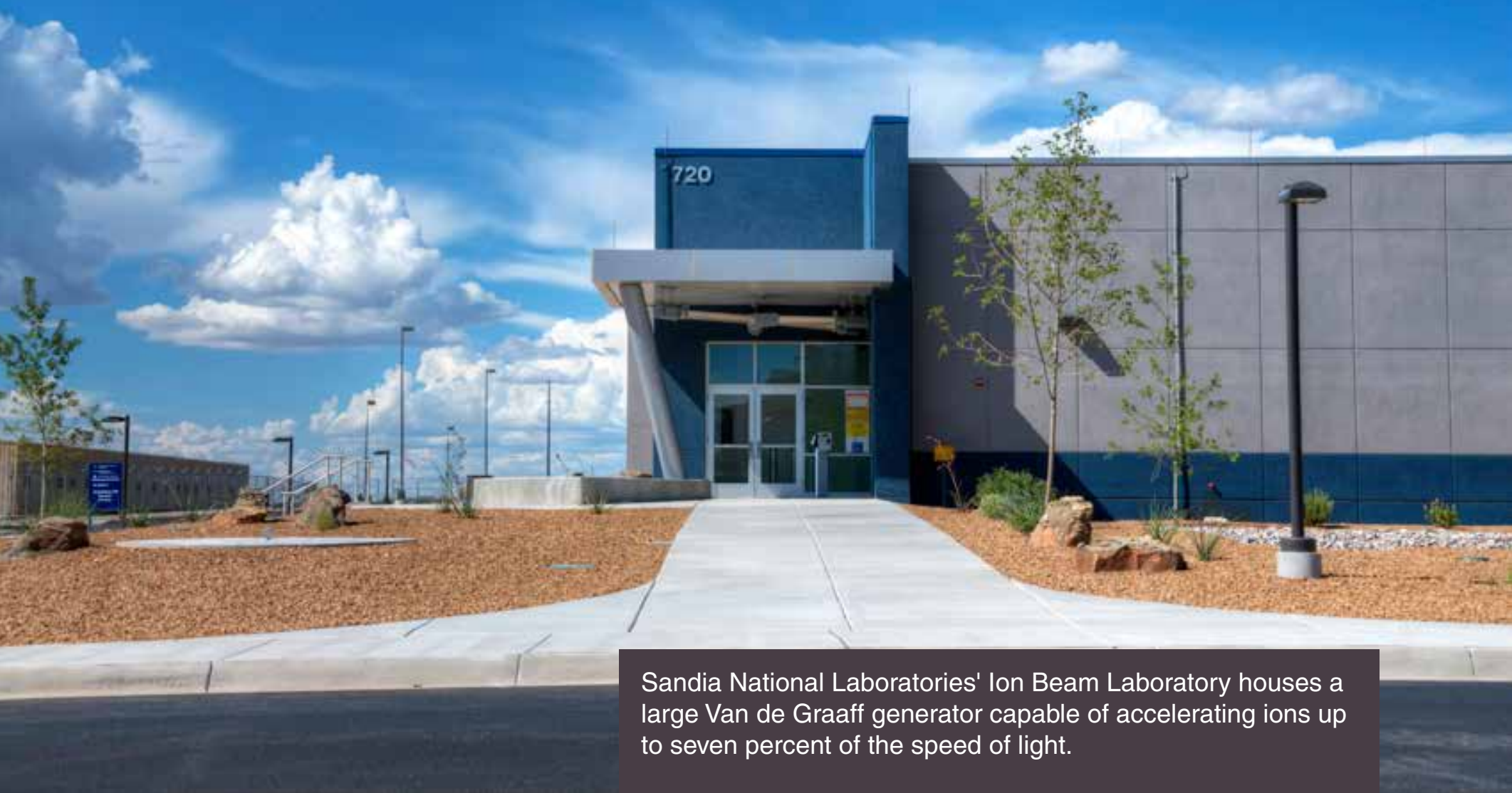

Texas A\&M University (TAMU): 12 , $34,38,98,99,103,104$

Texas A\&M University: Accelerator Laboratory, 99, 103

Texas A\&M University: Ion Beam Laboratory, 98, 103

University of California, Berkeley (UCB): 12, 38, 90, 91, 103
University of California, Berkeley: Nuclear Materials Laboratory, 90, 91, 103

University of Florida (UF): 12, 13, 37 , $38,39,73,103,104$

University of Michigan (UM): 12, $14,18,35,37,38,39,44,51,75,89$, 103,104
University of Michigan:

Michigan Ion Beam Laboratory (MIBL), $18,44,74,75,88,89,100,103$

University of Wisconsin, Madison: 12 , $82,85,92,103,104$

University of Wisconsin, Madison: Ion Beam Laboratory, 82, 103

Westinghouse: 12, 76, 89, 103, 104 


\section{Collaborators}

Aerne, Nicholas

Oregon State University, 97, 104

Andersson, David

Los Alamos National Laboratory, 68, 71, 73, 104

Arregui-Mena, J. David

Oak Ridge National Laboratory, 50, 51, 104

Bachhav, Mukesh

Idaho National Laboratory, 34, 75, 84, 85, 104

Baker, Brad

United States Naval Academy, 75, 104

Barsoum, Michel W.

Drexel University, 89, 104

Blondel, Sophie

University of Tennessee, Knoxville, 70, 71, 73, 104

Campbell, Anne

Oak Ridge National Laboratory, 50, 51, 104

Delville, Rémi

SCK CEN, 89, 104

Edmondson, Philip

Oak Ridge National Laboratory, 39, 81, 104

Edwards, Danny

Pacific Northwest National Laboratory, 93, 104

Hadermann, Joke

University of Antwerp, 89, 104

He, Guanze

University of Oxford, 79, 104

He, Lingfeng

Idaho National Laboratory, 84, 85, 104

$\mathrm{Hu}$, Jing

Argonne National Laboratory, 79, 84, 104
Hu, Xunxiang

Oak Ridge National Laboratory, 50, 51, 70,

81,104

Hunn, John

Oak Ridge National Laboratory, 50, 51, 104

Jolly, Brian

Oak Ridge National Laboratory, 50, 51,104

Kim, Dong-Uk

University of Florida, 73, 104

Lahoda, Edward J.

Westinghouse Electric Company, 89, 104

Leonard, Keith

Oak Ridge National Laboratory, 81, 104

Li, Congyi

University of Tennessee, Knoxville, 87, 104

Liu, Junliang

University of Oxford, 79, 104

McMahan, J.

United States Naval Academy, 75, 104

Nathan, Nicholas

United States Naval Academy, 75, 104

Nygren, Kelly

University of Wisconsin, Madison, 84, 85, 104

Schumacher, Austin

Oak Ridge National Laboratory, 50, 51, 104

Schumacher, Austin

University of Tennessee, 50, 51, 104

Seibert, Rachel

Oak Ridge National Laboratory, 44, 50, 51 , 104

Shao, Lin

Texas A\&M University, 99, 104

Sievers, Natalie

Virginia Polytechnic Institute and State

University, 51, 104
Sprouster, David

Stony Brook University, 97, 104

Teng, Fei

Idaho National Laboratory, 38, 97, 104

Teng, Fei

Oregon State University, 90, 91, 104

Toader, Ovidiu

University of Michigan, 51, 104

Toloczko, Mychailo

Pacific Northwest National Laboratory, 93, 104

Tonks, Mike

University of Florida, 68, 71, 72, 73, 104

Tunca, Bensu

Katholieke Universiteit Leuven, 89, 104

Tunca, Bensu

SCK CEN, 88, 89, 104

Vleugels, Jozef

Katholieke Universiteit Leuven, 88, 89, 104

Wang, Fei

University of Nebraska-Lincoln, 99, 104

Wang, Ling

University of Tennessee, Knoxville 38, 87, 104

Was, Gary S.

University of Michigan, 18, 89, 104

Wu, Yaqiao

Center for Advanced Energy Studies 99, 104

Yan, Xueliang

University of Nebraska-Lincoln, 99, 104

Yang, Tengfei

University of Tennessee, Knoxville, 87, 104

Yu, Zefeng

University of Wisconsin, Madison, 84, 85, 104 

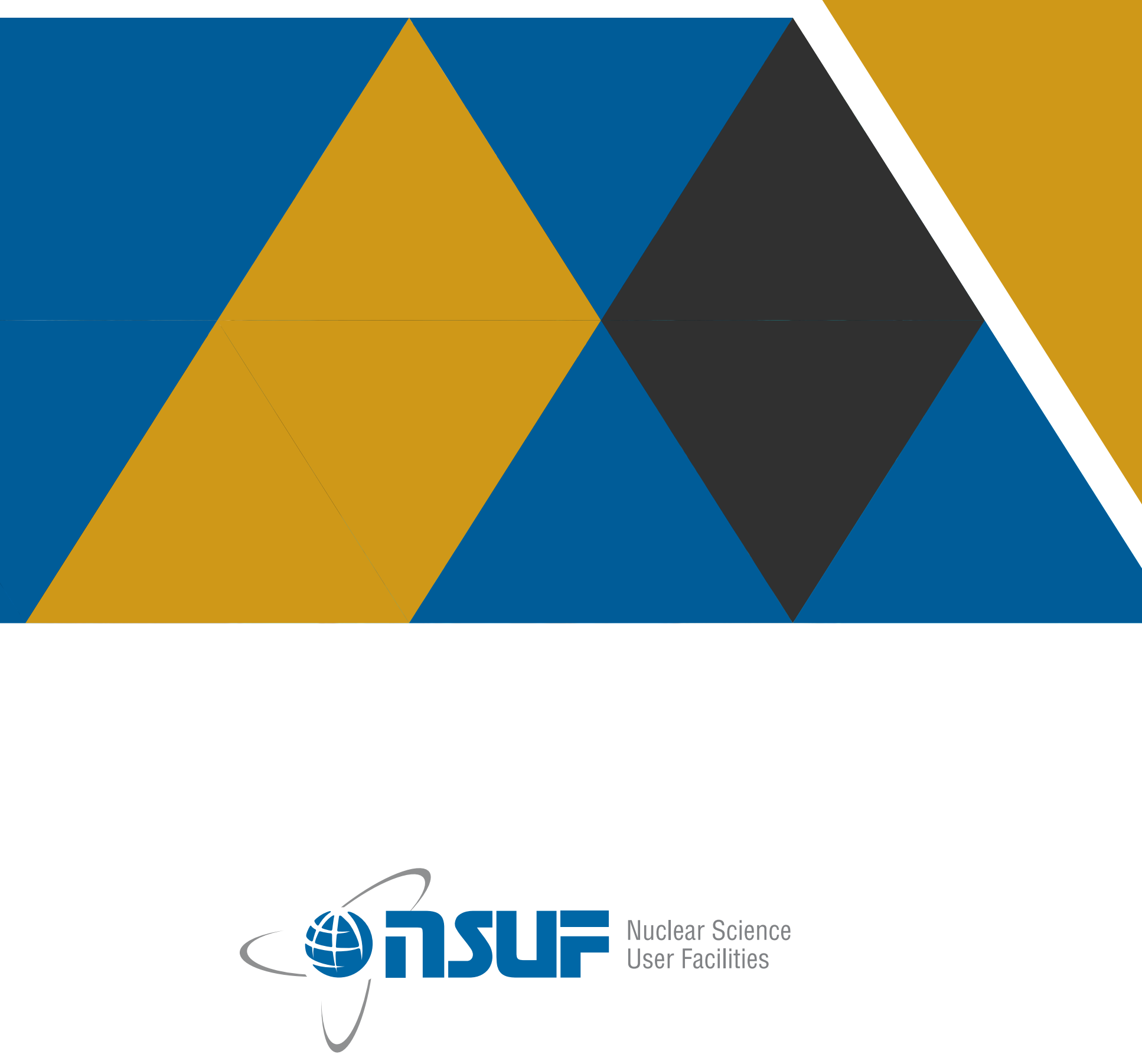